\title{
The Heart's Content: The Association Between Positive Psychological Well-Being and Cardiovascular Health
}

\author{
Julia K. Boehm and Laura D. Kubzansky \\ Harvard School of Public Health
}

\begin{abstract}
This review investigates the association between positive psychological well-being (PPWB) and cardiovascular disease (CVD). We also consider the mechanisms by which PPWB may be linked with CVD, focusing on the health behaviors (e.g., smoking, alcohol consumption, physical activity, sleep quality and quantity, and food consumption) and biological functions (e.g., cardiovascular, inflammatory, and metabolic processes) that are most relevant for cardiovascular health. Because PPWB is a broad concept, not all aspects of PPWB may be associated with cardiovascular health. Thus, we distinguish between eudaimonic well-being, hedonic well-being, optimism, and other measures of well-being when reviewing the literature. Findings suggest that PPWB protects consistently against CVD, independently of traditional risk factors and ill-being. Specifically, optimism is most robustly associated with a reduced risk of cardiovascular events. In general, PPWB is also positively associated with restorative health behaviors and biological function and inversely associated with deteriorative health behaviors and biological function. Cardiovascular health is more consistently associated with optimism and hedonic well-being than with eudaimonic well-being, although this could be due in part to more limited evidence being available concerning eudaimonic well-being. Some similarities were also evident across different measures of PPWB, which is likely due to measurement overlap. A theoretical context for this research is provided, and suggestions for future research are given, including the need for additional prospective investigations and research that includes multiple constructs of psychological well-being and ill-being.
\end{abstract}

Keywords: cardiovascular disease, health behaviors, biological function, eudaimonic well-being, hedonic well-being

Scholars have long recognized the connection between mental health and physical health. From the ancient Roman poet Juvenal who declared, "A healthy mind in a healthy body," to early 20th century psychoanalysts who investigated the connection between mental states and physiology (Menninger \& Menninger, 1936), and to researchers in the late 20th century seeking to identify disease-prone personalities (H. S. Friedman \& Booth-Kewley, 1987; Rosenman et al., 1964), the complex relationship between psychological attributes and physical ailments has been the subject of fascination across time. Although past research has predominantly focused on the relationship between poor psychological functioning (e.g., anxiety, depression, hostility) and physical health, increasing research also suggests that a protective relationship exists between positive psychological functioning and physical health (Diener \& Chan, 2011; Pressman \& Cohen, 2005). Because the effects of psychological well-being and psychological ill-being are not merely opposites of one another and the absence

This article was published Online First April 16, 2012.

Julia K. Boehm and Laura D. Kubzansky, Department of Society, Human Development, and Health, Harvard School of Public Health.

Support for this research was provided by the Robert Wood Johnson Foundation's Pioneer Portfolio through the Exploring Concepts of Positive Health Grant.

Correspondence concerning this article should be addressed to Julia K. Boehm, Department of Society, Human Development, and Health, Harvard School of Public Health, Landmark Center, Room 428A, 401 Park Drive, Boston, MA 02215. E-mail: jboehm@hsph.harvard.edu of one does not necessarily indicate the presence of the other (Ryff et al., 2006; Ryff \& Singer, 1998), it is critical to consider each separately in relation to health. Thus, we specifically investigate the relationship between positive psychological well-being (PPWB) - a broad construct that includes indicators such as life purpose, personal growth, positive emotion, life satisfaction, happiness, and optimism — and cardiovascular disease (CVD), which encompasses two of the leading causes of death in the United States: coronary heart disease (CHD) and stroke (Heron et al., 2009).

Although PPWB has been linked with a range of health outcomes, the present review focuses exclusively on cardiovascular health. Besides being a major contributor to mortality and disease globally, CVD has been commonly investigated in relation to PPWB, and thus a sufficient amount of evidence has accumulated from which to draw conclusions. Moreover, disease onset or CVD diagnosis can be identified with a straightforward set of criteria comprising objective endpoints and disease-related markers. This makes it possible to examine PPWB's effects on the onset versus the progression of disease with study designs that reduce concerns about reverse causality. Previous reviews have considered the association between ill-being and CHD (Chida \& Steptoe, 2009; Kubzansky, Kawachi, Weiss, \& Sparrow, 1998; Rugulies, 2002; Suls \& Bunde, 2005) or PPWB and general physical health (Diener \& Chan, 2011; Dockray \& Steptoe, 2010; Howell, Kern, \& Lyubomirsky, 2007; Lyubomirsky, King, \& Diener, 2005; Pressman \& Cohen, 2005; Steptoe, Dockray, \& Wardle, 2009), but this is the 
first review that exclusively emphasizes the role of PPWB in the context of cardiovascular health.

In addition to considering CVD, we review evidence regarding potential pathways linking PPWB and CVD. Behavioral and biological mechanisms are the two most prominent pathways by which psychosocial factors may influence disease-related outcomes. However, most research to date has focused on how PPWB is associated with the absence of unhealthy behaviors or biological dysfunction. Less attention has been paid to whether PPWB is associated with the presence of healthy behaviors (e.g., adequate sleep, fruit and vegetable consumption) or biological function (e.g., autonomic cardiac control, antioxidants). In addition to examining the association between PPWB and deteriorative processes, we examine the association between PPWB and restorative processes that may protect against CVD. This is consistent with the American Heart Association's recent emphasis on ideal cardiovascular health, which is defined by more than just the absence of risk factors (Lloyd-Jones et al., 2010).

Furthermore, previous reviews have primarily focused on positive affect (for an exception, see Rasmussen, Scheier, \& Greenhouse, 2009). In contrast, we take a broad perspective on PPWB and consider a wide range of positive constructs that we classify by the dominant theoretical approaches to well-being. Little work to date has distinguished between different indicators of PPWB (e.g., Chida \& Steptoe, 2008) or considered whether some constructs have stronger associations with cardiovascular health than others. However, because PPWB comprises diverse indicators, it is reasonable to expect that unique constructs may have different associations with CVD-related outcomes. Thus, we seek to identify those aspects of PPWB that are specifically associated with cardiovascular health.

\section{Theoretical Perspectives on PPWB}

PPWB reflects the positive feelings, cognitions, and strategies of individuals who function well in their life and evaluate their life favorably. Two distinct theoretical approaches characterize wellbeing research—namely, eudaimonic and hedonic well-being. Both eudaimonia and hedonia stem from Aristotle's philosophizing about what constitutes the good life, but applying centuries-old philosophical definitions to modern day psychological science is not without its difficulties. Today, eudaimonic well-being is typically defined as fulfilling one's potential and identifying meaningful life pursuits (Waterman, 2007). By contrast, hedonic wellbeing refers to the pursuit of pleasure and happiness (Waterman, 2008). Eudaimonic well-being emphasizes an individual's evaluations of functioning in life, whereas hedonic well-being emphasizes an individual's evaluations of feelings regarding life (Keyes \& Annas, 2009; Ryan, Huta, \& Deci, 2008). Some skepticism exists regarding the degree to which eudaimonic and hedonic well-being can be meaningfully separated because they may overlap conceptually and share underlying psychological mechanisms (Kashdan, Biswas-Diener, \& King, 2008). However, other research suggests that a distinction can be made (Keyes \& Annas, 2009; Keyes, Shmotkin, \& Ryff, 2002; Linley, Maltby, Wood, Osborne, \& Hurling, 2009; Ryff \& Keyes, 1995).

Other positive factors may be considered under the broad category of PPWB but are not easily classified into the eudaimonic or hedonic approaches to well-being. These include constructs like optimism and vitality, which may contain elements of both eudaimonic and hedonic well-being, but are not pure measures of either. Such constructs have been strongly linked to PPWB and fit within a broad perspective that seeks to characterize relevant positive feelings, cognitions, and strategies that are associated with positive functioning (Gallagher \& Lopez, 2009). These constructs have also been linked with cardiovascular health. Thus, we explicitly consider relevant PPWB constructs that may not easily fit within a hedonic or eudaimonic framework. Although we do our best to distinguish between the dominant theoretical perspectives of wellbeing when reviewing the association between PPWB and cardiovascular health, given the true correlation between eudaimonic well-being, hedonic well-being, optimism, and other aspects of well-being, as well as difficulties in drawing clear distinctions in assessment, we expect to find that multiple constructs of PPWB are associated with better cardiovascular health. Table 1 describes the typical measures of PPWB used in studies of cardiovascular health. ${ }^{1}$

\section{Eudaimonic Well-Being}

Work by Ryff and colleagues (e.g., Ryff \& Keyes, 1995) exemplifies a eudaimonic perspective on well-being. They propose that six distinct components form the basis of psychological wellbeing: purpose in life, personal growth, self-acceptance, positive relations, environmental mastery, and autonomy. These components may be related but have unique meanings. Having life purpose is to have goals for one's life and to find meaning in what one does. The Japanese concept of ikigai-having a life worth living - is similar. Having a sense of personal growth is to recognize the self as capable of improvement over time and to seek to fulfill one's potential. Having self-acceptance is to have a positive opinion about one's self and to recognize both one's positive and one's negative characteristics. Having positive relations is being able to maintain warm and trusting relationships with other people and to recognize the needs of others. ${ }^{2}$ Having environmental mastery is to competently manage and control one's environment, as well as identify environments to which one is well-suited. Finally, having autonomy is being able to independently evaluate and regulate one's behavior without being unduly influenced by external pressures. Taken together, these theoretically based components comprise a multidimensional conceptualization of eudaimonic well-being.

\footnotetext{
${ }^{1}$ Information about PPWB measurement is constrained by the details provided by the original authors. When proprietary scales or items in foreign languages were used, PPWB measurement is less clear.

${ }^{2}$ We consider all well-being components of Ryff's theory with the exception of positive relations (e.g., Ryff \& Keyes, 1995). Research indicates that social relationships are closely tied with well-being (Diener \& Seligman, 2002), but theorists question whether positive relationships are a defining aspect of eudaimonic well-being or merely a correlate (Waterman, 2008). Even more important is that a significant and separate literature already exists regarding the association between social relationships and health (e.g., Holt-Lunstad, Smith, \& Layton, 2010; Uchino, 2006; Uchino, Cacioppo, \& Kiecolt-Glaser, 1996). As a result, links between social relationships, CVD, health behaviors, and biological function are best explored separately.
} 
Table 1

Description of Common Measures of Positive Psychological Well-Being (PPWB)

\begin{tabular}{ll} 
PPWB construct $^{\text {a }}$ & Definition \\
\hline $\begin{array}{c}\text { Eudaimonic well-being } \\
\text { Purpose in life }\end{array}$ & $\begin{array}{l}\text { The extent to which individuals have } \\
\text { purpose and meaning in their lives }\end{array}$
\end{tabular}

Typical scale and psychometric properties

Personal growth

Self-acceptance ${ }^{\mathrm{b}}$

Environmental

mastery

Autonomy

Ikigai

Hedonic well-being

Happiness

Satisfaction with life

Positive affect ${ }^{\mathrm{C}}$
The extent to which individuals seek to realize their full potential and recognize that the self is constantly developing

The extent to which individuals hold favorable views of the self

The extent to which individuals effectively manage their environments or perceive life as being under their control
- 6-item Life Engagement Test (Scheier et al., 2006): $\alpha=.72-.87$; test-retest reliability $=.61-.76$ across 4 months; e.g., "I value my activities a lot."

- 20-item and 3-item Purpose in Life Scale (Ryff, 1989; Ryff \& Keyes, 1995): $\alpha_{20 \text { item }}=.90 ; \alpha_{3 \text { item }}=.33$; test-retest reliability ${ }_{20 \text { item }}=.82$ across 6 weeks; e.g., "I have a sense of direction and purpose in my life."

- 20-item Purpose in Life Test (Crumbaugh, 1968; Crumbaugh \& Maholick, 1964): split-half reliability corrected with Spearman Brown formula $=.90$; test-retest reliability $=.83$ across 1 week (Meier \& Edwards, 1974); e.g., "In life I have: no goals or aims ... clear goals and aims."

- 20-item and 3-item Personal Growth Scale (Ryff, 1989; Ryff \& Keyes, 1995) $\alpha_{20 \text { item }}=.87$; test-retest reliability 20 item $=.81$ across 6 weeks; e.g., "I have the sense that I have developed a lot as a person over time.'”

- 20-item and 3-item Self-Acceptance Scale (Ryff, 1989; Ryff \& Keyes, 1995): $\alpha_{20 \text { item }}=.93$; test-retest reliability ${ }_{20}$ item $=.85$ across 6 weeks; e.g., "I like most parts of my personality."

- 20-item and 3-item Environmental Mastery Scale (Ryff, 1989; Ryff \& Keyes, 1995): $\alpha_{20}$ item $=.90$; test-retest reliability 20 item $=.81$ across 6 weeks; e.g., "In general, I feel I am in charge of the situation in which I live."

- 7-item Personal Mastery Scale (Pearlin \& Schooler, 1978): $\alpha=.69$ (T. E. Seeman, 1991); e.g., "I can do just about anything I really set my mind to do."

- 23-item force-choice Internal-External Locus of Control Scale (Rotter, 1966) split-half reliability corrected with Spearman Brown formula $=.73$; e.g., "In my case getting what I want has little or nothing to do with luck. Or, many times we might just as well decide what to do by flipping a coin."

- 187-item Shapiro Control Inventory (Shapiro, 1994): $\alpha=.70-.89$ for the scales in the inventory; test-retest reliability $=.67-.93$ across 6 weeks for the scales in the inventory.

- 20-item and 3-item Autonomy Scale (Ryff, 1989; Ryff \& Keyes, 1995): $\alpha_{20}$ item $=.86$; test-retest reliability ${ }_{20}$ item $=.88$ across 6 weeks; e.g., "I am not afraid to voice my opinions, even when they are in opposition to the opinions of most people."

- 12 items from the General Causality Orientations Scale (Deci \& Ryan, 1985): $\alpha=.74$; test-retest reliability $=.75$ across 2 months; e.g., "You have been offered a new position in a company where you have worked for some time. The first question that is likely to come to mind is: I wonder if the new work will be interesting, will I make more at this position, or what if I can't live up to the new responsibility."

- Single item: "Do you have ikigai in your life?" (Sone et al., 2008; Tanno \& Sakata, 2007)
The extent to which individual
sense that life is worth living

The extent to which individuals consider themselves a happy or unhappy person

The extent to which individuals judge the overall quality of their life to be satisfactory

The extent to which individuals experience pleasurable feelings
- 4-item Subjective Happiness Scale (Lyubomirsky \& Lepper, 1999): $\alpha=$.79.94 ; test-retest reliability $=.55-.90$ across 3 weeks to 1 year; e.g., "In general, I consider myself: not a very happy person or a very happy person."

- 5-item Satisfaction With Life Scale (Diener, Emmons, Larsen, \& Griffin, 1985 Pavot \& Diener, 2008): $\alpha=.87$; test-retest reliability $=.82$ across 2 months; e.g., "In most ways my life is close to my ideal."

- 10 items from the Positive and Negative Affect Schedule ${ }^{\mathrm{d}, \mathrm{e}}$ (Watson \& Clark, 1994; Watson, Clark, \& Tellegen, 1988): $\alpha=.88$; test-retest reliability $=.68$ across 8 weeks; e.g., "enthusiastic."

- 5 items from the Affect Balance Scale ${ }^{\mathrm{f}}$ (Bradburn, 1969): $\alpha=.65$ (Harding, 1982); e.g., "particularly excited or interested in something."

- 24 items from the Mood and Anxiety Symptom Questionnaire (Watson et al., 1995): $\alpha=.95$ (Geisser, Cano, \& Foran, 2006); e.g., "felt cheerful." 
Table 1 (continued)

\begin{tabular}{|c|c|c|}
\hline PPWB construct ${ }^{\mathrm{a}}$ & Definition & Typical scale and psychometric properties \\
\hline \multicolumn{3}{|c|}{ Optimism and other measures of well-being } \\
\hline $\begin{array}{l}\text { Optimism (and } \\
\text { hope) }\end{array}$ & $\begin{array}{l}\text { The extent to which individuals have } \\
\text { expectancies for positive outcomes in } \\
\text { the future }\end{array}$ & $\begin{array}{l}\text { - } 6 \text {-item or } 8 \text {-item Life Orientation Test }{ }^{\mathrm{h}}(\text { Scheier \& Carver, 1985; Scheier et al., } \\
\text { 1994): } \alpha_{8} \text { item }=.76 ; \alpha_{6 \text { item }}=.78 ; \text { test-retest reliability }{ }_{8} \text { item }=.79 \text { across } 1 \\
\text { month; test-retest reliability } 6 \text { item }=.68-.79 \text { across } 4 \text { to } 28 \text { months; e.g., "In } \\
\text { uncertain times, I usually expect the best." }\end{array}$ \\
\hline Vitality & $\begin{array}{l}\text { The extent to which individuals display } \\
\text { enthusiasm for life }\end{array}$ & $\begin{array}{l}\text { - } 7 \text {-item Subjective Vitality Scale (Ryan \& Frederick, 1997): } \alpha=.84-.86 \text {; test- } \\
\text { retest reliability }=.64 \text { across } 8 \text { weeks; e.g.. "I feel alive and vital." }\end{array}$ \\
\hline
\end{tabular}

a Other indices of PPWB have been derived from depression measures (e.g., the Center for Epidemiologic Studies Depression Scale; Radloff, 1977) because they were often one of the few psychosocial factors included in studies of cardiovascular disease. ${ }^{\mathrm{b}}$ Although self-acceptance is highly correlated with traditional measures of self-esteem, they are considered distinct constructs, and both are often used in the same study (Paradise \& Kernis, 2002; Ryff, 1989). In this review, we only consider self-esteem if it is included in a composite with other well-being measures. ${ }^{\mathrm{c}}$ Most studies assessed trait positive affect in a single instance; however, occasionally studies measured positive affect repeatedly with either ambulatory methods, daily diaries, ecological momentary assessment, or the day reconstruction method (Kahneman, Krueger, Schkade, Schwarz, \& Stone, 2004). d The original positive affect scale was designed to be independent of negative affect and thus emphasized activated emotions like "active." An expanded version subsequently added conventional positive emotions like "happy." " Different time frames can be used when administering the Positive and Negative Affect Schedule to assess state or trait affect. Most studies considered trait PPWB rather than state PPWB. Studies that considered state PPWB (i.e., current well-being) are specified in Table 2 or in the text. ${ }^{\mathrm{f}}$ Studies that used the total Affect Balance Scale (i.e., negative affect score subtracted from positive affect score) or similar affect measures (e.g., McAuley et al., 2007) were not included because they represent a balance between positive and negative affect rather than positive affect exclusively. ${ }^{\mathrm{g}}$ Another perspective on optimism relates to the attributions that individuals make regarding past negative or positive events (i.e., explanatory style). The association between an optimistic disposition and an optimistic explanatory style is modest (Peterson \& Vaidya, 2001), suggesting that the two approaches to optimism are similar but emphasize different aspects of the construct (Carver et al., 2010). ${ }^{\mathrm{h}}$ The Life Orientation Test can yield either a total sum score with higher values indicating greater optimism or an optimism subscale and a pessimism subscale. We considered studies that reported findings for either the total sum score or the optimism subscale, but not the pessimism subscale.

\section{Hedonic Well-Being}

The dominant theory of hedonic well-being comes from Diener's notion of subjective well-being, which includes both cognitive and affective evaluations of one's life as a whole (Diener, Suh, Lucas, \& Smith, 1999; Kahneman, Diener, \& Schwarz, 1999). Cognitive evaluations are represented by life satisfaction assessments (both general and domain specific) and affective evaluations are represented by general levels of positive and negative affect. More colloquially, subjective well-being is often referred to as happiness and can be characterized as either a trait (i.e., a long lasting and relatively stable disposition) or a state (i.e., a short-term or temporary experience of a specific feeling; Diener et al., 1999). Although the vast majority of studies described in this review use trait measures of hedonic well-being, we specify when hedonic well-being is assessed as a state when pertinent.

\section{Optimism and Other Measures of Well-Being}

Other positive factors fall under the broad category of PPWB but are not easily classified as eudaimonic or hedonic. For example, optimism reflects generalized expectancies for the future and can be characterized either as a dispositional tendency to believe that good things will occur or as attributions regarding the causes of past events (Carver, Scheier, \& Segerstrom, 2010). Similarly, vitality (i.e., an enthusiastic zest for life and the capacity for regulation) and curiosity (i.e., inquisitiveness and desire to explore the surrounding world) do not perfectly reflect the dominant theoretical conceptions of eudaimonic and hedonic well-being. However, given their relevance to psychological functioning and to the larger concept of PPWB (Gallagher \& Lopez, 2009; Rozanski \& Kubzansky, 2005; Ryan \& Frederick, 1997) and because they have been strongly linked with cardiovascular outcomes, we include these constructs in our review.

\section{Conceptualizing the Role of PPWB in Cardiovascular Health}

Previous theoretical models regarding the association between positive psychological factors and health have largely been based on the literature linking psychological ill-being and health. Moreover, most theoretical models have emphasized a disease model of health - that is, they assume that the absence of unhealthy behaviors or disease-related biological markers is indicative of health. A focus on the absence of deteriorative processes in the context of disease has overshadowed the potential role of restorative processes (Pressman \& Cohen, 2005; Smith \& Baum, 2003). We posit that the relationship between PPWB and CVD is mediated by both the presence of restorative processes and the absence of deteriorative processes and propose a theoretical model to reflect this expanded approach (see Figure 1). PPWB is expected to be associated with engaging in restorative health behaviors like consuming fruits and vegetables and getting $8 \mathrm{hr}$ of sleep each night, as well as markers of restorative biological function like serum antioxidants (Smith \& Baum, 2003). Furthermore, PPWB is expected to be associated with a lower likelihood of engaging in deteriorative health behaviors like smoking and excessive alcohol consumption, as well as less biological dysfunction like inflammation.

In fact, many behavioral and biological factors lie on a continuum from restorative to deteriorative (e.g., ranging from frequent physical activity to complete inactivity or from low to high levels of cholesterol; Figure 2). However, some factors may be nonlinear, such that different levels have restorative or deteriorative effects on cardiovascular health (e.g., moderate 


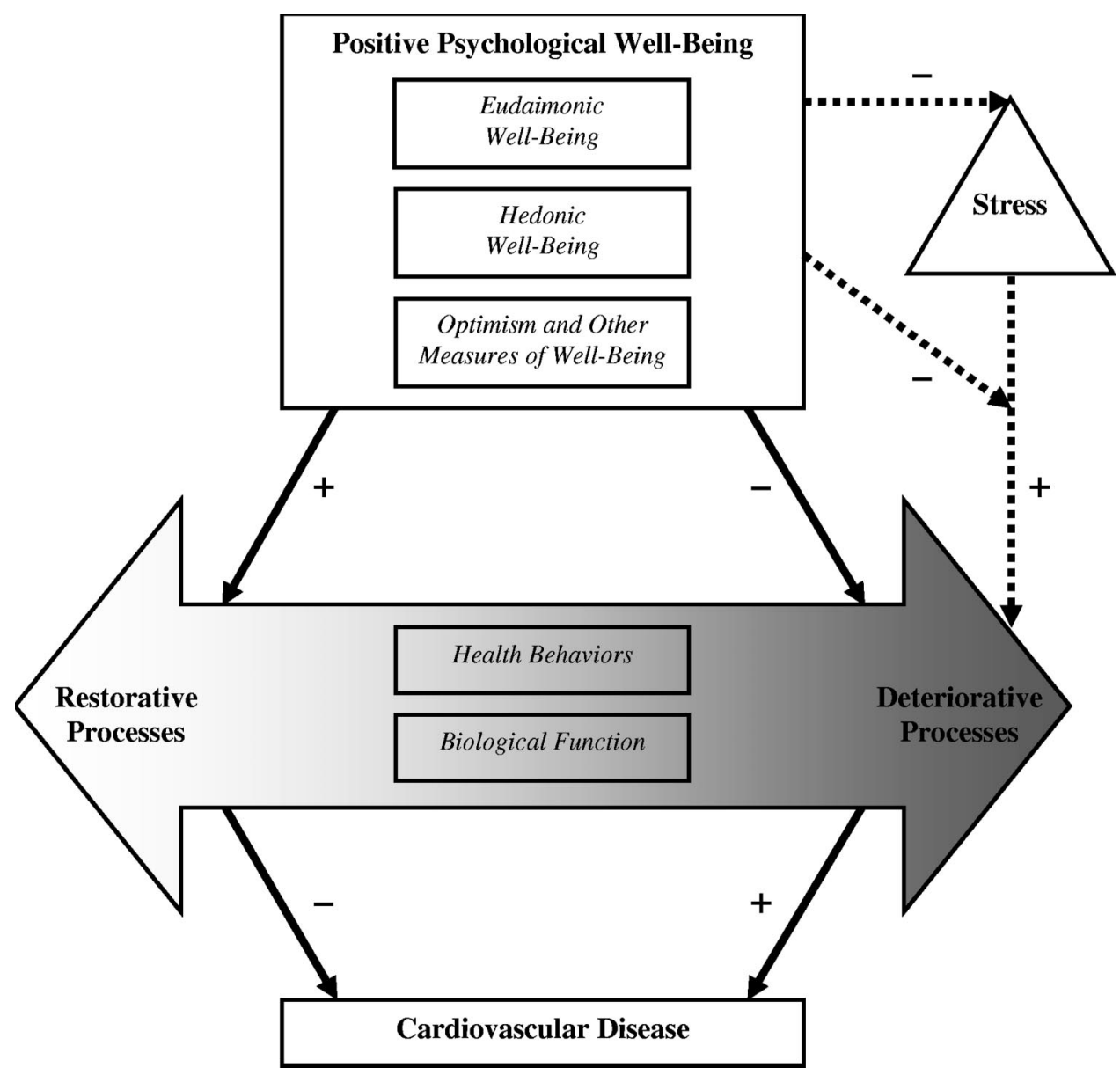

Figure 1. Model of positive psychological well-being and cardiovascular disease. Although the majority of health behaviors and biological function lie on a continuum from restorative to deteriorative, some may be nonlinear (e.g., too little or too much sleep is inversely associated with cardiovascular disease). For ease of presentation, such nonlinear relationships are not explicitly depicted in the model. In addition, the absence of arrows does not indicate that pathways do not exist but does indicate that they are not the focus of the present research.

versus excessive alcohol consumption). Additionally, some factors may clearly have primarily restorative (e.g., meditation) or deteriorative effects (e.g., cigarette smoking, atherosclerosis), whereby the absence of a process does not confer either deterioration or restoration. For biological markers in particular, researchers have yet to establish whether there are levels that might be restorative in relation to cardiovascular health rather than simply marking the absence of a deteriorative process (i.e., "normal" levels). Thus, at present, when considering their role in relation to PPWB and CVD, the appropriate continuum for many of these markers may be from nondeteriorative to deteriorative, and whether there is a restorative level per se remains to be determined. Although current knowledge is somewhat limited in terms of identifying processes that may enhance cardiovascular health, we believe that this reflects a lack of attention to this domain rather than that there is only a narrow set of restorative processes.

Another component of the model depicted in Figure 1 relates to the role of stress. PPWB could either directly reduce levels of experienced stress and/or could buffer the effects of stress
(Rozanski \& Kubzansky, 2005). The notion that PPWB may buffer the effects of stress has received somewhat more empirical attention. For example, in several experiments, Fredrickson and colleagues demonstrated that cardiovascular reactivity following an initially stressful situation (e.g., preparing a speech) returned to baseline more quickly among individuals who experienced a positive mood than among individuals who experienced a neutral mood (Fredrickson \& Levenson, 1998; Fredrickson, Mancuso, Branigan, \& Tugade, 2000). Less work has directly tested whether greater PPWB may mitigate the effect of stress on the likelihood of engaging in deteriorative health behaviors (e.g., consuming fatty and sugary food).

This review focuses specifically on evidence for an association between PPWB and CVD, as well as between PPWB and the restorative and deteriorative processes (i.e., health behaviors and biological function) involved in cardiovascular health. We also examine the extent to which the causal direction of the relationships can be determined. For the sake of simplicity, we do not indicate reverse causality in Figure 1 (or review studies depicting the reverse causal direction); however, this is not 


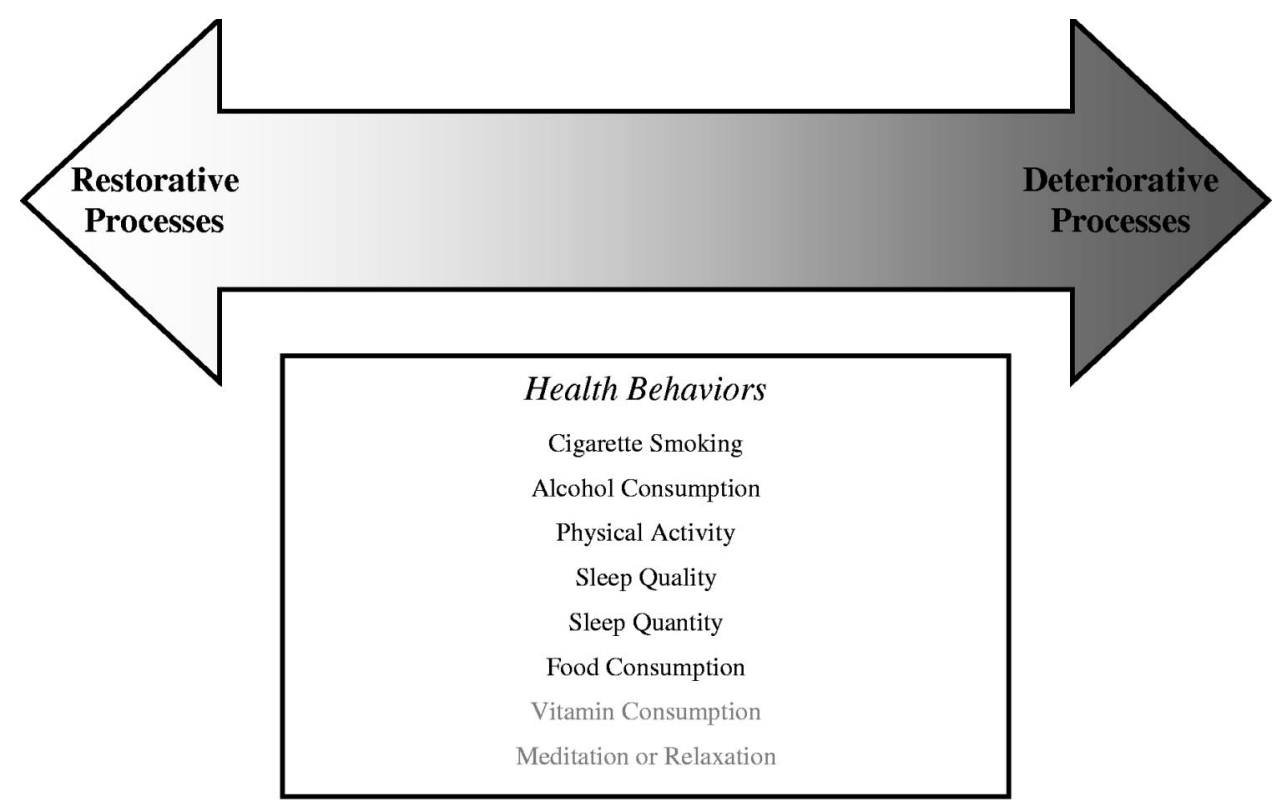

\begin{tabular}{|c|}
\hline Biological Function \\
Atherosclerosis and Calcification \\
Autonomic Cardiac Control \\
Blood Pressure \\
Heart Rate \\
C-Reactive Protein \\
Interleukin-6 \\
Soluble Interlukin-6 Receptor \\
Fibrinogen \\
Interleukin-10 \\
Telomere Length \\
Glycosylated Hemoglobin \\
Total Cholesterol \\
High-Density Lipoprotein Cholesterol \\
Low-Density Lipoprotein Cholesterol \\
Triglycerides \\
Body Mass Index \\
Antioxidants
\end{tabular}

Figure 2. Health behaviors and biological function associated with cardiovascular disease. Processes in gray are expected to be associated with positive psychological well-being, but no empirical evidence is yet available to support such predictions. Although many processes lie on a continuum from restorative to deteriorative (e.g., physical activity to physical inactivity), some may range from nondeteriorative to deteriorative (e.g., triglycerides), and others may be nonlinear (e.g., no versus moderate versus excessive alcohol consumption) or clearly deteriorative (e.g., cigarette smoking).

intended to suggest that it is not a possibility. Similarly, few studies of PPWB and cardiovascular health explicitly address the question of whether PPWB directly influences stress levels or buffers the effects of stress. As a result, these issues are rarely addressed in the review but remain to be evaluated in future research. In sum, the proposed model is a simplification of how these processes likely operate in the real world.

\section{Definition and Measurement of CVD, Health Behaviors, and Biological Function}

\section{Disease-Related Endpoints}

CVD generally represents a class of diseases such as CHD and cerebrovascular disease (i.e., stroke) that share similar physiolog- 
ical mechanisms. CHD can be characterized by fatal CHD (death occurring within $24 \mathrm{hr}$ of a myocardial infarction [MI]), nonfatal MI, and angina. Specific events like MI and stroke are considered "hard" outcomes because they are assessed by medical tests such as electrocardiograms, cardiac enzymes, and angiography. In contrast, a diagnosis of angina is based on self-reported pain and symptoms, which is considered a "soft" outcome because it is potentially confounded by self-report bias.

Although the physiological pathways leading to an initial cardiovascular event are similar to the physiological pathways leading to a secondary cardiovascular event, we review evidence regarding initial and secondary events separately. That is, studies with healthy populations are discussed separately from those with patient populations to account for PPWB's potentially distinct effects in the onset and progression of disease. PPWB may matter for both the onset and progression of disease or may differ based on the initiation versus exacerbation of disease.

\section{Health Behaviors}

Outcomes related to health behaviors are nearly all self-reported; we specify when objective assessments are used instead. Because most health behaviors are assessed on a continuum from restorative to deteriorative (e.g., healthy to unhealthy diet), we review studies without explicitly classifying behaviors as restorative or deteriorative. However, for those behaviors that have nonlinear associations with cardiovascular health (i.e., alcohol consumption, sleep quantity) or that are clearly deteriorative (i.e., cigarette smoking), we review studies according to whether the behavior measured is restorative or deteriorative. Meditation and vitamin consumption are included in Figure 2 but are not discussed further as no research has examined whether PPWB is associated with being more or less likely to meditate or take vitamins. Moreover, some research examines specialized populations (e.g., smokers) to see whether PPWB improves prior behavior, whereas other research examines healthy populations to see whether PPWB is related to initiating healthy behaviors or reducing unhealthy behaviors. Similar to the distinction between disease onset and progression, effects of PPWB on behaviors may differ depending on health status. However, because no review to date has compiled this research broadly, we include both types of studies and note the sample when relevant, but we recognize that processes may not be identical across samples.

Cigarette smoking. Smoking status is assessed by asking whether individuals are currently, were previously, or ever have been smokers. It is well-established that smoking has detrimental consequences for CVD, with evidence coming from epidemiologic studies (Ambrose \& Barua, 2004; Willett et al., 1987) and statements from the American Heart Association (Ockene \& Miller, 1997).

Alcohol consumption. Epidemiologic studies suggest that there is a $U$-shaped relationship between alcohol consumption and CVD risk, whereby low to moderate levels of alcohol consumption (typically defined as no more than 21 alcoholic drinks per week for men and 14 alcoholic drinks per week for women) are associated with a reduced risk of CVD and heavy alcohol consumption is associated with an increased risk of CVD (Elkind et al., 2006; Ikehara et al., 2008; Stampfer, Colditz, Willett, Speizer, \& Hennekens, 1988). Given that the amount of alcohol consumed is critical to cardiovascular health, we review studies based on a classification of self-reported restorative drinking (i.e., little to moderate consumption) and deteriorative drinking (i.e., excessive or problematic drinking, especially in underage samples). ${ }^{3}$

Physical activity. Physical activity is typically assessed by asking participants to indicate the extent to which they engage in light, moderate, or vigorous activity. Substantial evidence suggests that increased physical activity is associated with decreased risk of CVD (Nocon et al., 2008; Shiroma \& Lee, 2010) and that inactive or sedentary lifestyles are associated with increased risk (Katzmarzyk, Church, Craig, \& Bouchard, 2009; Stamatakis, Hamer, \& Dunstan, 2011).

Sleep quality. Sleep quality is usually assessed via selfreport. Poor sleep quality, which is often assessed with symptoms of insomnia (e.g., restless sleep, trouble falling asleep or staying asleep, waking up tired), has been associated with incident CVD (Phillips \& Mannino, 2007; S. W. Schwartz et al., 1998) and the recurrence of cardiac events in CHD patients (Leineweber, Kecklund, Janszky, Akerstedt, \& Orth-Gomer, 2003).

Sleep quantity. Sleep quantity has been characterized as restorative (adequate) or deteriorative (inadequate or excessive) and is typically assessed via self-report, although occasionally researchers use a small wrist sensor (i.e., a sleep actigraph) to measure sleep duration objectively. Especially short (6 hr or fewer per night) or long ( $9 \mathrm{hr}$ or more per night) sleep duration is associated with increased CVD risk (Ayas et al., 2003; Cappuccio, Cooper, D’Elia, Strazzullo, \& Miller, 2011; Shankar, Koh, Yuan, Lee, \& Yu, 2008). Thus, we review studies based on the classifications of adequate or inadequate/excessive sleep duration.

Food consumption. Dietary intake is routinely assessed through self-reported food frequency questionnaires. Food consumption encompasses diverse outcomes including restorative food intake such as fruits, vegetables, and fiber, as well as deteriorative food intake such as high fat food and refined sugar. Some studies combine food outcomes into dietary "patterns," whereas others separate food-related outcomes and examine individual associations with disease outcomes. Regardless, substantial evidence suggests that healthy food intake is inversely associated with CVD, and unhealthy food intake is positively associated with CVD (Hu et al., 2000; Hu \& Willett, 2002; Mente, de Koning, Shannon, \& Anand, 2009).

\section{Biological Function}

Outcomes related to the underlying biological processes of CVD are considered relatively objective endpoints because they are assessed with well-established medical tests. Atherosclerosis and calcification are underlying disease processes that lead to CVD, and they can be measured to assess the level of atherosclerotic burden; such measurements are often used as surrogate or predisease indicators of CVD risk. Heart rate variability (HRV; an indicator of autonomic cardiac control), blood pressure (BP), and heart rate are measures of cardiovascular function. Other biological measures include markers of inflammation, endothelial function, and metabolic function. An exception to objectively assessed biological markers is body mass index (BMI), which is an indicator of metabolic function. When objective measures of weight and

\footnotetext{
${ }^{3}$ Alcohol abstinence was not often examined in the reviewed studies, so we do not discuss that consumption level.
} 
height are unavailable, some studies use self-reported weight and height to calculate BMI.

Biological markers may indicate deteriorative, nondeteriorative (i.e., in the normal range), or restorative processes, depending on the level. However, much of the research to date has focused on whether PPWB protects from deteriorative processes rather than enhances restorative ones. Indeed, no known standards indicate whether certain levels signal anything desirable beyond the absence of deteriorative processes or, in other words, superior biological functioning. Although autonomic cardiac control and highdensity lipoprotein (HDL) cholesterol are often discussed as potentially "good" biological markers (Segerstrom \& Nes, 2007; Toth, 2005), they still lie on a continuum of low to high where it is unclear whether benefit exists beyond "normal" levels. Other biological markers like serum antioxidants are also associated with a reduced risk of CVD, but to date no research has investigated their association with PPWB. Thus, with the exception of atherosclerosis and calcification (for which any level signals deterioration), we review the evidence in the context of a continuum ranging from deteriorative to nondeteriorative.

Atherosclerosis and calcification. Atherosclerosis occurs when an artery wall thickens due to the buildup of fatty materials resulting from endothelial injury, production of adhesion molecules, stickiness of platelets, increases in proinflammatory cytokines, and lipid accumulation in plaque. Such plaque may narrow and/or rupture the arteries, causing an insufficient blood supply to the tissues and organs or a clot that could abruptly slow or stop blood flow. Coronary artery calcification occurs with other atherosclerotic processes and refers to the thickening of the arteries due to calcium buildup. Both atherosclerosis and calcification indicate an increased risk of CVD (Black \& Garbutt, 2002; Wexler et al., 1996) and are exclusively deteriorative.

Autonomic cardiac control. The sympathovagal balance in the autonomic innervation of the heart predicts the risk of adverse cardiac events. Sympathetic activity decreases the threshold for cardiac dysfunction, whereas vagal (parasympathetic) activity raises the threshold and protects against various forms of dysfunction (Thayer \& Lane, 2007; van Ravenswaaij-Arts, Kollee, Hopman, Stoelinga, \& van Geijn, 1993; Wharton, Coleman, \& Strauss, 1992). HRV provides a noninvasive measure of sympathovagal balance, and low levels serve as a marker for an increased risk of cardiac death (G. J. Martin et al., 1987; Mølgaard, Sorensen, \& Bjerregaard, 1991; Thayer \& Lane, 2007). Vagal tone may be assessed with measures of respiratory sinus arrhythmia or by the high frequency components of HRV (Thayer \& Lane, 2007).

Cardiovascular function. $\mathrm{BP}$ and heart rate are indicators of cardiovascular function. High BP is one of the most important risk factors for CVD (Chobanian et al., 2003). Normal tonic heart rate indicates appropriate sympathovagal balance (Uijtdehaage \& Thayer, 2000); high heart rate indicates autonomic imbalance and is associated with elevated cardiovascular morbidity and mortality (Brook \& Julius, 2000; Thayer \& Lane, 2007).

Inflammation and hemostasis. Several inflammatory biological markers have been used as markers of CVD risk. High levels of C-reactive protein (CRP) are indicative of chronic inflammation and are consistently associated with an increased risk for adverse cardiac outcomes (Danesh et al., 2004; Pearson et al., 2003; Pradhan, Manson, Rifai, Buring, \& Ridker, 2001). Interleukin-6 (IL-6) is a proinflammatory cytokine that promotes production of CRP, that increases in response to acute stress, and that has also been linked with risk of CVD (Black \& Garbutt, 2002; Steptoe et al., 2009). Similarly, soluble IL-6 receptor (sIL-6r) is another proinflammatory factor. Fibrinogen is a precursor to fibrin that can form stable clots and increase coagulation and blood viscosity. One study has also considered PPWB in relation to a nonstimulated "healthy" inflammatory response or circulating anti-inflammatory marker (e.g., interleukin-4, interleukin-10, interleukin-12), and we mention it briefly. Most studies assess circulating levels of inflammatory biomarkers rather than stimulated cytokines. Limited work has considered other biological markers of immunosenescence (e.g., telomere length) or hemostasis (e.g., D-dimer).

Metabolic function. Metabolic function refers to chemical reactions that enable individuals to function and respond to their environment. Metabolic markers that are of particular relevance for cardiovascular health include glucose, lipids, and BMI. Glycosylated hemoglobin $\left(\mathrm{HbA}_{1 \mathrm{c}}\right)$ indicates blood glucose concentrations and reflects how well glucose levels are controlled over time (American Diabetes Association, 2008). Monitoring $\mathrm{HbA}_{1 \mathrm{c}}$ can identify people at risk for CVD in healthy populations and people who are prediabetic or diagnosed with diabetes (Gerstein, 2004; Khaw et al., 2004; Muntner et al., 2005). Lipids include total cholesterol, HDL cholesterol, low-density lipoprotein (LDL) cholesterol, and triglycerides. The increased risk of CVD due to unhealthy lipid levels (i.e., high levels of total cholesterol, low levels of HDL cholesterol, high levels of LDL cholesterol, and high levels of triglycerides) is well-established (Gordon, Castelli, Hjortland, Kannel, \& Dawber, 1977; Sarwar et al., 2007; Stamler et al., 2000). BMI has also been identified as a risk factor for CVD (Manson et al., 1990) and represents body fat calculated from an individual's weight and height.

\section{Methodology and Organization of the Review}

In the following sections, we review evidence examining an association between PPWB and cardiovascular health. To this end, we first consider prospective studies investigating the relationship between PPWB and CVD, defined by objective indicators of CHD, stroke, or cardiovascular mortality (see Table 2). Because experimental studies are not feasible, prospective studies represent the strongest possible test of the hypothesis that PPWB influences disease rather than vice versa. We examine separately how PPWB is related to CVD incidence (i.e., onset of a first disease-related event in healthy populations) or CVD progression (i.e., recurrence of a disease-related event in patient populations). For disease incidence, we include only those studies that exclude individuals with some form of CVD at the time PPWB is assessed. For disease progression, we include studies regardless of whether they account for disease severity at the time PPWB is assessed but highlight studies that account for baseline disease status because these are the strongest methodologically. In addition, in our review of incident disease, we do not separate studies with fatal versus nonfatal outcomes because these both represent first cardiac events. Similarly, researchers often collapse CHD and stroke outcomes into a broader CVD category, so we do the same here and separate the two only when data are available to do so.

Next, we consider the restorative and deteriorative processes by which PPWB may be associated with CVD: via health behaviors and 
WELL-BEING AND CARDIOVASCULAR HEALTH

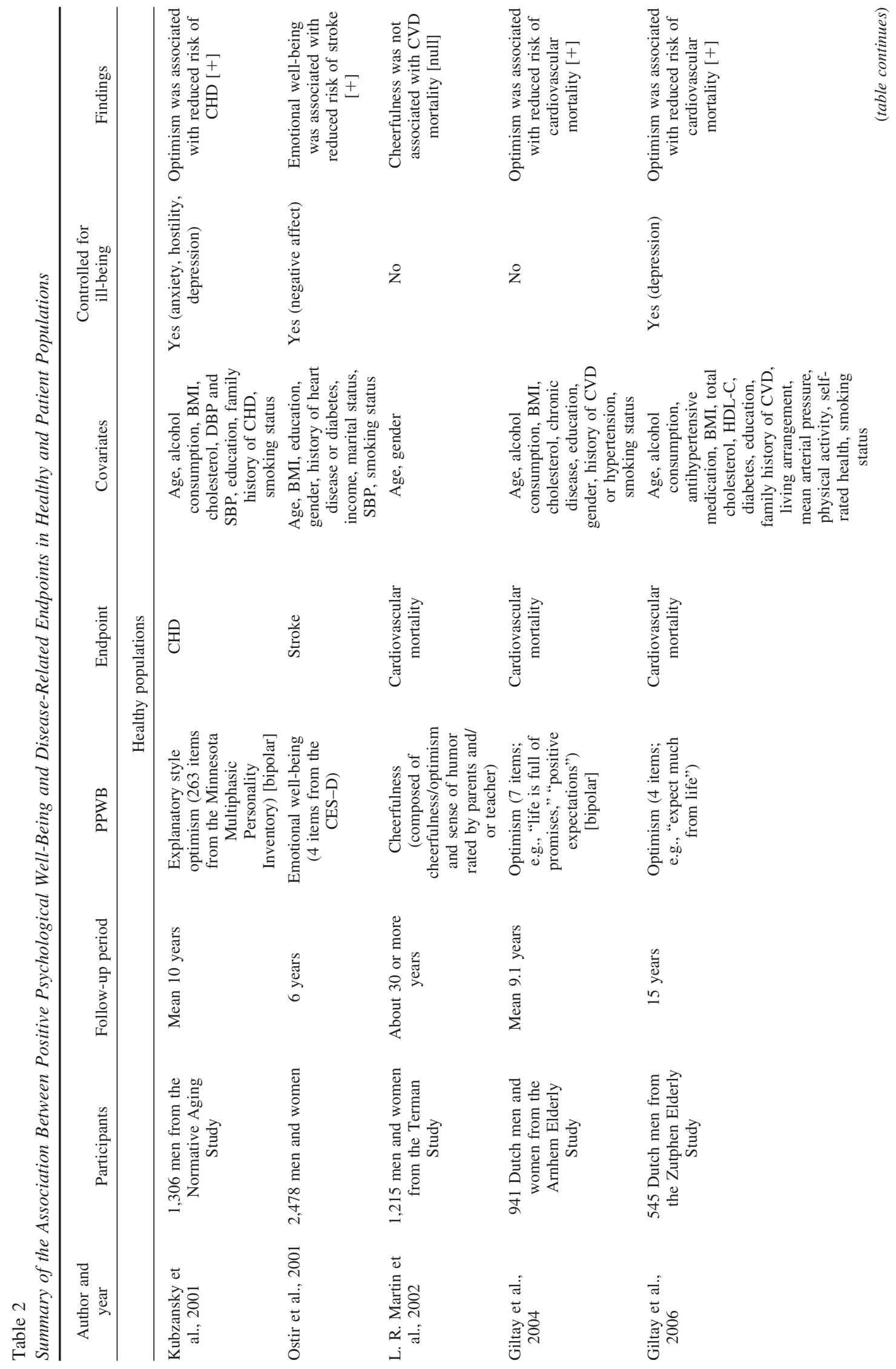




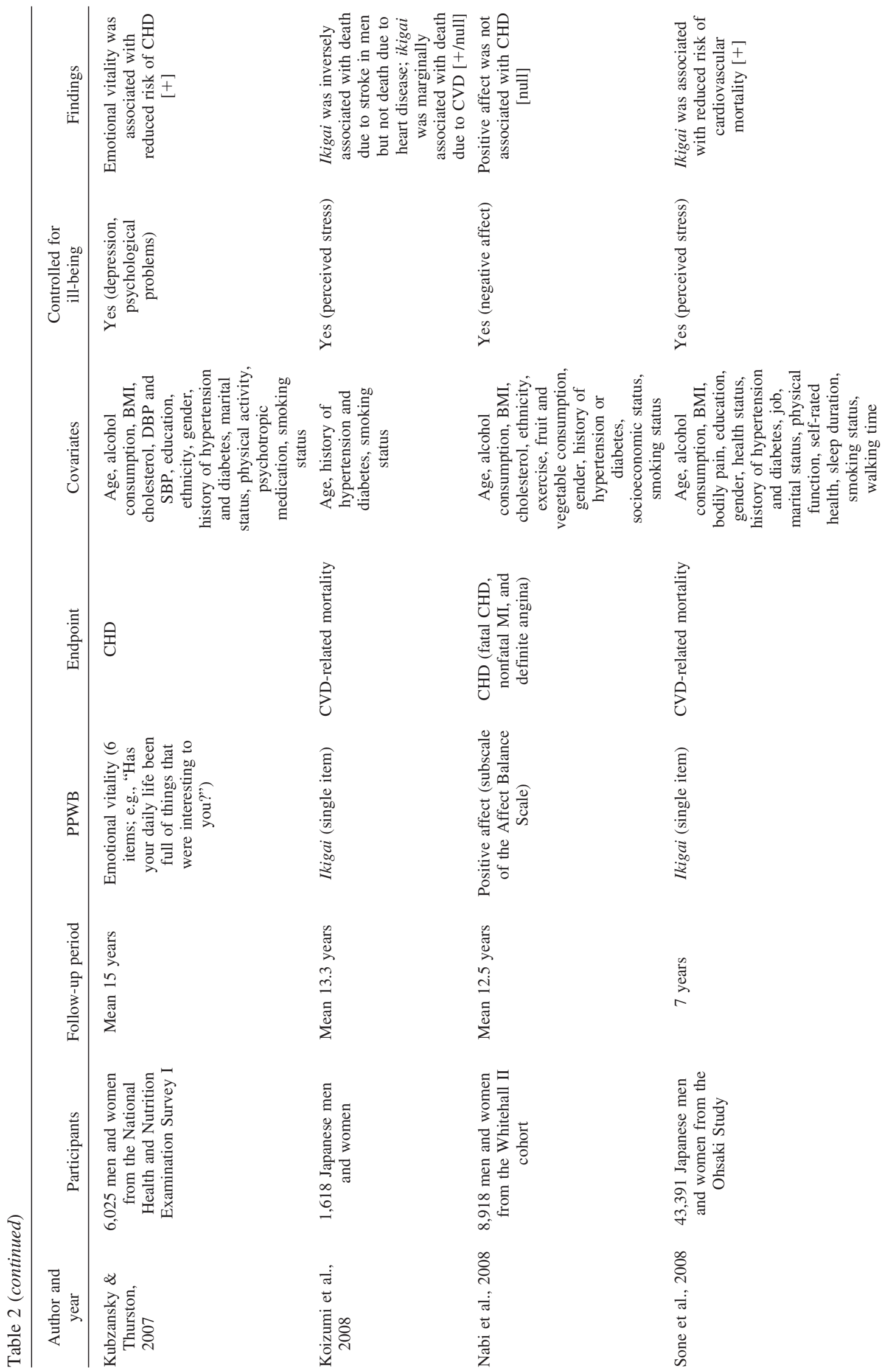




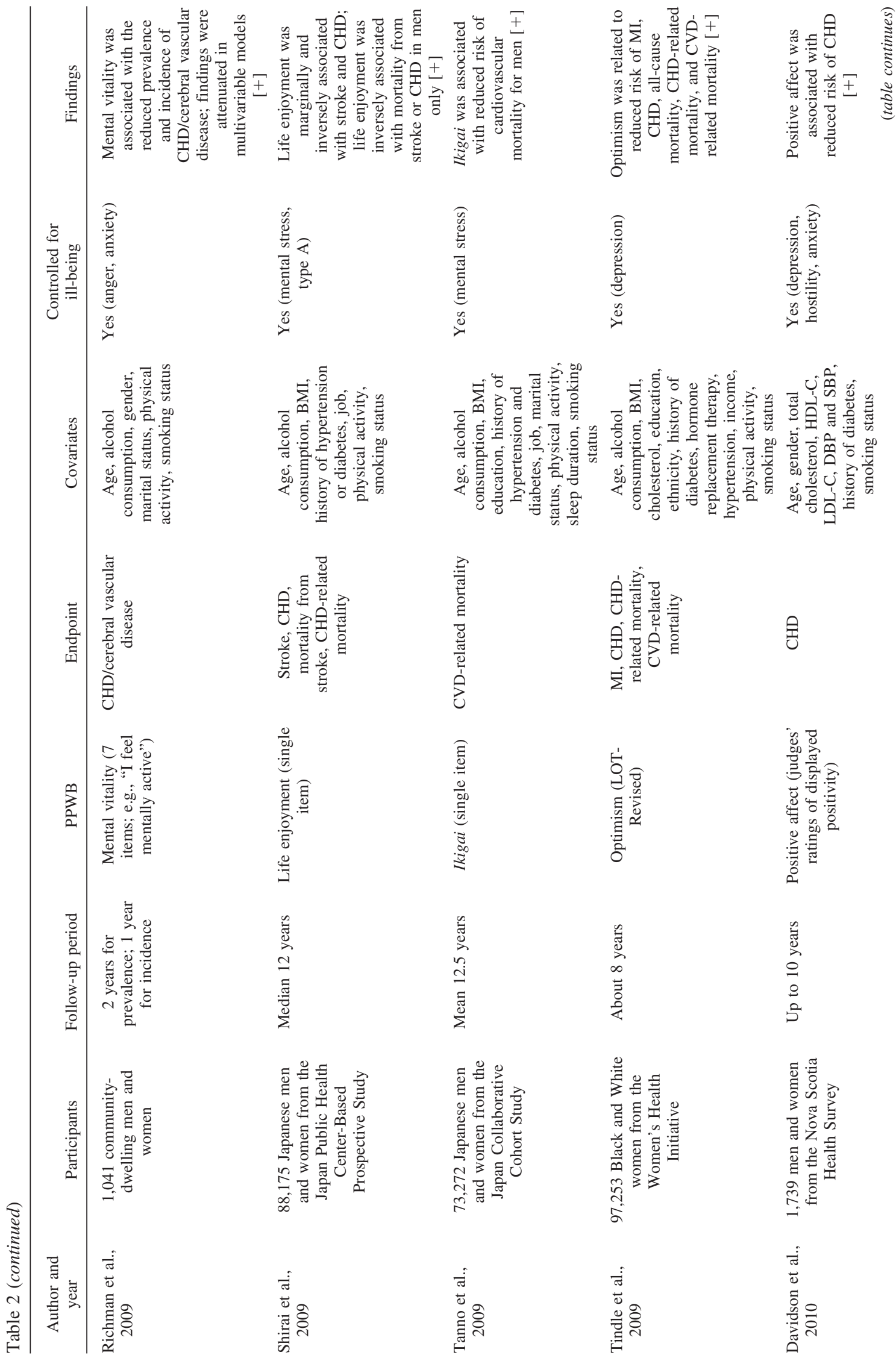




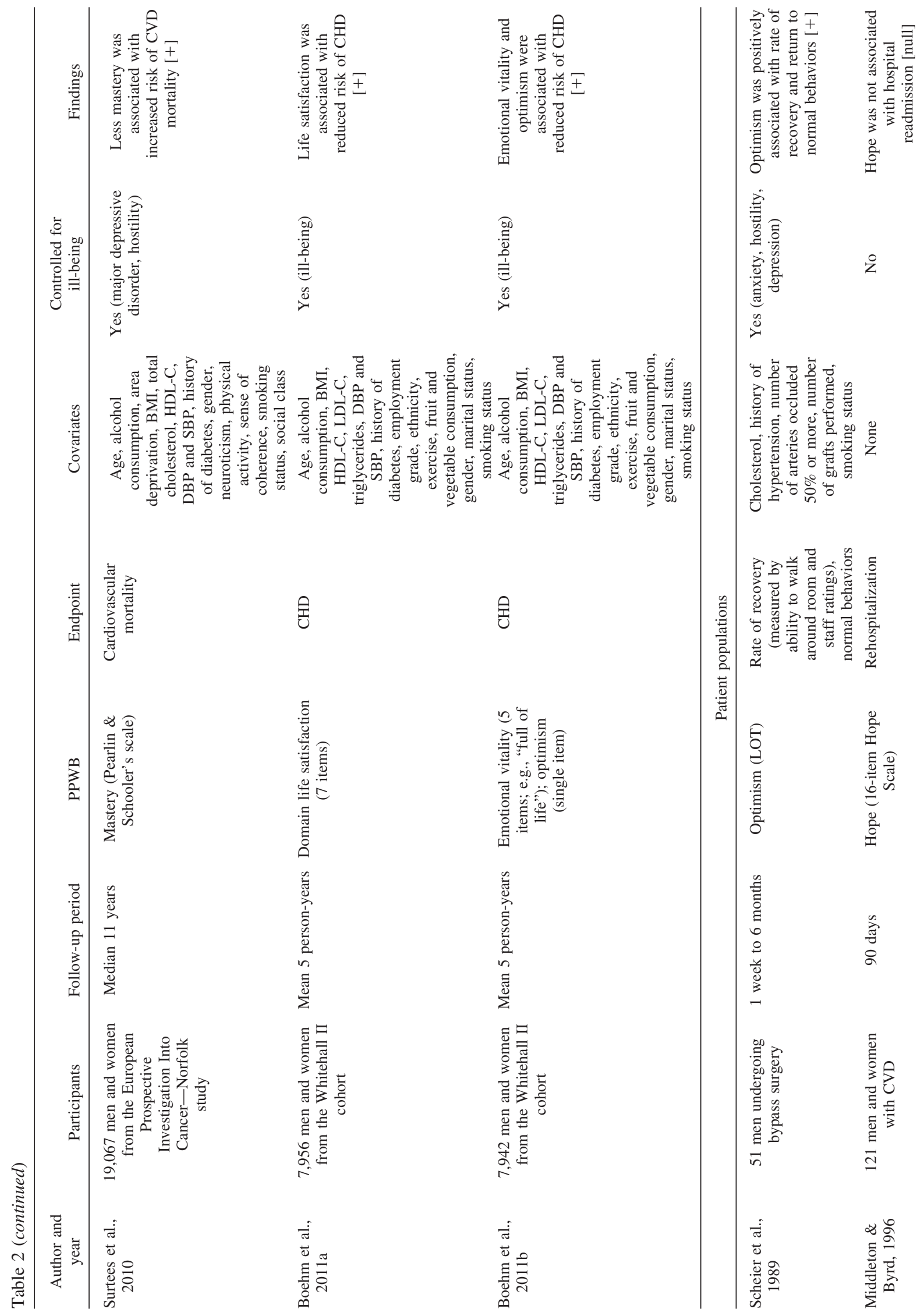




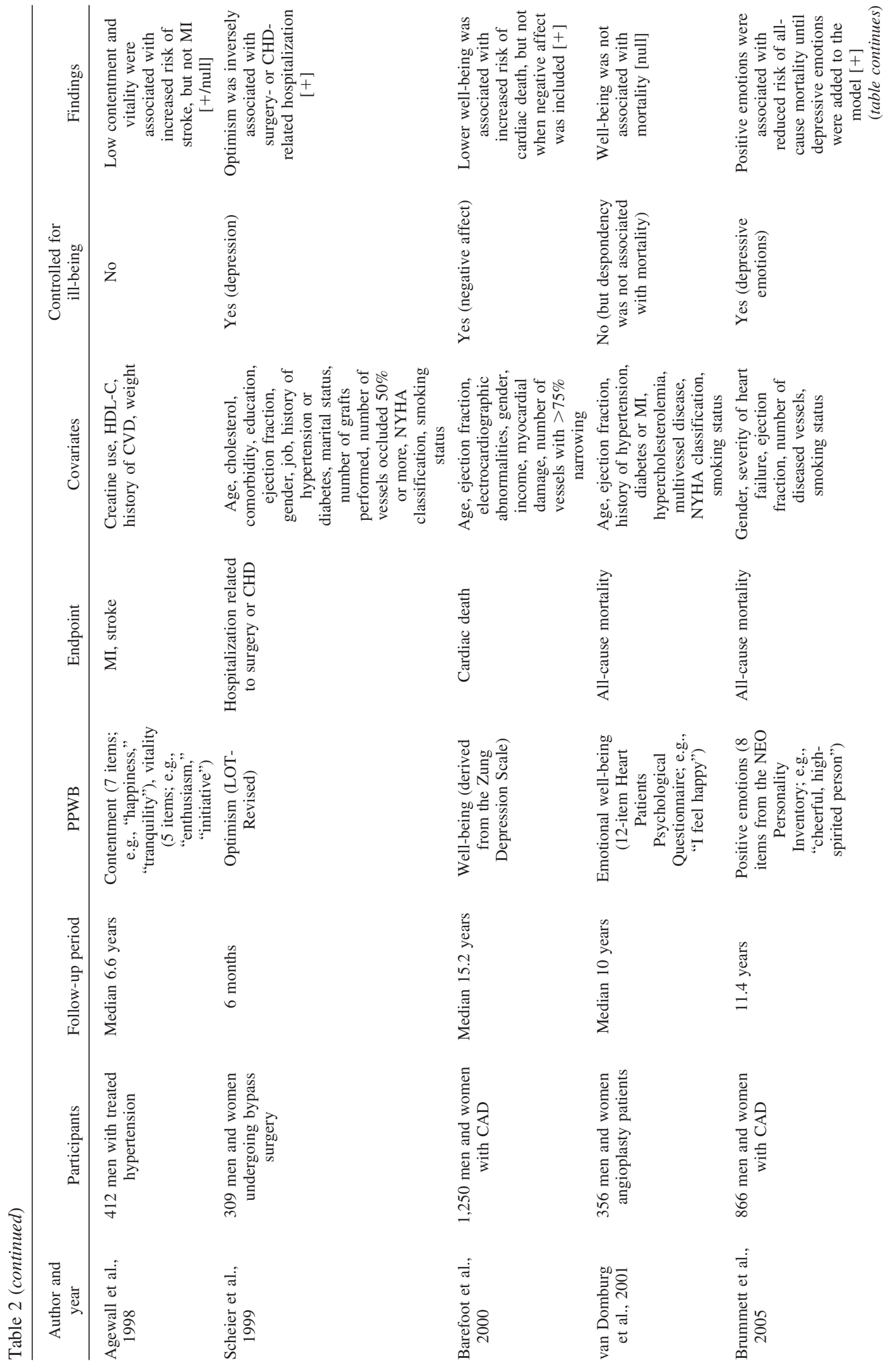




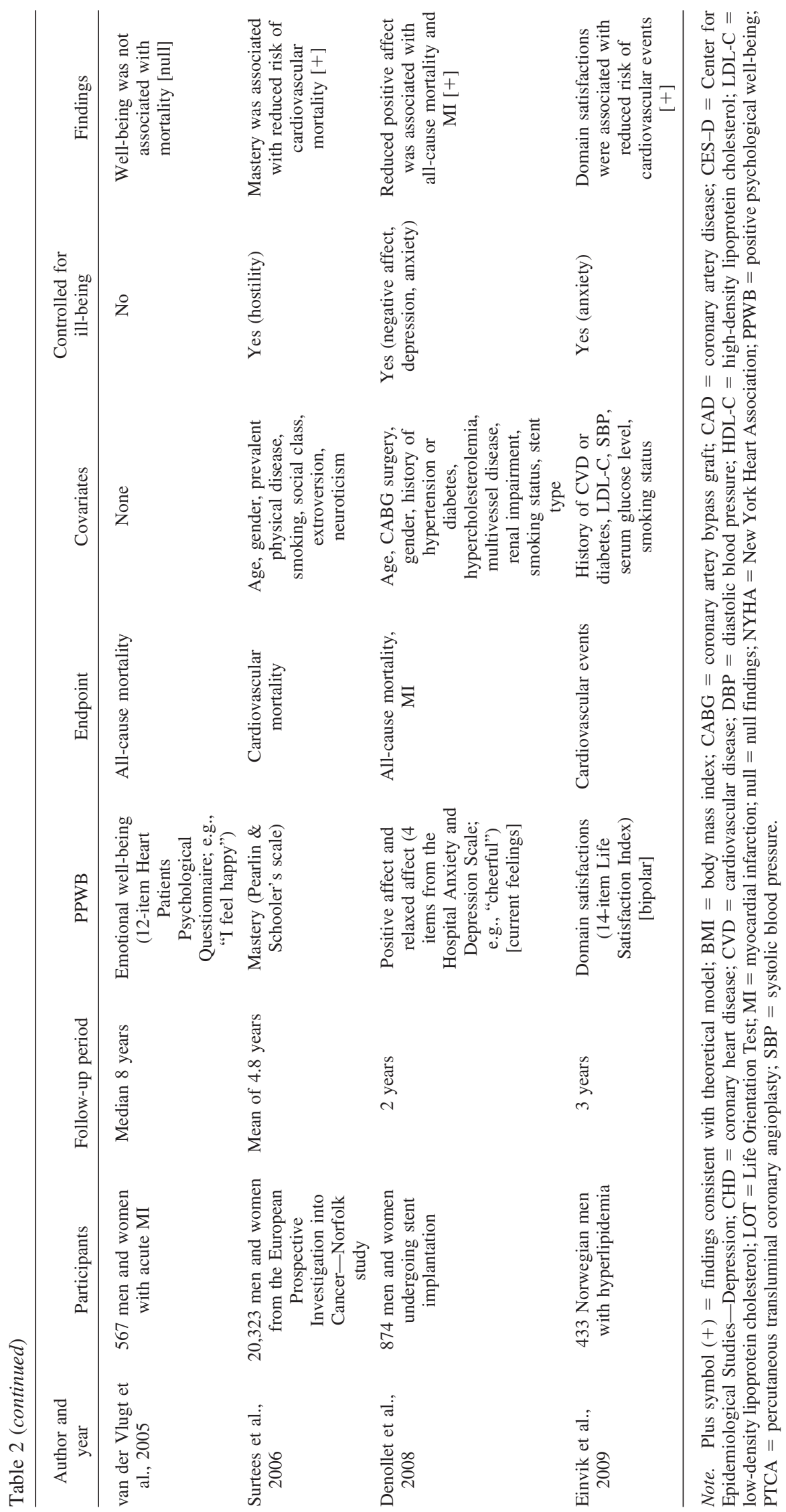


biological function. We consider behaviors and biological processes that have been identified as relevant for CVD and that have been empirically examined in relation to PPWB. Thus, because the direct relationship between cortisol and risk of CVD is still somewhat unclear (Kubzansky \& Adler, 2010), we do not review evidence of the association between PPWB and cortisol. For similar reasons, we do not consider opioids. In addition, although aldosterone has been identified as a potentially relevant biological marker by which psychosocial factors may influence CVD (Kubzansky \& Adler, 2010), we know of no work to date that has looked at aldosterone in conjunction with a measure of PPWB.

We conducted literature searches in the PubMed and PsycINFO databases to identify relevant articles. CVD search terms included variations of $C V D, C H D$, and stroke. Search terms for health behaviors and biological function included variations of cigarette smoking, alcohol consumption, physical activity or sedentary lifestyle, sleep, nutrition, vitamin consumption, atherosclerosis, calcification, $H R V, B P$, hypertension, heart rate, fibrinogen, IL-6, $C R P, H b A_{I c}$, cholesterol or lipids, and BMI. PPWB-related search terms included variations of well-being, purpose in life, mastery or control, personal growth, self-acceptance, autonomy, happiness, satisfaction, positive affect/emotion/mood, optimism or hope, and vitality. Well-being constructs that were specific to a single life domain (e.g., job control, marital satisfaction) are often covered in other literatures and are not included here to maintain reasonable limits on the scope of the current review. CVD-related terms and PPWB-related terms were crossed in all searches. Reference lists of obtained articles were also reviewed for additional sources.

We excluded studies if they (a) were not written in English, (b) included only measures of PPWB that overlapped substantially with self-reported health or physical functioning (including physical exhaustion $){ }^{4}$ (c) included only reverse indicators of PPWB (e.g., pessimism) or constructs that reflected varying levels of ill-being, ${ }^{5}$ (d) included only PPWB measures related to humor or laughter, ${ }^{6}$ (e) included experimental manipulations of state PPWB, ${ }^{7}$ (f) included only self-reported measures of disease events or mortality, ( $\mathrm{g}$ ) did not include a relevant disease, behavioral, or biological outcome, (h) included heart transplant patients or a majority of patients with congestive heart failure (or heart failure outcomes), ${ }^{8}$ (i) included patients with diseases other than CVD, ${ }^{9}$ (j) included the administration of a vaccine or virus and then subsequently measured a biological marker, and (k) included infants or young children.

In addition, for studies with disease-related endpoints, we included only longitudinal designs so that we could make stronger conclusions about causal direction. In contrast, because much of the evidence regarding behaviors and biology is cross-sectional, it would be difficult to evaluate the state of the knowledge if such studies were excluded. ${ }^{10}$ Thus, where possible, we describe evidence directly assessing whether PPWB precedes alterations in behaviors and biology but include exemplar cross-sectional studies when longitudinal studies do not exist or findings are mixed. When only cross-sectional studies are described, longitudinal evidence is unavailable. We also note when studies control for potential confounders (e.g., age, education) or ill-being but do not mention covariates when studies do not include them. Finally, we refer to single studies multiple times if they examine several different behavioral or biological outcomes.
To gain greater insight into PPWB's role in cardiovascular health and utilize the greatest amount of information currently available, the review that follows is narrative rather than quantitative. A meta-analysis is not feasible because we consider diverse measures of PPWB in various forms (e.g., continuous versus dichotomous), as well as a diverse set of outcomes. Thus, our goals in this article are to comprehensively review previous work to assess the state of the current research, determine the overall relationship between PPWB and cardiovascular health, evaluate the different theoretical approaches to PPWB (i.e., eudaimonic well-being, hedonic well-being, optimism, and other measures of well-being) for their relevance to cardiovascular health, and discuss methodological challenges and directions for future research (Bem, 1995).

\section{PPWB and Cardiovascular Health}

\section{Disease-Related Endpoints}

Healthy populations.

Eudaimonic well-being. In the four studies examining the association between eudaimonic well-being and incident CVD, researchers considered two different constructs: mastery and ikigai. Having a sense of mastery or control over one's environment was associated with a reduced risk of CVD in a cohort from the European Prospective Investigation into Cancer (Surtees et al., 2010). That is, after controlling for traditional risk factors (e.g., demographic, biological, and behavioral factors), as well as major depressive disorder and hostility, individuals with a greater sense of control had a diminished risk of cardiovascular-related death over 11 years.

Three studies investigated the association between ikigai and CVD-related mortality. In general, Japanese people with higher

\footnotetext{
${ }^{4}$ This exclusion criterion refers specifically to studies that used an indicator of quality of life or of health-related quality of life, which are often confounded by physical symptoms or health. One study reported here did use the term quality of life to refer to the constructs of contentment and vitality (Agewall, Wikstrand, \& Fagerberg, 1998), but for greater specificity we described the study in terms of the more precise indicators of contentment and vitality.

${ }^{5}$ Bipolar scales (e.g., happy to unhappy) were included and are noted in Table 2 .

${ }^{6}$ Some multi-item composites of PPWB included items about laughter or humor; when these were combined with other PPWB items, we reported the findings but recognize that they are a less "pure" measure.

${ }^{7}$ We did not review studies that experimentally manipulated positive affect; evaluating whether induced transient states create biological and behavioral alterations similar to enduring dispositions is beyond the scope of this review.

${ }^{8}$ We excluded this group of patients because the underlying processes leading to heart failure or transplant may be related to congenital defects or infection, which may differ from the processes leading to CVD.

${ }^{9}$ Because diabetes is a strong risk factor for CVD, we included individuals with Type II diabetes (adult onset, noninsulin dependent) in studies of glucose regulation.

${ }^{10}$ Prospective designs that control for baseline levels of an outcome are very rare in the behavioral and biological literatures, but we note any longitudinal study that controls for initial levels of an outcome.
} 
levels of ikigai were less likely to die from CVD over follow-up periods ranging from 7-13 years than were their counterparts with lower levels of ikigai, and effects were maintained after accounting for traditional risk factors and ill-being (Koizumi, Ito, Kaneko, \& Motohashi, 2008; Sone et al., 2008; Tanno et al., 2009). In one study that followed more than 70,000 Japanese men and women for an average of 12 years, death from CVD was less likely for men who reported having ikigai (hazard ratio $[\mathrm{HR}]=0.78,95 \%$ confidence interval [CI] [0.64, 0.96]), relative to those without ikigai (Tanno et al., 2009). For women, the same association was evident in age-adjusted models, but the effect became slightly attenuated in multivariable models. In another Japanese sample that followed 40,000 men and women for 7 years, individuals without ikigai were at greater risk of death from cardiovascularrelated causes $(\mathrm{HR}=1.6,95 \%$ CI $[1.2,2.9])$, relative to individuals with ikigai (Sone et al., 2008). Although some of the ikigai studies reported stronger findings for men versus women or one type of CVD versus another, most of these inconsistencies seem to be related to inadequate power to detect effects. For example, in one study, there were less than 10 cases of women who died from stroke (Koizumi et al., 2008). Even though ikigai was assessed with a single item across all three studies, it was still consistently related to risk of CVD.

Hedonic well-being. Findings regarding the association between hedonic well-being and cardiovascular events are somewhat less consistent across six total studies but still point to a relationship. One study of nearly 2,500 North American men and women showed that emotional well-being (derived from items on a depression scale) was associated with a $26 \%$ reduced risk of stroke 6 years later, 95\% CI [0.62, 0.88], even after accounting for traditional risk factors and negative affect (Ostir, Markides, Peek, \& Goodwin, 2001). Similarly, in a study of nearly 8,000 British civil servants, greater life satisfaction was associated with a reduced risk of CHD after accounting for relevant risk factors (Boehm, Peterson, Kivimaki, \& Kubzansky, 2011a). Another study of approximately 88,000 Japanese men and women replicated these results over a median of 12 years (Shirai et al., 2009). In men, low life enjoyment was associated with an increased risk of nonfatal CVD $(\mathrm{HR}=1.23,95 \%$ CI $[1.05,1.44])$, and mortality from CVD $(\mathrm{HR}=1.61,95 \% \mathrm{CI}[1.32,1.96])$. These findings—which controlled for cardiovascular risk factors and were slightly attenuated after including perceived stress and Type A traits- did not hold for women, perhaps because case counts were too small.

Three additional studies have considered the relationship between positive affect and CHD. In one, judges assessed the positivity depicted in the faces of 1,700 participants during a structured interview, which served as a non-self-report measure of dispositional positive affect (Davidson, Mostofsky, \& Whang, 2010). Greater displays of positive affect were associated with a $22 \%$ reduced risk of CHD up to 10 years later, 95\% CI [0.63, 0.96], controlling for major coronary confounders and three measures of ill-being. By contrast, another study showed no relationship between self-reported positive affect and incident CHD over 12 years of follow-up, regardless of which covariates were (or were not) included in the models (Nabi, Kivimaki, De Vogli, Marmot, \& Singh-Manoux, 2008). The null findings in this study are particularly striking given the extensive follow-up period, a sufficient number of cases to detect effects $(>600)$, and a well-validated measure of well-being (a subscale of the Affect Balance Scale).
One other study has also reported a null association between positive affect and CVD. In the Terman Study of gifted children, parents and/or teachers rated children's cheerfulness in 1922, when children were on average 11 years old (L. R. Martin et al., 2002). Mortality was assessed in an adult follow-up of these children (from 1950 to 1986), but mortality due to CVD was not associated with cheerfulness. The weak reliability of the cheerfulness measure $(\alpha=.52)$ may be partly responsible for the null findings. However, considering the limited set of studies to date, findings for an association between positive affect and CHD are not entirely consistent.

Optimism and other measures of well-being. Eight total studies have investigated the association between CVD and indicators such as optimism and vitality; all have demonstrated a reduced risk of CVD with greater levels of well-being. For example, more than 1,000 men from the Normative Aging Study were followed an average of 10 years (Kubzansky, Sparrow, Vokonas, \& Kawachi, 2001). An explanatory style measure of optimism was associated with reduced CHD risk after accounting for typical risk factors (e.g., age, education, alcohol intake, BMI, cholesterol, BP, family history of CHD), and findings were not attenuated after controlling for three measures of ill-being (anxiety, anger/hostility, and depression).

The association between optimism and CHD has been replicated with dispositional optimism measures as well. For example, greater optimism was related to a reduced risk of death from cardiovascular events in elderly Dutch men and women 9 and 15 years later, even when accounting for traditional cardiovascular risk factors and depression (Giltay, Geleijnse, Zitman, Hoekstra, \& Schouten, 2004; Giltay, Kamphuis, Kalmijn, Zitman, \& Kromhout, 2006). In a study by Tindle et al. (2009), nearly 100,000 Black and White women were followed over 8 years. Dispositional optimism was associated with a reduced risk of CVD and CVDrelated mortality, controlling for risk factors and depression. Furthermore, among British men and women followed for an average of 5 person-years, the highest levels of optimism were associated with a reduced risk of CHD, accounting for a wide range of covariates, including ill-being (Boehm, Peterson, Kivimaki, \& Kubzansky, 2011b). Notably, all of these prospective studies of optimism had lengthy follow-up periods, controlled for potential confounders, and with the exception of one (Giltay et al., 2004), accounted for some form of ill-being such as anxiety, depression, or anger. In all cases, evidence for an association was maintained after adjusting for potential confounders and ill-being. It is also striking how similar the magnitude of the effect was even when different measures of optimism were used, with most studies demonstrating an approximately 50\% reduced risk of CVD associated with optimism.

Three other studies investigated the association between vitality and CVD. One study examined emotional vitality in relation to CHD in a nationally representative sample of 6,000 men and women from the National Health and Nutrition Examination Survey (Kubzansky \& Thurston, 2007). An average of 15 years after baseline, higher levels of vitality were associated with a $20 \%$ reduced risk of incident $\mathrm{CHD}$, controlling for traditional cardiovascular risk factors and ill-being. A second study examined the association between emotional vitality and CHD in a sample of British civil servants (Boehm et al., 2011b). After accounting for conventional risk factors as well as ill-being, the highest levels of 
emotional vitality were associated with a $28 \%$ reduced risk of CHD, 95\% CI [0.54, 0.97]. A third study considered vitality in relation to incident CHD and cerebrovascular disease (Richman, Kubzansky, Maselko, Ackerson, \& Bauer, 2009). One year after the initial assessment of vitality, a reduced risk of CHD and cerebrovascular disease was evident for men and women with the greatest vitality. These findings were somewhat attenuated in models that accounted for confounders as well as anger and anxiety.

Summary of disease-related findings in healthy populations. Taken together, studies that investigated the association between PPWB and first occurrences of cardiovascular events demonstrate that PPWB protects against CVD, even when controlling for typical cardiovascular risk factors and ill-being. Findings are strongest with optimism and vitality.

\section{Patient populations.}

Eudaimonic well-being. Only one study examined the association between eudaimonic well-being and CVD in a patient population. In more than 20,000 participants aged $40-80$ years, a greater sense of control was associated with a reduced risk of cardiovascular mortality 5 years later (Surtees, Wainwright, Luben, Khaw, \& Day, 2006). The association held after controlling for demographics, prevalent disease (e.g., heart attack, stroke, diabetes), smoking, and personality factors like extroversion, neuroticism, and hostility.

Hedonic well-being. Evidence from seven studies tentatively points to an association between hedonic well-being and disease progression. In many of these studies, however, the effects of the absence rather than the presence of hedonic well-being were assessed. For example, men and women with reduced positive affect had an increased risk of all-cause mortality and MI in the 2 years following stent implantation, relative to those with greater positive affect $(\mathrm{HR}=2.55,95 \%$ CI $[1.46,4.34]$; Denollet et al., 2008). The analyses, in which severity of disease and other risk factors were controlled for, also suggested that the effect of low positive affect on prognosis was comparable to the effect of having diabetes, a conventional risk factor for CVD.

Two studies examined the association between hedonic wellbeing and death in male and female patients with coronary artery disease. In the first $(N=1,200)$, low levels of positive well-being were associated with an increased risk of cardiac death over a median of 15 years (Barefoot et al., 2000). The effect remained after controlling for risk factors and disease severity but was attenuated to nonsignificance after adjusting for negative affect. In the second, a similar pattern was evident in 800 cardiac patients. Higher levels of positive emotions were associated with a reduced risk of all-cause mortality over 11 years $(\mathrm{HR}=0.88,95 \% \mathrm{CI}$ $[0.72,1.07])$, controlling for disease severity and risk factors (Brummett et al., 2005). However, the effect was slightly attenuated when depressive emotions were simultaneously included. Thus, both studies suggest that well-being and ill-being were not completely independent, which may be because the well-being and ill-being items were drawn from a single scale.

In contrast, two other long-term studies showed no relationship between all-cause mortality and hedonic well-being, as assessed with a questionnaire designed especially for cardiac patients. The first study followed 300 angioplasty patients for a median of 10 years. Accounting for disease severity and coronary risk factors, higher levels of well-being were not associated with all-cause mortality (van Domburg, Pedersen, van den Brand, \& Erdman, 2001). The second study followed 500 acute MI patients for a median of 8 years (van der Vlugt et al., 2005). Well-being was not associated with all-cause mortality on its own, and because no multivariable analyses were conducted, it is unclear whether accounting for disease severity or traditional cardiovascular risk factors would have altered this null relationship.

Additional studies have considered the association between hedonic well-being and other CVD-related outcomes. Among 400 men with treated hypertension, reduced feelings of contentment were associated with a $4 \%$ increased risk of stroke, 95\% CI [1.01, 1.06], but not MI, after controlling for severity of CVD at baseline (Agewall, Wilkstrand, \& Fagerberg, 1998). In another study among men with hyperlipidemia, diminished satisfaction across a variety of life domains was associated with greater risk of cardiovascular events 3 years later $(\mathrm{HR}=2.6,95 \%$ CI $[1.1,5.8]$; Einvik, Ekeberg, Klemsdal, Sandvik, \& Hjerkinn, 2009). This association held after accounting for disease severity, cardiovascular risk factors, and anxiety.

Optimism and other measures of well-being. Four studies investigated optimism or vitality in relation to disease endpoints among patients diagnosed with CVD or undergoing a CVDrelated procedure. Scheier et al. (1989) found that dispositional optimism-assessed 1 day before 51 men were to undergo bypass surgery - was associated with a faster rate of recovery in the short-term, as indicated by medical staff ratings and the patient's ability to walk around the room. The number of complications a patient experienced postsurgery was also investigated but was not associated with optimism. In a different sample of 300 men and women awaiting bypass surgery, high levels of dispositional optimism were associated with a reduced risk of being hospitalized for CHD-related or surgery-related problems 6 months later (odds ratio [OR $]=0.58,95 \%$ CI $[0.34$, 0.99]; Scheier et al., 1999). Effects in this latter study remained significant despite accounting for baseline disease severity, cardiovascular risk factors, and depression. In a smaller study of men and women initially admitted to the hospital with a CVD diagnosis, participants' levels of hope were assessed at hospital discharge. Hope was not associated with all-cause mortality or readmission to the hospital over a 90-day follow-up period, but neither disease severity nor other confounders were controlled (Middleton \& Byrd, 1996).

In another study, low levels of vitality were associated with an increased risk of stroke (although not MI) over approximately 6 years of follow-up in a sample of 400 men with treated hypertension (Agewall et al., 1998). These findings were maintained when accounting for previous history of CVD, as well as other conventional risk factors.

Summary of disease-related findings in patient populations. Although the evidence for a relationship between PPWB and cardiovascular-related outcomes in patient populations is not quite as consistent as it is in healthy populations, the evidence still suggests that PPWB plays a role in the progression of CVD. Findings for optimism are consistent with those found in healthy populations, whereas findings for hedonic well-being are sometimes significantly attenuated when controlling for ill-being, suggesting that hedonic well-being and ill-being may be more closely correlated than are other measures of PPWB in patient populations. 


\section{Health Behaviors}

\section{Cigarette smoking.}

Eudaimonic well-being. Most longitudinal studies have shown that eudaimonic well-being is associated with a reduced likelihood of initiating or continuing to smoke. For example, in the 1970 British Cohort study, more than 7,000 British boys and girls reported their locus of control at age 10 years and smoking status 20 years later (Gale, Batty, \& Deary, 2008). A greater internal locus of control was associated with a reduced risk of smoking during adulthood ( $\mathrm{OR}=0.85,95 \%$ CI $[0.81,0.89])$, although findings were attenuated to nonsignificance once gender, childhood intelligence, and socioeconomic status were taken into account. Most cross-sectional studies are consistent with the longitudinal studies, indicating that individuals higher versus lower in eudaimonic well-being are less likely to smoke or be dependent on nicotine (e.g., Konkolÿ Thege, Bachner, Kushnir, \& Kopp, 2009). However, cross-sectional evidence is weakest for the association between mastery and smoking status, suggesting that mastery may not be as robustly associated with smoking status as other eudaimonic constructs.

Hedonic well-being. Only one longitudinal study has examined positive affect among participants in a smoking cessation treatment program. For each one-unit reduction in positive affect at baseline, participants were $9 \%$ less likely to be abstinent 26 weeks after their planned quit date (Leventhal, Ramsey, Brown, LaChance, \& Kahler, 2008). Analyses controlled for nicotine dependence, number of cigarettes smoked per day, negative affect, and depression. Cross-sectional evidence also generally suggests an inverse association between hedonic well-being and cigarette smoking (e.g., Strine, Chapman, Balluz, Moriarty, \& Mokdad, 2008).

Optimism and other measures of well-being. Longitudinal evidence shows that optimism and vitality are associated with a reduced likelihood of smoking. For example, ethnically diverse adolescents with lower optimism and hope were more likely to smoke 1 year later, controlling for demographics and baseline smoking status (Carvajal, Wiatrek, Evans, Knee, \& Nash, 2000). Moreover, in a trial of more than 1,000 smokers, individuals with increases in vitality over the follow-up were more likely to abstain from tobacco at 24 months (Niemiec, Ryan, Patrick, Deci, \& Williams, 2010). Evidence from numerous cross-sectional studies is consistent with the longitudinal studies (e.g., Steptoe, Wright, Kunz-Ebrecht, \& Iliffe, 2006).

Summary of cigarette smoking findings. Despite a limited set of studies, longitudinal evidence suggests an association between PPWB and a reduced risk of smoking, although mixed findings have been reported for eudaimonic well-being. Being a current smoker is also inversely associated with all types of PPWB in cross-sectional studies, although findings appear to be weakest for the eudaimonic construct of mastery.

\section{Moderate alcohol consumption.}

Eudaimonic well-being. Two cross-sectional studies (but no longitudinal studies) have examined eudaimonic well-being in relation to moderate alcohol consumption. One reported that in age-adjusted analyses, greater mastery was associated with moderate alcohol consumption in more than 2,000 Dutch adults (van Loon, Tijhuis, Surtees, \& Ormel, 2001); the other reported that mastery was weakly associated with moderate alcohol consump- tion in approximately 5,000 Canadians (Bailis, Segall, Mahon, Chipperfield, \& Dunn, 2001).

Hedonic well-being. Evidence is somewhat mixed for an association between hedonic well-being and moderate alcohol consumption, but no longitudinal evidence is available. For example, among 1,500 older men and women, greater levels of life satisfaction were associated with light to moderate consumption of alcohol, adjusted for age, BMI, exercise, smoking status, and estrogen use among women (A. M. Chan, von Muhlen, KritzSilverstein, \& Barrett-Connor, 2009). However, in a study of more than 17,000 college students that controlled for age, gender, and country of origin, life satisfaction was not associated with being a heavy drinker versus a light drinker, a moderate drinker, or a nondrinker (N. Grant, Wardle, \& Steptoe, 2009).

Optimism and other measures of well-being. Cross-sectional (but no longitudinal) studies have reported an association between optimism and moderate alcohol consumption (e.g., Giltay, Geleijnse, Zitman, Buijsse, \& Kromhout, 2007). For example, among healthy men and women aged 65-80 years, high versus low optimism levels were associated with moderate versus low alcohol intake, controlling for demographics, illness, and medications (Steptoe et al., 2006).

\section{Excessive alcohol consumption.}

Eudaimonic well-being. Among longitudinal studies, one was consistent with theoretical predictions, and one reported null findings. In the Amsterdam Growth and Health Study, adolescent self-sufficiency was associated with a reduced consumption of excessive alcohol an average of 14 years later, controlling for gender and age but not ill-being (Twisk, Snel, Kemper, \& van Mechelen, 1998). In a study of Icelandic adolescents, perceived control was not related to heavy alcohol consumption 3 years later, adjusting for demographics and baseline substance use (although sense of control was associated with less risk of heavy drinking in cross-sectional analyses; Adalbjarnardottir \& Rafnsson, 2001). In cross-sectional analyses, eudaimonic well-being is inversely associated with drinking problems generally (e.g., Marsh, Smith, Piek, \& Saunders, 2003), although null findings have been reported for an association between mastery and heavy drinking or alcohol dependence (e.g., Prescott, Neale, Corey, \& Kendler, 1997).

Hedonic well-being. Most longitudinal investigations of the association between PPWB and alcohol consumption examine how alcohol is associated with subsequent PPWB rather than vice versa (e.g., Bogart, Collins, Ellickson, \& Klein, 2007). An exception comes from Molnar et al. (2009), who examined the bidirectional relationship between hedonic well-being and alcohol use among nearly 500 freshman college students. Greater satisfaction and positive affect were not associated with frequency and quantity of alcohol intake, frequency of intoxication, or heavy episodic drinking 2 years later, controlling for baseline alcohol use. Findings from cross-sectional studies of hedonic well-being and problem drinking are somewhat mixed and suggest that the relationship may depend on age. Studies with adults or young adolescents show that greater hedonic well-being is inversely associated with alcohol use characterized by binge drinking or dependence (e.g., Zullig, Valois, Huebner, Oeltmann, \& Drane, 2001). In contrast, studies of mostly college students show a positive or null relationship between hedonic well-being and excessive alcohol consumption. Because young adults may consume alcohol for different reasons than other age groups-for example, for celebratory or social 
reasons (Hussong, Hicks, Levy, \& Curran, 2001)—findings need to be evaluated accordingly.

Optimism and other measures of well-being. Evidence from longitudinal studies of optimism and problem alcohol consumption is mixed. For example, among 54 alcoholic men, the most optimistic were more likely to successfully complete an inpatient aftercare program following 30 days of treatment, accounting for demographics, alcohol history, and daily uplifts and hassles (Strack, Carver, \& Blaney, 1987). However, among more than 300 alcohol-dependent individuals undergoing treatment, baseline optimism was not associated with drinking-related outcomes 15 months later, controlling for baseline drinking characteristics (Litt, Tennen, Kadden, \& Affleck, 2001). In cross-sectional studies, optimism is inversely associated with problematic alcohol use (e.g., Burris, Brechting, Salsman, \& Carlson, 2009). Thus, optimistic individuals may be less likely to engage in problem drinking, but once treatment is required, optimism may be less relevant.

Summary of alcohol consumption findings. Among the limited studies considering an association between PPWB and moderate alcohol consumption, evidence is mixed. Of the crosssectional studies, findings are most consistent with optimism and somewhat less consistent for eudaimonic and hedonic well-being. Evidence for an inverse association between PPWB and problem drinking is more consistent across PPWB constructs. A likely moderator of the association is age, so further replication with a range of ages and consumption levels is critical to understanding the association between PPWB and alcohol use.

Physical activity.

Eudaimonic well-being. Longitudinal studies have mostly reported null associations of eudaimonic well-being with subsequent physical activity (e.g., Williams, Gagne, Mushlin, \& Deci, 2005). For example, in the Amsterdam Growth and Health Study, adolescent self-sufficiency was not associated with activity levels an average of 14 years later, controlling for gender and age but not baseline physical activity (Twisk et al., 1998). One longitudinal study, however, reported a reduced risk of sedentary behavior among people with greater PPWB followed from ages 10 years to 30 years (the 1970 British cohort study). Each standard deviation increase in childhood locus of control was associated with a 7\% reduced risk of a sedentary lifestyle in adulthood, controlling for childhood characteristics (Gale et al., 2008). In cross-sectional studies, higher levels of eudaimonic well-being are generally associated with more physical activity (e.g., Cotter \& Lachman, 2010).

Hedonic well-being. Most longitudinal and experimental studies assessing the PPWB-physical activity relationship have considered how physical activity leads to improved PPWB (e.g., Elavsky \& McAuley, 2007; Netz, Wu, Becker, \& Tenenbaum, 2005). Only one study has considered whether PPWB leads to more physical activity. Among 2,100 initially inactive but healthy men and women, the happiest men were more likely to engage in physical activity than were their less happy peers an average of 2 years later (Baruth et al., 2011). Analyses adjusted for gender, age, self-rated health, BMI, and chronic health conditions but were only marginally significant for women. Cross-sectional research also demonstrates a positive association between hedonic well-being and physical activity (e.g., N. Grant et al., 2009; Strine et al., 2008).
Optimism and other measures of well-being. Some shortterm longitudinal studies with cardiac patients have demonstrated positive associations between optimism and increased physical activity (e.g., I. W. S. Chan, Lai, \& Wong, 2006). For example, in a study of 22 participants in an 18-week cardiac rehabilitation program, dispositional optimism was measured at the start of the program. Higher baseline optimism was associated with increased aerobic capacity at the end of the program, controlling for age and magnitude of goal (Shepperd, Maroto, \& Pbert, 1996). However, findings are not uniform across all studies. In one study that followed patients through a 12-week cardiac rehabilitation program, baseline optimism was not associated with improved oxygen consumption during exercise, controlling for age, gender, neuroticism, and depression (Glazer, Emery, Frid, \& Banyasz, 2002). Cross-sectional studies do generally suggest that greater optimism is associated with more physical activity though (e.g., Giltay et al., 2007).

Summary of physical activity findings. PPWB and physical activity tend to be associated. However, most studies in this area assessed well-being and physical activity via self-report, which may inflate the strength of the association by shared methods. Moreover, most studies assessed hedonic well-being; fewer studies examined eudaimonic well-being or optimism. Findings seem particularly consistent for hedonic well-being and optimism but somewhat more inconsistent for eudaimonic well-being. Longitudinal and intervention studies hint that PPWB may have long-term implications for physical activity and sedentary behavior, but additional research directly assessing the effect of PPWB on physical activity is needed to determine whether PPWB interventions can alter physical activity.

\section{Sleep quality.}

Eudaimonic well-being. In the only longitudinal study investigating PPWB and sleep-related outcomes, 115 aging women reported their eudaimonic well-being at baseline and were followed for 8 and 10 years (Phelan, Love, Ryff, Brown, \& Heidrich, 2010). Higher levels of environmental mastery, personal growth, purpose in life, and self-acceptance were associated with a reduced risk of sleep problems at follow-up, accounting for initial sleep quality. Depression was also associated with an increased risk of sleep problems in this study. In cross-sectional studies, individuals with greater eudaimonic well-being also tend to report enhanced sleep quality and fewer sleep problems (e.g., Steptoe, O'Donnell, Marmot, \& Wardle, 2008).

Hedonic well-being. No longitudinal evidence is available, but cross-sectional studies suggest that higher levels of hedonic well-being are associated with better sleep quality. For example, among older individuals, a latent variable comprising life satisfaction, positive affect, and reverse-scored negative affect was inversely associated with sleep problems, controlling for demographic characteristics, comorbid disease, and sedative use (N. A. Hamilton, Gallagher, et al., 2007). An inverse association for eudaimonic well-being and sleep problems was also reported in this study, but effects for hedonic well-being were stronger.

Optimism and other measures of well-being. One crosssectional study reported an inverse association between optimism and poor sleep quality among young grandmothers, controlling for demographics and pessimism (Conway, Magai, Springer, \& Jones, 2008). 
Summary of sleep quality findings. Cross-sectional findings suggest that individuals with greater levels of PPWB tend to have better quality sleep, but only one longitudinal investigation (with eudaimonic well-being) can confirm this association. Additional longitudinal research in this area is needed given that perceptions of sleep quality and perceptions of well-being may share a reporting bias.

\section{Adequate sleep quantity.}

Eudaimonic well-being. Individuals with greater eudaimonic well-being tend to report sufficient sleep quantity, but only crosssectional studies are available. In one cross-sectional study that objectively assessed sleep quantity with an eyelid motion sensor, mastery was associated with longer sleep duration, more time in bed, and less time to the first onset of rapid eye movement sleep (Ryff, Singer, \& Love, 2004).

Hedonic well-being. Cross-sectional studies provide mixed evidence for an association between hedonic well-being and adequate sleep duration. Among ethnically diverse adolescents, happiness was positively associated with more sleep each night and negatively associated with irregular sleep duration (Fuligni \& Hardway, 2006). However, in a study of Canadian college students that controlled for covariates including negative affect and stress, positive affect was not associated with sleep quantity (Galambos, Dalton, \& Maggs, 2009).

Optimism and other measures of well-being. In a crosssectional study of more than 150 elderly men and women, optimism was positively associated with getting enough sleep, but purpose in life was not (Holahan \& Suzuki, 2006). Similarly, in a cross-sectional sample of children, those who were the most optimistic slept a sufficient amount each night and took less time to fall asleep (Lemola et al., 2010). These analyses controlled for child gender, age, and BMI, as well as parental education and optimism.

Inadequate or excessive sleep quantity.

Eudaimonic well-being. Only one cross-sectional study has examined the association between eudaimonic well-being and deteriorative levels of sleep duration. In approximately 500 adults, inadequate or excessive hours of sleep were associated with lower levels of environmental mastery, personal growth, purpose in life, and self-acceptance (N. A. Hamilton, Nelson, Stevens, \& Kitzman, 2007). These findings mostly held when controlling for demographic characteristics and when excluding depressed individuals from analyses.

Hedonic well-being. Cross-sectional (but no longitudinal) evidence is somewhat mixed regarding hedonic well-being's relationship with too little or too much sleep. For example, adults with low life satisfaction were more likely to report insufficient sleep than were the very satisfied, independent of demographics (Strine et al., 2008). However, in a sample of adults age 60 years or older, positive affect was not associated with more time awake during the night when assessed objectively with an actigraph but was associated with more time awake during the night when assessed subjectively (McCrae et al., 2008).

Optimism and other measures of well-being. No studies to date have considered the association between optimism and inadequate or excessive sleep quantity.

Summary of sleep quantity findings. Cross-sectional evidence suggests that PPWB may be positively associated with adequate sleep duration and negatively associated with inadequate or excessive sleep duration. However, findings were somewhat inconsistent, and longitudinal studies are notably lacking.

\section{Food consumption.}

Eudaimonic well-being. One study followed nearly 400 individuals with chest pain for 3 years (Williams et al., 2005). Baseline autonomy was not associated with maintaining a healthy diet or avoiding fatty foods, accounting for initial diet. Similarly, in the Amsterdam Growth and Health Study, adolescent selfsufficiency was not associated with dietary intake 14 years later, although analyses did not account for initial diet (Twisk et al., 1998). However, one cross-sectional study of Dutch adolescents showed that greater autonomy and self-control were associated with fewer purchases of unhealthy snacks independent of gender (Stok, De Ridder, Adriaanse, \& De Wit, 2010).

Hedonic well-being. Cross-sectional studies (but no longitudinal studies) suggest an association between hedonic well-being and healthy eating behaviors. For example, among more than 17,000 college students across the world, those with the highest versus the lowest levels of satisfaction were more likely to consume fruit and avoid fat (N. Grant et al., 2009). Results were independent of age, gender, and country of origin.

Optimism and other measures of well-being. Despite somewhat limited evidence, optimism seems to be related to healthier food consumption. Patients undergoing cardiac rehabilitation who were initially optimistic reduced their dietary intake of saturated fat 18 weeks later, accounting for age, initial dietary goal, and depression (Shepperd et al., 1996). Cross-sectional studies show a similar pattern. For example, among Finnish 31-year-olds, optimistic individuals reported eating more fruits, vegetables, and low-fat dairy products (and fewer sweets; Kelloniemi, Ek, \& Laitinen, 2005). In the same sample, optimistic men reported eating more fiber rich bread, and optimistic women reported eating more fish.

Summary of food consumption findings. Evidence for an association between PPWB and food consumption is generally consistent, particularly in relation to optimism. However, findings vary somewhat depending on which aspect of diet is considered. Moreover, because almost all food-related studies are crosssectional, the causal direction cannot be determined and longitudinal studies are needed to assess the associations more comprehensively.

\section{Biological Function}

\section{Atherosclerosis and calcification.}

Eudaimonic well-being. In the Healthy Women Study (comprising women undergoing menopausal transitions), women with high levels of mastery and life purpose had diminished aortic calcification but not coronary calcification 6 months later, adjusting for smoking status, waist-to-hip ratio, and lipids (Matthews, Owens, Edmundowicz, Lee, \& Kuller, 2006). By contrast, in a cross-sectional study of mastery and coronary atherosclerosis among men and women with suspected coronary artery disease, higher levels of mastery were associated with greater atherosclerosis after controlling for traditional risk factors, hostility, and Type A behavior (T. E. Seeman, 1991).

Hedonic well-being. In the only study examining hedonic well-being, participants in the Healthy Women Study with greater life satisfaction showed reduced aortic, but not coronary, calcifi- 
cation 6 months later, controlling for relevant risk factors (Matthews et al., 2006). Well-being and ill-being measures were considered separately but not simultaneously, and effects of negative factors (e.g., depression, anxiety) tended to be larger than effects of positive factors.

Optimism and other measures of well-being. The Healthy Women Study also reported findings with optimism in two separate longitudinal investigations. Among approximately 200 women, those with the greatest optimism had the slowest rate of carotid atherosclerosis progression 3 years later after controlling for a range of cardiovascular risk factors (Matthews, Räikkönen, Sutton-Tyrrell, \& Kuller, 2004). Depression was not included in models with optimism, although it was not independently associated with carotid atherosclerosis. In another sample of women from the same cohort, optimism was not associated with rate of change in coronary or aortic calcification 6 months later (Matthews et al., 2006).

Summary of atherosclerosis and calcification findings. Inconsistent evidence exists for an association between PPWB and atherosclerosis or calcification. The majority of findings were based on three PPWB measures assessed in a single cohort of women. Findings differed for each PPWB measure, but intercorrelations were not reported. Other psychosocial factors have demonstrated inconsistent associations with atherosclerosis and calcification (Rozanski et al., 2011), so additional research is needed before firm conclusions are made.

\section{Autonomic cardiac control.}

Eudaimonic well-being. No studies to date have considered the association between eudaimonic well-being and autonomic cardiac control.

Hedonic well-being. The association between PPWB and HRV has typically been investigated through mood inductions of hedonic well-being (e.g., Rainville, Bechara, Naqvi, \& Damasio, 2006). Evidence is somewhat mixed for an association between naturally occurring positive mood and HRV. For example, there was no association between happy mood and HRV in an ambulatory monitoring study of 50 female students (Myrtek, Aschenbrenner, \& Brugner, 2005). However, in two studies of patients with suspected or verified coronary artery disease, both demonstrated an association between higher levels of positive affect and increased vagal activity, independent of relevant covariates and, in one case, depression (Bacon et al., 2004; Bhattacharyya, Whitehead, Rakhit, \& Steptoe, 2008). Furthermore, independent of negative affect, trait positive affect among college students was associated with more efficient recovery from stress, as assessed with a ratio of low to high frequency HRV (Papousek et al., 2010).

Optimism and other measures of well-being. The crosssectional association between optimism and HRV was examined in nine competitive chess players (Schwarz, Schachinger, Adler, \& Goetz, 2003). After playing a chess game, participants retrospectively assessed whether game transitions were characterized by optimism or hopelessness. Increases in vagal activity were more likely during optimistic transitions; decreases were more likely during hopeless transitions. Although this study is unique in that optimistic moments were examined rather than trait optimism, it hints that optimism may be related to parasympathetic nervous system activation.
Summary of autonomic cardiac control findings. In sum, cross-sectional evidence suggests that higher levels of PPWBspecifically, positive affect and optimism—-may be associated with greater parasympathetic control. Longitudinal studies and research regarding the association between eudaimonic well-being and HRV are greatly needed, however.

Cardiovascular function.

Eudaimonic well-being. Longitudinal studies have reported mixed findings. In the Amsterdam Growth and Health Study that followed young adolescents into adulthood, baseline selfsufficiency was not associated with subsequent BP, controlling for age, gender, and health behaviors (but not initial BP; Twisk et al., 1998). However, in the 1970 British Cohort study, each standard deviation increase in childhood internal locus of control was associated with a reduced risk of self-reported hypertension in adulthood $(\mathrm{OR}=0.91,95 \%$ CI $[0.81,1.02])$, controlling for gender, childhood intelligence, and socioeconomic status (Gale et al., 2008). In cross-sectional studies, the association between eudaimonic well-being and BP is also inconsistent. For example, in a study of 224 older Blacks and Whites, those with greater versus lesser life purpose exhibited lower sleep-wake mean arterial pressure ratios (a summary measure of BP) when controlling for age, gender, ethnicity, BMI, hypertension, and hostility (Mezick et al., 2010). However, in a cross-sectional sample of 135 older women, none of Ryff's well-being constructs was related to resting systolic BP (Ryff et al., 2006).

Hedonic well-being. Pressman and Cohen (2005) reviewed the primarily experimental studies of positive affect and cardiovascular function and concluded that state positive emotions were generally associated with short-term increases in BP but less often associated with changes in heart rate. Notably, those increases in BP were not as large as those for negative emotions, suggesting that state positive affect is associated with attenuated cardiovascular reactivity relative to state negative affect. In the only longitudinal study of its kind, 162 British civil servants rated their happiness over the course of a day. Aggregate happiness was inversely associated with ambulatory systolic BP 3 years later, adjusting for demographics, smoking status, BMI, antihypertensive medication, and ill-being (Steptoe $\&$ Wardle, 2005). Some cross-sectional studies have also detected an association between trait hedonic well-being and poor cardiovascular function (e.g., Ostir, Berges, Markides, \& Ottenbacher, 2006; Steptoe, Gibson, Hamer, \& Wardle, 2007), although there have been some null findings (e.g., Ryff et al., 2006).

Optimism and other measures of well-being. Two longitudinal studies have shown an association between hypertension and other measures of well-being. In a study of 1,000 communitydwelling men and women, individuals with the highest versus lowest levels of dispositional hope or curiosity were less likely to develop incident hypertension over a 1 year follow-up when controlling for potential confounders, anger, and anxiety (Richman et al., 2005). Also, baseline vitality in this sample was associated with a reduced risk of hypertension 1 year later (Richman et al., 2009). Although findings were somewhat attenuated when controlling for covariates and ill-being, these longitudinal studies indicate that well-being is related to better cardiovascular functioning. Some cross-sectional studies reach similar conclusions (e.g., Räikkönen, Matthews, Flory, \& Owens, 1999), although 
some null findings have been reported as well (e.g., Räikkönen \& Matthews, 2008).

Summary of cardiovascular function findings. The unique effects of state versus trait measures of well-being are critical to understanding the association between PPWB and cardiovascular functioning. State positive affect may increase cardiovascular reactivity in the short-term, but generally not to the same degree as negative affect. Trait measures of positive affect, however, are commonly associated with lower resting heart rate and BP. Because most findings on trait measures come from cross-sectional designs, it is difficult to assess the causal direction. For eudaimonic well-being and optimism, findings from the cross-sectional research are somewhat mixed. However, for most PPWB constructs, the limited longitudinal research suggests that PPWB may help maintain healthy cardiovascular function over time.

\section{Inflammation and hemostasis.}

Eudaimonic well-being. Eudaimonic well-being is not consistently associated with inflammation. In a large cross-sectional investigation of Black and White individuals, mastery was not associated with CRP levels (Taylor, Lehman, Kiefe, \& Seeman, 2006). Similarly, a cross-sectional study investigating community relocation in more than 100 elderly women did not show statistically significant associations between IL-6 and Ryff's well-being measures, controlling for demographics, health, behaviors, and depressive symptoms (E. M. Friedman, Hayney, Love, Singer, \& Ryff, 2007). However, environmental mastery and purpose in life were inversely associated with sIL-6r, with the same set of covariates (E. M. Friedman et al., 2007).

Hedonic well-being. Hedonic well-being and inflammation are somewhat more consistently associated in cross-sectional studies. In one study of British civil servants, low positive affect was associated with higher levels of CRP in women after accounting for demographics, BMI, waist-to-hip ratio, smoking status, employment status, time of waking, and depression (Steptoe, O'Donnell, Badrick, Kumari, \& Marmot, 2008). Greater positive affect also tends to be associated with lower IL-6 levels (e.g., Steptoe, O'Donnell, Badrick, et al., 2008). For example, trait positive affect was related to lower levels of stimulated IL-6 in adults (Prather, Marsland, Muldoon, \& Manuck, 2007). ${ }^{11}$ This association remained when accounting for age, gender, race, BMI, and white blood cell count; moreover, negative affect was not associated with IL-6. In contrast, positive affect was not associated with IL-6 in the relocation study of older women, which accounted for risk factors and depressive symptoms (E. M. Friedman et al., 2007). Finally, in a study that measured positive affect through ecological momentary assessment, men and women with low versus high positive affect tended to have greater fibrinogen responses to stress, controlling for age, employment, smoking status, BMI, and distress (Steptoe, Wardle, \& Marmot, 2005).

Optimism and other measures of well-being. Only one longitudinal study of optimism has been conducted in which measures of inflammation and endothelial function were obtained repeatedly over time in a sample of men (Ikeda et al., 2011). In models that adjusted for demographics, behaviors, health status, and depressive symptoms, greater dispositional optimism was associated with lower levels of IL-6, and soluble intercellular adhesion molecule-1 pooled across multiple time points, but not CRP, soluble vascular cell adhesion molecule-1, or soluble tumor necrosis factor receptor. Effects for pessimism were stronger than effects for optimism, and optimism was not associated with rate of change in these markers over time. In cross-sectional analyses within the MultiEthnic Study of Atherosclerosis (MESA) - a diverse cohort of nearly 7,000 men and women-greater dispositional optimism was not associated with CRP in analyses adjusted for age, gender, and race (Roy et al., 2010). However, the most optimistic MESA participants had lower levels of IL-6 after adjusting for age, race, and gender (Roy et al., 2010). Furthermore, greater optimism in the MESA cohort was related to lower fibrinogen levels independent of age, race, and gender (Roy et al., 2010). However, these findings did not hold when the optimism subscale rather than the full scale of the Life Orientation Test-Revised was used. Moreover, the hemostasis markers of D-dimer, factor VIII, and plasminantiplasmin were not associated with optimism among MESA participants (Roy et al., 2010). Finally, in a small cross-sectional study of postmenopausal women, optimism was positively associated with longer telomere length, an indicator of cellular aging (O'Donovan et al., 2009). However, when age, caregiver status, and pessimism were controlled, the association did not remain.

Summary of inflammation and hemostasis findings. The small number of studies investigating the association between PPWB and inflammation is suggestive of an inverse relationship. Although findings are promising, most of the work to date is cross-sectional. Findings seem strongest for an association between inflammation and positive affect or optimism, although more research is needed to address the most relevant types of well-being.

\section{Metabolic function.}

Eudaimonic well-being. Studies show mixed but mostly null findings for a relationship between eudaimonic well-being and $\mathrm{HbA}_{1 \mathrm{c}}$ (e.g., Bradshaw et al., 2007; Feldman \& Steptoe, 2003). For example, in longitudinal analyses of relocating women, eudaimonic well-being was not associated with $\mathrm{HbA}_{1 \mathrm{c}} 2$ years later, controlling for baseline $\mathrm{HbA}_{1 \mathrm{c}}$, demographics, health, and negative affect (Tsenkova, Love, Singer, \& Ryff, 2007). In crosssectional analyses with the same cohort, eudaimonic well-being was still not associated with $\mathrm{HbA}_{1 \mathrm{c}}$ (Ryff et al., 2006).

Evidence is mixed for an association between eudaimonic wellbeing and lipids. In the longitudinal Amsterdam Growth and Health Study, adolescent self-sufficiency was associated with lower total cholesterol in adult men but not women, after adjusting for lifestyle and biological factors (Twisk et al., 1998). Selfsufficiency was not associated with HDL cholesterol levels, however. In the cross-sectional study of relocating women, personal growth (but not other measures of eudaimonia) was, as predicted, inversely associated with the ratio of total-to-HDL cholesterol (Ryff et al., 2006). Personal growth and purpose in life were also positively associated with HDL cholesterol in the same study, but measures of ill-being were not.

Inverse associations between eudaimonic well-being and BMI have been reported in some but not all longitudinal studies. For example, in the 1970 British Cohort study, each standard deviation

\footnotetext{
${ }^{11}$ This same study also examined the association between trait positive affect and stimulated levels of the anti-inflammatory cytokine interleukin10. Greater positive affect was associated with lower levels of interleukin10 , controlling for demographic factors, BMI, and white blood cell count (Prather et al., 2007).
} 
increase in childhood locus of control was associated with a reduced risk of being overweight $(\mathrm{OR}=0.87,95 \% \mathrm{CI}[0.82$, $0.93])$ or obese $(\mathrm{OR}=0.86,95 \%$ CI $[0.78,0.95])$ in adulthood, controlling for childhood intelligence, gender, education, and socioeconomic status (Gale et al., 2008). However, among 71 female nurses, mastery was not associated with a 12-week change in BMI, although higher mastery was associated with a lower BMI at baseline (Roberts, Troop, Connan, Treasure, \& Campbell, 2007). Most cross-sectional studies have also reported inverse associations between eudaimonic well-being and BMI (e.g., Carr \& Friedman, 2005).

Hedonic well-being. One longitudinal analysis in a study of older women showed that positive affect was related to lower levels of $\mathrm{HbA}_{1 \mathrm{c}} 2$ years later, controlling for many covariates including baseline $\mathrm{HbA}_{1 \mathrm{c}}$ (Tsenkova et al., 2007). Moreover, when eudaimonic well-being was simultaneously included or negative affect and depression were controlled, the effects of positive affect remained. However, cross-sectional studies have reported null associations between hedonic well-being and $\mathrm{HbA}_{1 \mathrm{c}}$ (e.g., Paschalides et al., 2004).

Two cross-sectional studies have examined the association between hedonic well-being and cholesterol. In a study of 20 male Navy trainees, greater happiness was associated with lower levels of total cholesterol over 2 months, without adjustment for other variables (Rahe, Rubin, Gunderson, \& Arthur, 1971). Among relocating women, positive affect was associated with higher HDL cholesterol, but not the ratio of total-to-HDL cholesterol (Ryff et al., 2006).

The only longitudinal investigation to test whether life satisfaction predicted weight change occurred among Finnish twin pairs (Korkeila, Kaprio, Rissanen, Koshenvuo, \& Sorensen, 1998). Initially low levels of life satisfaction predicted weight gain 6 years later for older but not younger women $(\mathrm{OR}=2.21,95 \%$ CI $[1.05$, 4.64]). The association was not evident in men but was maintained among older women after controlling for education, dieting, smoking status, alcohol consumption, and pregnancy. Numerous crosssectional studies have also shown an inverse association between hedonic well-being and BMI (e.g., Saloumi \& Plourde, 2010).

Optimism and other measures of well-being. Very limited work has been done to study other measures of well-being and $\mathrm{HbA}_{1 \mathrm{c}}$, but optimism was not strongly related to $\mathrm{HbA}_{1 \mathrm{c}}$ in a cross-sectional study of diabetic African Americans (Brody, Kogan, Murry, Chen, \& Brown, 2008).

Short-term longitudinal studies provide mixed evidence regarding lipids. For example, in a study of 22 patients undergoing 18 weeks of cardiac rehabilitation, baseline dispositional optimism was not related to total cholesterol, HDL cholesterol, or LDL cholesterol at follow-up, adjusting for age, depression, and other relevant factors (Shepperd et al., 1996). However, vitality was associated with the prevalence and incidence of high cholesterol over 1 year (Richman et al., 2009). Compared with individuals with low vitality, those with high vitality had a $43 \%$ reduced risk (95\% CI $[0.43,0.78])$ of having high cholesterol or a $49 \%$ reduced risk $(95 \% \mathrm{CI}[0.31,0.82])$ of developing high cholesterol over the follow-up. Associations were maintained after controlling for age, marital status, behaviors, anger, and anxiety.

Findings regarding BMI are not entirely consistent based on evidence from relatively short-term longitudinal studies (8-18 weeks) of participants undergoing cardiac rehabilitation or weight- loss programs. For example, among 22 patients in cardiac rehabilitation, baseline dispositional optimism was associated with reduced body fat (but not weight) at the end of the program (Shepperd et al., 1996). Findings held after controlling for age, depression, and other relevant factors. In another study of cardiac rehabilitation patients, baseline resilience (optimism, perceived control, self-esteem) was not associated with change in BMI after the program ended (I. W. S. Chan et al., 2006). However, one cross-sectional study among more than 8,000 Finnish adults showed that more versus less optimistic individuals were likely to have lower BMI, although no demographic or other risk factors were controlled (Kelloniemi et al., 2005).

Summary of metabolic function findings. The association between PPWB and metabolic function varies by outcome. The limited work regarding the relationship between PPWB and $\mathrm{HbA}_{1 \mathrm{c}}$ reports mostly null findings for all types of PPWB. More studies have examined the association between PPWB and lipids and provide some evidence for an association between PPWB and cholesterol levels. However, too few studies exist to adequately distinguish between effects of different types of well-being. PPWB tends to be inversely associated with excessive weight, although some cross-sectional studies have not detected an association between PPWB and BMI. This could be due to a nonlinear relationship (i.e., both underweight and overweight or obese individuals may have lower PPWB relative to normal weight individuals). Cross-sectional studies of PPWB and BMI are problematic for establishing a causal direction because obesity may increase the likelihood of psychological distress (Atlantis \& Baker, 2008); therefore, longitudinal evidence is needed.

\section{Overall Summary}

Taken together, evidence indicates that PPWB is related to cardiovascular health (see Table 3). Studies of healthy individuals consistently suggest that high levels of PPWB are associated with a reduced risk of incident CVD, even when controlling for traditional risk factors and ill-being. The pattern of findings is similar among studies with patients, despite being a more heterogeneous body of work. Compared with studies with patient populations, those with healthy populations followed participants for longer periods of time, controlled for more comprehensive confounders (including ill-being), and used clinically defined outcomes. By contrast, studies with patient populations considered wide-ranging types of CVD and had varying follow-up periods. Associations for hedonic well-being were sometimes attenuated after accounting for ill-being in patient populations, suggesting that hedonic wellbeing and ill-being may operate on similar pathways among individuals who are already ill. Although unique types of PPWB may be differentially associated with disease onset versus progression, the limited evidence to date does not yet strongly suggest this to be the case. Indeed, across both healthy and patient populations, optimism is the most reliably associated with a reduced risk of cardiac events.

In terms of PPWB's association with behaviors and biology, studies are significantly more limited, and overall findings are less clear. Worth noting is that many findings come from the same small set of studies that considered one or two well-being constructs in relation to an array of outcomes; thus, findings may appear more consistent than if they were derived from a hetero- 


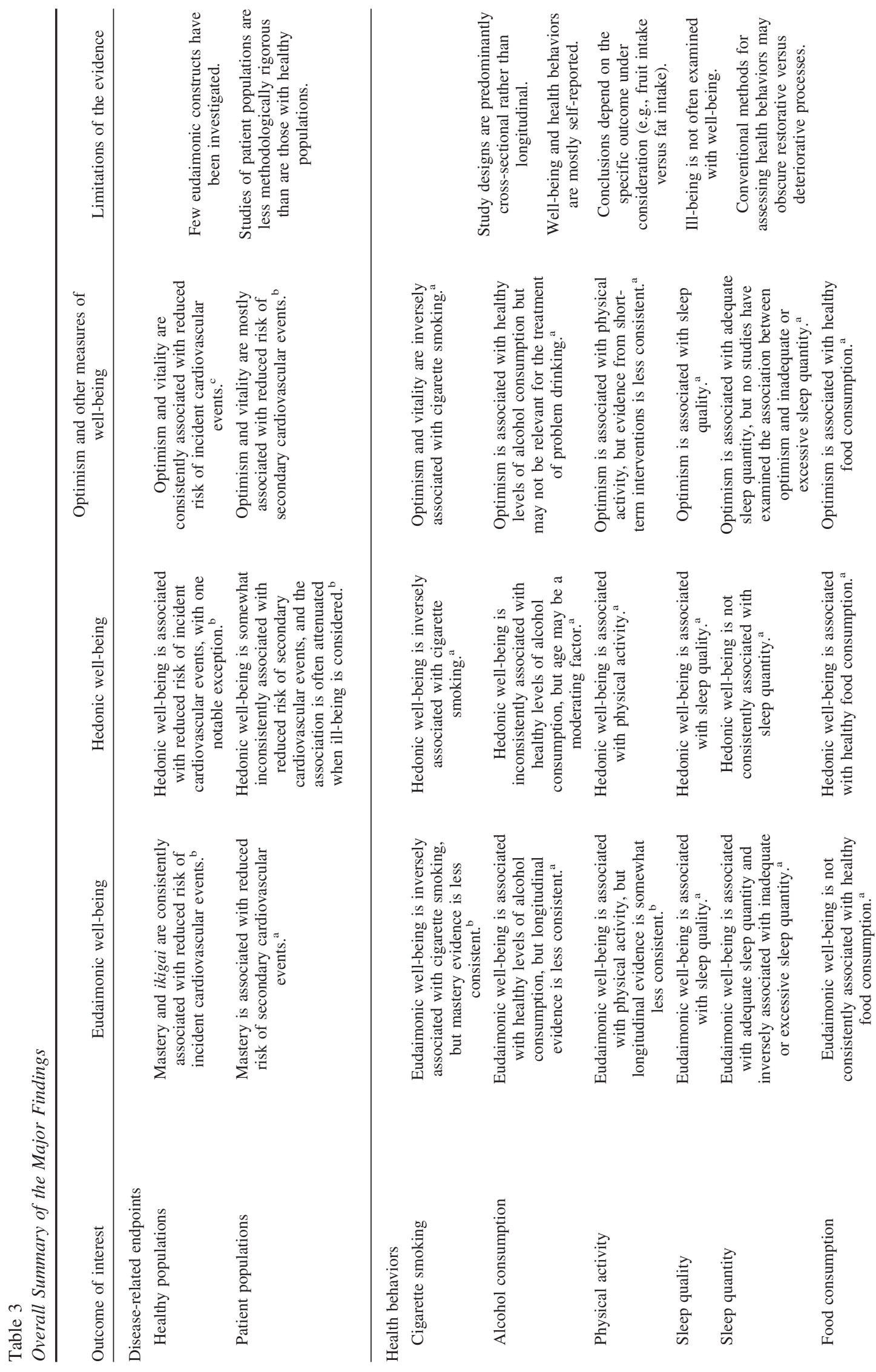




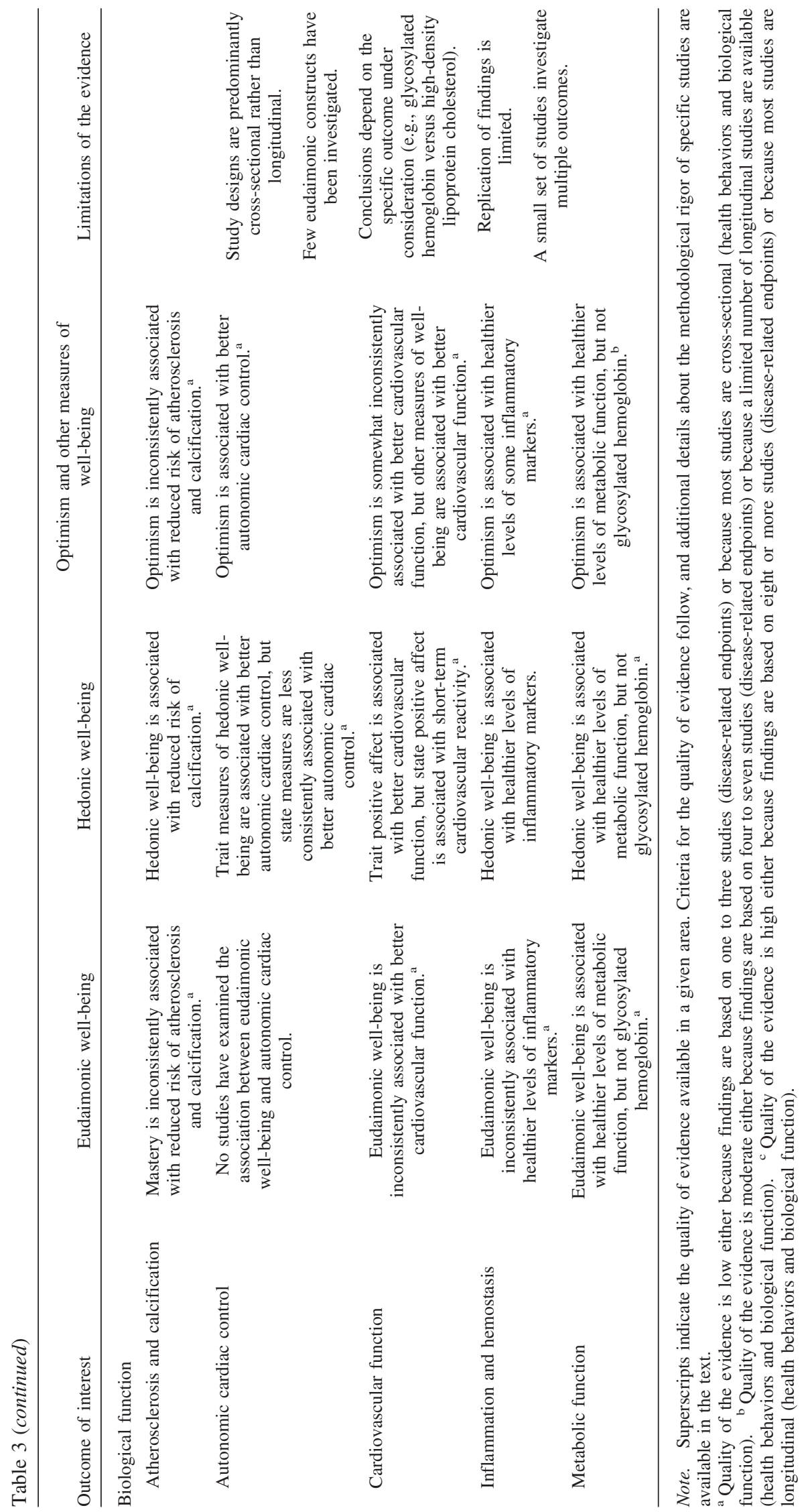


geneous set of studies. Findings also appeared to be more consistent in healthy versus patient populations. In fact, many of the studies with patients considered the effects of a well-being intervention on outcomes. Such studies are appealing, particularly in light of the scarcity of longitudinal studies, but effects can be assessed accurately only if well-being is successfully manipulated. It is also possible that the effects of PPWB differ in patient populations - that is, reversing or arresting unhealthy behavioral or biological processes that have already been initiated may be very different from preventing deterioration or promoting restoration.

The vast majority of studies regarding health behaviors are cross-sectional. Overall, findings indicate that higher levels of PPWB are positively associated with restorative health behaviors and negatively associated with harmful health behaviors. Evidence suggests that higher levels of PPWB are associated with a reduced risk of smoking. We posited a nonlinear relationship between PPWB and drinking such that light to moderate drinking is related to greater PPWB and abstinence or heavy drinking is related to lower PPWB. Findings were somewhat mixed for an association between moderate alcohol consumption and PPWB but were slightly more consistent for an inverse association between excessive alcohol consumption and PPWB (although the drinking habits of young adults versus older adults may be a critical moderating factor). Physical activity seemed to be associated with greater PPWB. In addition, findings suggest that PPWB is positively associated with restorative sleep processes and negatively associated with deteriorative sleep processes. Finally, PPWB seems to be associated with the consumption of healthier foods; however, findings vary depending on the specific food outcome. Although the association between PPWB and health behavior is almost certainly bidirectional, for the purposes of understanding the role of PPWB in CVD, the most relevant issue is whether PPWB leads to healthy behaviors. Ultimately, so few longitudinal studies have been conducted that conclusions must be made cautiously. Perhaps one of the most striking findings in this review is just how few studies have addressed issues related to the direction of the association between PPWB and health behaviors.

Findings regarding biological function varied depending on the specific biological system under consideration. Again, the vast majority of studies were cross-sectional, making it difficult to assess whether PPWB influences biology or vice versa. Evidence for an inverse association between PPWB and atherosclerotic processes is limited but suggestive. HRV findings are restricted to hedonic well-being and optimism but suggest that enhanced PPWB is associated with greater parasympathetic control. Given the importance of vagal tone for cardiovascular health and selfregulation (Segerstrom \& Nes, 2007), studies of PPWB and autonomic function should be high priority for future work (especially for eudaimonic well-being and optimism, for which studies are nonexistent or very limited). In cross-sectional research on PPWB and other cardiovascular indicators, associations are somewhat inconsistent for eudaimonic well-being and even optimism but are more consistent for trait hedonic well-being. Although state positive affect may be associated with adaptive arousal of the autonomic nervous system in the short term, trait measures of PPWB may be associated with better regulation of the autonomic nervous system in the long term. The limited number of longitudinal studies more consistently showed associations between different aspects of PPWB and cardiac function, suggesting that the endur- ing feelings individuals have toward their life may have implications for improved cardiovascular function.

Limited work has examined the association between PPWB and inflammation, although what exists suggests that hedonic wellbeing and optimism may be more strongly associated with inflammatory markers than with eudaimonic well-being. Moreover, the association between PPWB and metabolic function depends on the biological marker, a somewhat surprising finding given the strong interrelationships between these processes. $\mathrm{HbA}_{1 \mathrm{c}}$ does not seem to be strongly related to PPWB, whereas lipids and BMI do seem to be related in the expected directions. However, this lack of consistency may be due in part to the relatively few studies looking at these relationships and the heterogeneity of the samples (i.e., healthy and patient populations). In sum, there appears to be an important role for PPWB in cardiovascular health, although the restorative and deteriorative processes underlying the relationship remain understudied.

\section{The Importance of PPWB for Cardiovascular Health}

This review is the first of its kind to consider in detail how PPWB - not merely ill-being-plays a role in cardiovascular health. As noted in the introduction, a connection between mental and physical states has long been recognized. However, until recently, the psychological and epidemiological research linking mental and physical states has focused on how ill-being is associated with physical health. Building on prior conceptual and empirical work (e.g., Chida \& Steptoe, 2008; Ryff \& Singer, 1998; Ryff et al., 2004; Steptoe et al., 2009), we sought to demonstrate that PPWB is specifically relevant for cardiovascular health. Because not all aspects of well-being may necessarily be salutogenic in relation to cardiovascular health, we also sought to identify whether there are particular facets of PPWB that are most relevant for cardiovascular outcomes. To this end, we distinguished between eudaimonic well-being, hedonic well-being, optimism, and other measures of well-being. Past theory and research has hinted that the conceptual distinction between eudaimonic and hedonic well-being may be important for physical health (e.g., Dockray \& Steptoe, 2010; Ryff et al., 2004), but few investigations of health or CVD have deliberately examined such constructs in the same study (for exceptions, see E. M. Friedman et al., 2007; Ryff et al., 2006; Tsenkova et al., 2007).

Clearly distinguishing between PPWB constructs may provide greater understanding of what aspects are particularly relevant for cardiovascular health. This may serve not only to enhance understanding of PPWB but also to increase conceptual and mechanistic understanding of how mental and physical health processes interact, to give insight into how to build resilience, and to contribute to the development of more targeted prevention and intervention programs. We recognize that distinct measures of PPWB can be highly correlated and, in some circumstances, one may serve as a proxy for the other (Diener, 2009). As a result, it may be difficult to disentangle the effects of one from the other. However, we suggest that with careful attention to methods and measures, future work can sufficiently tease apart the relevant factors to understand more clearly their association with cardiovascular health (Gallagher, Lopez, \& Preacher, 2009).

Considering the evidence to date does not permit an easy conclusion with regard to the relative strength of distinct PPWB 
indicators in relation to all aspects of cardiovascular health. In part, this is because few studies have explicitly tried to compare the effects of different facets of well-being and also because most studies of PPWB and cardiovascular health have been opportunistic (i.e., using whatever measures may be available) rather than using theory-driven, psychometrically sound measures. Moreover, in some domains, there are simply too few studies from which to draw conclusions about the effects of PPWB without trying to specify possible distinctions across different types of PPWB. Thus, we summarize the existing evidence both to determine how promising it may be and to assess the gaps in the literature.

In studies of incident CVD in healthy populations, optimism is most consistently associated with disease outcomes in terms of the magnitude of the effect and independence from conventional risk factors and ill-being. Indicators of eudaimonic well-being were limited to just two constructs-mastery and ikigai. Although the findings for these constructs consistently showed a reduced risk of CVD, no other eudaimonic constructs have been examined, so it is not possible to generalize findings to the multidimensional factor of eudaimonic well-being. The association between hedonic wellbeing and CVD in healthy populations was generally consistent, with one high-quality study reporting null findings but the rest demonstrating an inverse association. In patient populations of secondary cardiac events, only one study reported findings for eudaimonic well-being. Moreover, studies that considered measures of hedonic well-being were somewhat mixed but generally pointed to an inverse association. Similar to the incidence findings, optimism is fairly consistently associated with a reduced risk of secondary cardiac events among patient populations. Taken together, additional studies of eudaimonic well-being and CVD are greatly needed, positive affect and other hedonic constructs show a consistent association with CVD in healthy populations, and optimism is robustly related to better CVD outcomes in both healthy and patient populations.

Given the consistency of findings with optimism and disease endpoints, it is not surprising that optimism was also often reliably associated with healthier behaviors. Hedonic well-being was also associated with health behaviors in the expected directions, but mastery (a eudaimonic construct) demonstrated the most inconsistent associations. However, the evaluation of these studies is severely limited because most were cross-sectional, and hedonic well-being was more frequently assessed than were other types of PPWB. Thus, considering whether (and which aspects of) PPWB actually encourages restorative health behaviors and discourages deteriorative ones is difficult, given the likely bidirectionality of these factors. In fact, the strongest finding from this review is how few studies have purposefully tested this hypothesis, even though it is a commonly cited pathway linking PPWB and health. Additional studies explicitly designed to consider whether distinct types of well-being precede or predict health behaviors are necessary.

Studies of biological function are the most heterogeneous and cannot yet indicate the relative strength of the effects for different aspects of PPWB. The vast majority of this literature focused on hedonic well-being (e.g., no studies have considered the association between eudaimonic well-being and autonomic cardiac control). Hedonic well-being and optimism are more robustly associated with biological function than eudaimonic well-being, although for some biomarkers like $\mathrm{HbA}_{1 \mathrm{c}}$ no measure of PPWB was strongly related.
Eudaimonia, hedonia, optimism, and other measures of wellbeing may not have unique effects on cardiovascular health because they all represent a general tendency to do well and feel well. On the other hand, one might posit that compared with feelings about life (i.e., hedonic well-being), identifying meaningful life pursuits, setting goals, and fulfilling potential (i.e., eudaimonic well-being or optimism) may be more relevant for cardiovascular health because of the importance of behavioral and emotional regulation for maintaining health. Due in part to insufficient empirical evidence, we cannot yet fully evaluate the distinction between PPWB's theoretical approaches. However, this review does highlight nonsubstantive factors that may contribute to the difficulty in discerning distinct relations between aspects of PPWB and cardiovascular health. For example, the exact distinction between eudaimonic and hedonic well-being can be unclear (Kashdan et al., 2008), and the separation between indicators of PPWB may not be captured by the relatively crude measures that are used in existing studies. In our review, some measures of PPWB combined items or scales reflecting eudaimonia, hedonia, and optimism into a single composite. This was particularly true of studies investigating incident disease because secondary analyses of large data sets were often conducted, and measures of PPWB were derived from existing items. ${ }^{12}$ Although we classified measures of PPWB according to their most prominent features, there was undoubtedly ambiguity in some cases.

In more nuanced investigations of PPWB in relation to health, researchers will need to recognize that eudaimonic well-being, hedonic well-being, and optimism likely operate in tandem. That is, hedonic well-being may stem from pursuits related to eudaimonic well-being or optimism (e.g., feeling pleasure after accomplishing a long sought after life goal), hedonic well-being may exist on its own (e.g., savoring a delicious meal in a five-star restaurant), or all types of well-being may be absent (Waterman, 2008). Indeed, Keyes and Annas (2009) posited that individuals who are flourishing mentally and physically both feel good about their lives (i.e., have high levels of hedonic well-being) and function well in their lives (i.e., have high levels of eudaimonic well-being). By extension, flourishing individuals may also expect good things for their future lives (i.e., have high levels of optimism). Measures of PPWB that are most relevant to cardiovascular health may include multiple aspects of well-being. In fact, it is those measures of PPWB that cannot be easily classified because they include components of eudaimonia and hedonia, like optimism, that most powerfully predict CVD and related outcomes.

Another important consideration of the role of PPWB in cardiovascular health concerns whether PPWB's association is independent from ill-being. As noted earlier, considerable research has documented ill-being's relationship with CVD, health behaviors, and biological function. Given that well-being and ill-being can share an inverse relationship-particularly in the short-term but with increasing independence in the long-term (Diener \& Emmons, 1984; Diener, Scollon, \& Lucas, 2009) — it is important to determine whether relationships between PPWB and cardiovascu-

\footnotetext{
12 This also means that PPWB's psychometric properties may be less well-established than for measures of ill-being, which may influence conclusions about the magnitude of effect for positive versus negative psychological factors
} 
lar health merely repeat what is already known. The evidence so far suggests that PPWB may be considered an independent factor, especially among studies of incident disease. That said, it appears that effects for PPWB may not be as strong in magnitude as effects for ill-being for all cardiovascular-related outcomes and for all measures of PPWB. For example, some inflammation studies suggest stronger associations for pessimism than optimism (e.g., Roy et al., 2010). Although studies of PPWB and CVD are often required to adjust for ill-being to be considered methodologically rigorous, the inverse has not been true for studies of ill-being. Thus, few studies of ill-being have investigated whether effects of ill-being are independent of well-being. Presuming that ill-being is more relevant for cardiovascular health may be premature until more studies consider the effects of ill-being and well-being together. The most complete understanding of the interplay between mental and physical health will come from considering the full spectrum of human functioning and feeling.

\section{Restorative and Deteriorative Processes}

Previous work has most often considered how ill-being is associated with the presence of deteriorative processes-for example, how depression is associated with inflammation. When researchers consider the mechanisms by which well-being may influence health, they often posit that well-being protects against the occurrence of deteriorative processes, usually via a stress-buffering model. Thus, PPWB may reduce the intensity or frequency of negative feelings that motivate unhealthy behaviors, that are associated with chronic states of physiological arousal, or that activate neuroendocrine, cardiovascular, and inflammatory systems and other atherogenic processes (Rozanski, Blumenthal, Davidson, Saab, \& Kubzansky, 2005). Our review supports this idea, providing reasonably consistent evidence that PPWB is inversely associated with deteriorative behaviors and biology.

However, health is not merely the absence of deterioration. In fact, prior theorizing on how PPWB is associated with physical health suggests that similar to healthy physiological functioning, flourishing psychological states are likely to be characterized by inherent flexibility and resilience that allow individuals to respond rapidly to environmental challenges and provide reserve capacity for coping ("What Is Health," 2009; J. Seeman, 1989). This perspective suggests that PPWB may influence cardiovascular health not only by buffering the effects of stress or reducing deteriorative behaviors and biology but also by directly enhancing behavioral and biological functioning. Thus, individuals with high levels of PPWB may have more opportunities for processes that promote rest, restoration, and the capacity to regenerate (Rozanski, 2005; Smith \& Baum, 2003). Positive physiological responses have been linked with adaptive psychological processes and positive traits (Bower, Low, Moskowitz, Sepah, \& Epel, 2008). Other work has shown an increased capacity to mitigate adverse biological reactions (e.g., oxidative stress and cellular damage) with the relaxation response, a technique applied to enhance positive psychological states (Dusek et al., 2008). Building on this perspective, we posited that PPWB is associated with restorative processes that bolster cardiovascular health. Although work on PPWB and restorative processes is noticeably less abundant than work on deteriorative processes, PPWB generally seems to be positively associated with restorative behaviors and biology.
A simple model of well-being, ill-being, and health might suggest that well-being and ill-being have distinct pathways to disease or even that different types of well-being have distinct healthrelated effects. However, healthy physiological systems are characterized by complexity and redundancy (Goldberger, 1996), and behaviors occur on a spectrum and respond to a variety of motivational forces. The intricate interplay of these processes in the real world suggests that perfectly distinct mechanisms and effects of different psychological factors may be difficult to achieve. Moreover, the measurement of different aspects of PPWB is not yet differentiated enough to guarantee that constructs do not overlap or share meaningful correlations. Given the intricacy and measurement challenges, the current state of evidence is not far enough advanced to comment on whether the proposed intermediary restorative and deteriorative processes might differ for wellbeing and ill-being or, even more specifically, different constructs of PPWB. However, current evidence can suggest where wellbeing and ill-being may be differentially associated with cardiovascular health, point to important directions for new research, and highlight areas for further exploration that are likely to provide significant insight.

\section{Methodological Challenges}

The challenges of the current review stem primarily from the methodological limitations of the reviewed studies. Among studies investigating CVD endpoints, findings that suggest higher PPWB levels are associated with a reduced risk of disease may be subject to alternative explanations (i.e., an unmeasured third variable related to both PPWB and CVD). However, the vast majority of studies with disease endpoints controlled for a wide variety of potential confounders and variables that could be on the pathway between PPWB and CVD. These included demographic factors (e.g., gender, ethnicity), health behaviors (e.g., smoking status, physical activity), biological markers (e.g., BP, cholesterol, BMI), ill-being, and within patient populations, health status (e.g., hypertension and diabetic status, disease severity). Other candidate third variables-for example, a common genetic substrate or combination, or early experiences in utero or immediately postnatal - have been hypothesized but not yet identified in the literature. Thus, although we cannot be fully certain that an unidentified confounder does not exist, it is reassuring that most of the diseaserelated studies reviewed here have reasonably accounted for known third variables.

Another alternative explanation for the association between PPWB and CVD relates to the presence of early, asymptomatic disease. In studies of healthy populations, some individuals within the sample may have an undiagnosed disease such as atherosclerosis. One way to address this issue is by excluding individuals from a healthy cohort if, within several years of the baseline assessment, they are diagnosed with disease. Indeed, several studies reported here did such an analysis, and overall findings were mostly unchanged (e.g., Boehm et al., 2011b; Kubzansky \& Thurston, 2007; Shirai et al., 2009; Sone et al., 2008). Thus, the presence of incipient disease cannot be ruled out, but the chance that it would alter reported findings is small.

Other methodological challenges concern the measurement of PPWB. Many studies described here used single item indicators of PPWB or scales with unknown psychometric properties. Although 
the analysis of large-scale, secondary data sets sometimes necessitates the use of less than ideal PPWB measures, future research should be purposely designed to consider PPWB with psychometrically sound measures. Also related to the assessment of PPWB is that the majority of studies used self-reported PPWB. Relying exclusively on self-report increases the possibility of social desirability and other response biases. Self-reported well-being is generally consistent with other forms of measurement, but additional research could only be strengthened by diverse modes of assessment (e.g., informant reports, behavioral assessments, coding of facial expressions, evaluation of written text). The use of selfreported PPWB may be less of a concern in this review because except for self-reported health behaviors and BMI, we mostly excluded studies that exclusively investigated self-reported health.

The measurement of PPWB raises several other issues as well. It is unclear what levels of PPWB are required to detect associations with cardiovascular health. That is, are moderate levels of PPWB sufficient? Are high levels or extremely high levels of PPWB even better? There is too little evidence to assess whether a desirable threshold of PPWB exists for cardiovascular health or if the relationship is characterized by a dose-response. Moreover, curvilinear trends in PPWB are rarely examined, although it is plausible that manic states or extremely high levels of PPWB may not foster good outcomes (Oishi, Diener, \& Lucas, 2007). That is, even favorable correlates of positive states and traits may be diminished or become unfavorable at very extreme levels (A. M. Grant \& Schwartz, 2011). This suggests that rather than monotonic effects of PPWB (whereby if some is good, more is even better), nonmonotonic effects-especially in the shape of an inverted U-may be pertinent for the association between PPWB and health-related outcomes (A. M. Grant \& Schwartz, 2011).

In addition, the temporal characteristics of different PPWB indicators varies, which may have implications for associations with cardiovascular health. For example, constructs like purpose in life or optimism are fairly stable and traitlike compared with constructs like positive affect, which may change from minute to minute or day to day. We suspect that enduring (versus momentary) measures of PPWB are most likely to be associated with health outcomes, especially for incident disease. Some researchers have tried to address these concerns by averaging across multiple assessments of positive affect with ecological momentary assessment (Steptoe, O’Donnell, Badrick, et al., 2008; Steptoe, O'Donnell, Marmot, \& Wardle, 2008; Steptoe et al., 2005). Indeed, one study from this group compared the biological correlates of positive affect measured via ecological momentary assessment with the biological correlates of positive affect measured via a one-time self-report (Steptoe et al., 2007). Associations between positive affect and biological function were stronger when positive affect was assessed via ecological momentary assessment than when it was assessed with traditional methods. Work from other diseases also suggests that repeated measures of positive affect more effectively capture chronic levels of hedonic well-being and more strongly predict health-related outcomes (Moskowitz, 2003). Thus, unless considering acute exacerbation, enduring measures of PPWB may provide the strongest test of the PPWB-cardiovascular health association.

Furthermore, some indicators of PPWB are bipolar (e.g., endpoints range from very satisfied to very dissatisfied), and some commonly used multi-item PPWB scales include negatively worded items that are reverse-scored. For example, Ryff's eudaimonic well-being scales include negative items (Ryff \& Keyes, 1995), and the full Life Orientation Test includes reverse-scored pessimism items (Scheier, Carver, \& Bridges, 1994). The strongest evidence of an association between PPWB and cardiovascular health may come from scales that are unidimensional and that exclusively contain positive items because including both positive and negative items can make it difficult to determine whether well-being or ill-being is the "active" ingredient. Moreover, including reverse-scored items in scales may create psychometric difficulties like reduced internal consistency and lower item-scale correlations (Carlson et al., 2011). However, other researchers argue that an item's theoretical basis is more important than its positive or negative valence (Ryff \& Singer, 2007) or that including negative items in a PPWB composite may act like an adjustment for ill-being. Specific examination of these psychometric issues and whether they lead to different conclusions is needed.

Beyond the measurement of PPWB, the measurement of illbeing is also an issue for the current review. What is the most appropriate ill-being construct to measure (and adjust for) in analyses that examine the association between PPWB and cardiovascular health? Diverse measures of ill-being were used in the studies reviewed here, including symptoms of depression or anxiety, mental health problems, stress, general distress, anger, hostility, and pessimism. Although there is no clear theoretical basis for which measure of ill-being should be used, it seems reasonable to control for measures of ill-being that are associated with CVD (e.g., depression, anxiety, anger, hostility; Chida \& Steptoe, 2009; Kubzansky et al., 1998; Rugulies, 2002). Other research also indicates that general negative affect may be as relevant as or more relevant than specific types of negative affect for health outcomes (Suls \& Bunde, 2005). This suggests that selecting a specific type of ill-being to control for may be less critical than including a broad measure of distress. It is also useful to note that when ill-being is assessed in a comparable manner to its well-being counterpart (e.g., the pessimism and optimism subscales of the Life Orientation Test, negative affect and positive affect from the Positive and Negative Affect Schedule) then ill-being and wellbeing may be more highly correlated with one another than if they had been assessed with different scales or with constructs that were not developed as part of a single scale. Controlling for ill-being measures that are strongly correlated with well-being may provide a more rigorous test of the independence of well-being and illbeing.

A prevalent methodological drawback for studies investigating the association of PPWB with behaviors and biology is the use of cross-sectional designs. Although these are useful in the early stages of investigation, research regarding cardiovascular health will now benefit greatly from prospective and experimental studies that can more clearly establish causal relationships. Prospective studies examining whether and how trait levels of PPWB may precede changes in health behaviors and biological function across time would further illuminate the complex association between PPWB and cardiovascular health. Research designs that go beyond mere correlations will also permit the assessment of nonlinear relationships, which may be relevant for PPWB's association with factors such as alcohol consumption.

Another methodological challenge concerns the way in which health behaviors are assessed. Behaviors are sometimes measured 
with bipolar scales ranging from problematic behavior to good behavior (e.g., sedentary behavior to high levels of physical activity). This makes classification into restorative and deteriorative behaviors difficult and may obscure true relationships with PPWB. It may be the case that PPWB is more closely associated with restorative processes like exercise, whereas ill-being is more closely associated with deteriorative processes like sedentary behavior. Because the absence of one is not equivalent to the presence of the other (e.g., M. T. Hamilton, Hamilton, \& Zderic, 2007), failing to consider both ends of the spectrum leads to an incomplete understanding. However, until more distinct measurements of restorative and deteriorative behaviors are made, conclusions regarding the strength of their association with PPWB are premature.

Finally, we note that publication bias is inherent in a comprehensive review like this one. Studies that report null findings are less likely to be published than are studies that detect an association (Rosenthal, 1991).

\section{Future Research}

This review has highlighted many directions for future research. Chief among these is the need for prospective investigations that consider how initial PPWB is subsequently related to health behaviors and biological function across time. For example, are optimistic adolescents more likely to sleep well as adults? Do happy middle aged adults become older adults who are less likely to develop atherosclerosis? Moreover, future research should maintain a developmental perspective, recognizing that effects of PPWB during one developmental period may differ at another. Using longitudinal investigations at unique points in the lifespan is critical to expanding knowledge about the role of PPWB in cardiovascular health.

Research should continue to explore the promising role of optimism in cardiovascular health. Moreover, work should incorporate eudaimonic well-being measures (which have been infrequently assessed) but also explicitly focus on the distinction between different types of PPWB in relation to cardiovascular health. This would involve including a wide variety of PPWB measures in each study and comparing their effects. Then researchers could determine whether the association between cardiovascular health and eudaimonia, hedonia, and optimism is solely due to overlap between PPWB constructs or unique characteristics of each construct.

Studies that consider the potential stress-buffering effects of PPWB on cardiovascular-related biological function are also needed. Randomized experiments as well as prospective epidemiologic research would have to be designed explicitly with this question in mind. If PPWB does directly alter biological function, additional conceptual and empirical work may be needed to understand if this occurs through other direct biological effects (e.g., increasing endogenous opioids, influencing glucose metabolism) or via stress buffering. If effects primarily occur through the latter, then study designs that explicitly consider potential interactions or effect modifiers will be most informative.

To further address questions about the causal direction of effects, future research should also include clinical trials that seek to enhance PPWB. Although interventions to alleviate ill-being have had mixed results in reducing the risk of CVD (Writing Committee for the ENRICHD Investigators, 2003), there is some evidence to suggest that fostering assets like PPWB may be effective. For example, enhancing PPWB may better equip individuals to deal with challenge, thereby reducing the cardiotoxic effects of stress and improving function across a range of domains (Rozanski \& Kubzansky, 2005). Moreover, initial evidence indicates that certain interventions can increase PPWB (Lyubomirsky, Sheldon, \& Schkade, 2005; Seligman, Steen, Park, \& Peterson, 2005). Thus, there is reason to believe that experimental explorations of how to foster PPWB may also have important implications for cardiovascular health (see also Burton, Pakenham, \& Brown, 2009; Charlson et al., 2007). In addition, the distinction between eudaimonia, hedonia, and optimism may be instructive for designing conditions within a clinical trial (Ryan et al., 2008)—for example, by emphasizing engagement in fulfilling pursuits, savoring pleasant moments, or expressing favorable expectations for the future.

Although this review focused on CVD because it is a leading cause of death worldwide and a well-defined disease with evidence regarding PPWB, many of the conclusions drawn here are applicable to other diseases like cancer. For example, the methodological challenges of assessing PPWB are relevant to all health-related studies that examine positive factors. Moreover, considering the intermediary processes between PPWB and disease as potentially restorative versus deteriorative may help conceptualize underlying pathways to overall health. In fact, our theoretical model highlights the limited attention positive health factors (versus risk factors) have received (Lloyd-Jones et al., 2010), particularly with regard to biological processes that may actually enhance health. More attention to these processes is greatly needed.

\section{Concluding Remarks}

With this review, we sought to understand the association between PPWB and cardiovascular health. By reviewing evidence related to CVD events and mortality, as well as restorative and deteriorative health behaviors and biological function, we conclude that PPWB is clearly associated with cardiovascular health, often over and above the effects of ill-being. Thus, continued investigation of PPWB in the context of cardiovascular health is warranted not only because PPWB is desirable in its own right but also because it has critical implications for both the initiation and progression of CVD and may provide new avenues for intervention and prevention.

\section{References}

Adalbjarnardottir, S., \& Rafnsson, F. D. (2001). Perceived control in adolescent substance use: Concurrent and longitudinal analyses. Psychology of Addictive Behaviors, 15, 25-32. doi:10.1037/0893-164X .15 .1 .25

Agewall, S., Wikstrand, J., \& Fagerberg, B. (1998). Stroke was predicted by dimensions of quality of life in treated hypertensive men. Stroke, 29 2329-2333. doi:10.1161/01.STR.29.11.2329

Ambrose, J. A., \& Barua, R. S. (2004). The pathophysiology of cigarette smoking and cardiovascular disease: An update. Journal of the American College of Cardiology, 43, 1731-1737. doi:10.1016/j.jacc.2003.12.047

American Diabetes Association. (2008). Standards of medical care in diabetes-2008 Diabetes Care, 31(1, Suppl. 1), S12-S54. doi:10.2337/ dc08-S012

Atlantis, E., \& Baker, M. (2008). Obesity effects on depression: Systematic 
review of epidemiological studies. International Journal of Obesity, 32, 881-891. doi:10.1038/ijo.2008.54

Ayas, N. T., White, D. P., Manson, J. E., Stampfer, M. J., Speizer, F. E., Malhotra, A., \& Hu, F. B. (2003). A prospective study of sleep duration and coronary heart disease in women. Archives of Internal Medicine, 163, 205-209. doi:10.1001/archinte.163.2.205

Bacon, S. L., Watkins, L. L., Babyak, M., Sherwood, A., Hayano, J., Hinderliter, A. L., . . Blumenthal, J. A. (2004). Effects of daily stress on autonomic cardiac control in patients with coronary artery disease. American Journal of Cardiology, 93, 1292-1294. doi:10.1016/ j.amjcard.2004.02.018

Bailis, D. S., Segall, A., Mahon, M. J., Chipperfield, J. G., \& Dunn, E. M. (2001). Perceived control in relation to socioeconomic and behavioral resources for health. Social Science \& Medicine, 52, 1661-1676. doi: 10.1016/S0277-9536(00)00280-X

Barefoot, J. C., Brummett, B. H., Helms, M. J., Mark, D. B., Siegler, I. C., $\&$ Williams, R. B. (2000). Depressive symptoms and survival of patients with coronary artery disease. Psychosomatic Medicine, 62, 790-795.

Baruth, M., Lee, D. C., Sui, X., Church, T. S., Marcus, B. H., Wilcox, S., \& Blair, S. N. (2011). Emotional outlook on life predicts increases in physical activity among initially inactive men. Health Education \& Behavior, 38, 150-158. doi:10.1177/1090198110376352

Bem, D. J. (1995). Writing a review article for Psychological Bulletin. Psychological Bulletin, 118, 172-177. doi:10.1037/0033-2909.118 .2 .172

Bhattacharyya, M. R., Whitehead, D. L., Rakhit, R., \& Steptoe, A. (2008). Depressed mood, positive affect, and heart rate variability in patients with suspected coronary artery disease. Psychosomatic Medicine, 70, 1020-1027. doi:10.1097/PSY.0b013e318189afcc

Black, P. H., \& Garbutt, L. D. (2002). Stress, inflammation and cardiovascular disease. Journal of Psychosomatic Research, 52, 1-23. doi: 10.1016/S0022-3999(01)00302-6

Boehm, J. K., Peterson, C., Kivimaki, M., \& Kubzansky, L. D. (2011a). Heart health when life is satisfying: Evidence from the Whitehall II cohort study. European Heart Journal, 32, 2672-2677. doi:10.1093/ eurheartj/ehr203

Boehm, J. K., Peterson, C., Kivimaki, M., \& Kubzansky, L. D. (2011b). A prospective study of positive psychological well-being and coronary heart disease. Health Psychology, 30, 259-267. doi:10.1037/a0023124

Bogart, L. M., Collins, R. L., Ellickson, P. L., \& Klein, D. J. (2007). Are adolescent substance users less satisfied with life as young adults and if so, why? Social Indicators Research, 81, 149-169. doi:10.1007/s11205006-0019-6

Bower, J. E., Low, C. A., Moskowitz, J. T., Sepah, S., \& Epel, E. (2008). Benefit finding and physical health: Positive psychological changes and enhanced allostasis. Social and Personality Psychology Compass, 2, 223-244. doi:10.1111/j.1751-9004.2007.00038.x

Bradburn, N. M. (1969). The structure of psychological well-being. Chicago, IL: Aldine.

Bradshaw, B. G., Richardson, G. E., Kumpfer, K., Carlson, J., Stanchfield, J., Overall, J., .. Kulkarni, K. (2007). Determining the efficacy of a resiliency training approach in adults with Type 2 diabetes. The Diabetes Educator, 33, 650-659. doi:10.1177/0145721707303809

Brody, G. H., Kogan, S. M., Murry, V. M., Chen, Y. F., \& Brown, A. C. (2008). Psychological functioning, support for self-management, and glycemic control among rural African American adults with diabetes mellitus type 2. Health Psychology, 27, S83-S90. doi:10.1037/02786133.27.1.S83

Brook, R. D., \& Julius, S. (2000). Autonomic imbalance, hypertension, and cardiovascular risk. American Journal of Hypertension, 13(6, Pt. 4), 112S-122S. doi:10.1016/S0895-7061(00)00228-4

Brummett, B. H., Boyle, S. H., Siegler, I. C., Williams, R. B., Mark, D. B., \& Barefoot, J. C. (2005). Ratings of positive and depressive emotion as predictors of mortality in coronary patients. International Journal of Cardiology, 100, 213-216. doi:10.1016/j.ijcard.2004.06.016

Burris, J. L., Brechting, E. H., Salsman, J., \& Carlson, C. R. (2009). Factors associated with the psychological well-being and distress of university students. Journal of American College Health, 57, 536-544. doi: 10.3200/JACH.57.5.536-544

Burton, N. W., Pakenham, K. I., \& Brown, W. J. (2009). Evaluating the effectiveness of psychosocial resilience training for heart health, and the added value of promoting physical activity: A cluster randomized trial of the READY program. BMC Public Health, 9, 427. doi:10.1186/14712458-9-427

Cappuccio, F. P., Cooper, D., D’Elia, L., Strazzullo, P., \& Miller, M. A (2011). Sleep duration predicts cardiovascular outcomes: A systematic review and meta-analysis of prospective studies. European Heart Journal, 32, 1484-1492. doi:10.1093/eurheartj/ehr007

Carlson, M., Wilcox, R., Chou, C.-P., Chang, M., Yang, F., Blanchard, J., .. Clark, F. (2011). Psychometric properties of reverse-scored items on the CES-D in a sample of ethnically diverse older adults. Psychological Assessment, 23, 558-562. doi:10.1037/a0022484

Carr, D., \& Friedman, M. A. (2005). Is obesity stigmatizing? Body weight, perceived discrimination, and psychological well-being in the United States. Journal of Health and Social Behavior, 46, 244-259. doi: 10.1177/002214650504600303

Carvajal, S. C., Wiatrek, D. E., Evans, R. I., Knee, C. R., \& Nash, S. G. (2000). Psychosocial determinants of the onset and escalation of smoking: Cross-sectional and prospective findings in multiethnic middle school samples. Journal of Adolescent Health, 27, 255-265. doi: 10.1016/S1054-139X(00)00124-5

Carver, C. S., Scheier, M. F., \& Segerstrom, S. C. (2010). Optimism. Clinical Psychology Review, 30, 879-889. doi:10.1016/j.cpr.2010 .01 .006

Chan, A. M., von Muhlen, D., Kritz-Silverstein, D., \& Barrett-Connor, E. (2009). Regular alcohol consumption is associated with increasing quality of life and mood in older men and women: The Rancho Bernardo Study. Maturitas, 62, 294-300. doi:10.1016/j.maturitas.2009.01.005

Chan, I. W. S., Lai, J. C. L., \& Wong, K. W. N. (2006). Resilience is associated with better recovery in Chinese people diagnosed with coronary heart disease. Psychology \& Health, 21, 335-349. doi:10.1080/ 14768320500215137

Charlson, M. E., Boutin-Foster, C., Mancuso, C. A., Peterson, J. C., Ogedegbe, G., Briggs, W. M., ... Translational Behavioral Science Research Consortium. (2007). Randomized controlled trials of positive affect and self-affirmation to facilitate healthy behaviors in patients with cardiopulmonary diseases: Rationale, trial design, and methods. Contemporary Clinical Trials, 28, 748-762. doi:10.1016/j.cct.2007.03.002

Chida, Y., \& Steptoe, A. (2008). Positive psychological well-being and mortality: A quantitative review of prospective observational studies. Psychosomatic Medicine, 70, 741-756. doi:10.1097/ PSY.0b013e31818105ba

Chida, Y., \& Steptoe, A. (2009). The association of anger and hostility with future coronary heart disease: A meta-analytic review of prospective evidence. Journal of the American College of Cardiology, 53, 936-946. doi:10.1016/j.jacc.2008.11.044

Chobanian, A. V., Bakris, G. L., Black, H. R., Cushman, W. C., Green, L. A., Izzo, J. L., Jr., ... the National High Blood Pressure Education Program Coordinating Committee. (2003). Seventh report of the Joint National Committee on Prevention, Detection, Evaluation, and Treatment of High Blood Pressure. Hypertension, 42, 1206-1252. doi: 10.1161/01.HYP.0000107251.49515.c2

Conway, F., Magai, C., Springer, C., \& Jones, S. C. (2008). Optimism and pessimism as predictors of physical and psychological health among grandmothers raising their grandchildren. Journal of Research in Personality, 42, 1352-1357. doi:10.1016/j.jrp.2008.03.011

Cotter, K. A., \& Lachman, M. E. (2010). No strain, no gain: Psychosocial 
predictors of physical activity across the adult lifespan. Journal of Physical Activity \& Health, 7, 584-594.

Crumbaugh, J. C. (1968). Cross-validation of Purpose-in-Life test based on Frankl's concepts. Journal of Individual Psychology, 24, 74-81.

Crumbaugh, J. C., \& Maholick, L. T. (1964). An experimental study in existentialism: The psychometric approach to Frankl's concept of noogenic neurosis. Journal of Clinical Psychology, 20, 200-207. doi:10.1002/10974679(196404)20:2<200::AID-JCLP2270200203>3.0.CO;2-U

Danesh, J., Wheeler, J. G., Hirschfield, G. M., Eda, S., Eiriksdottir, G., Rumley, A., ... Gudnason, V. (2004). C-reactive protein and other circulating markers of inflammation in the prediction of coronary heart disease. New England Journal of Medicine, 350, 1387-1397. doi: 10.1056/NEJMoa032804

Davidson, K. W., Mostofsky, E., \& Whang, W. (2010). Don't worry, be happy: Positive affect and reduced 10-year incident coronary heart disease: The Canadian Nova Scotia Health Survey. European Heart Journal, 31, 1065-1070. doi:10.1093/eurheartj/ehp603

Deci, E. L., \& Ryan, R. M. (1985). The general causality orientations scale: Self-determination in personality. Journal of Research in Personality, 19, 109-134. doi:10.1016/0092-6566(85)90023-6

Denollet, J., Pedersen, S. S., Daemen, J., de Jaegere, P., Serruys, P. W., \& van Domburg, R. T. (2008). Reduced positive affect (anhedonia) predicts major clinical events following implantation of coronary-artery stents. Journal of Internal Medicine, 263, 203-211. doi:10.1111/j.13652796.2007.01870.x

Diener, E. (2009). Assessing well-being: The collected works of Ed Diener. New York, NY: Springer.

Diener, E., \& Chan, M. Y. (2011). Happy people live longer: Subjective well-being contributes to health and longevity. Applied Psychology: Health and Well-Being, 3, 1-43. doi:10.1111/j.1758-0854.2010.01045.x

Diener, E., \& Emmons, R. A. (1984). The independence of positive and negative affect. Journal of Personality and Social Psychology, 47, 1105-1117. doi:10.1037/0022-3514.47.5.1105

Diener, E., Emmons, R. A., Larsen, R. J., \& Griffin, S. (1985). The Satisfaction With Life Scale. Journal of Personality Assessment, 49, 71-75. doi:10.1207/s15327752jpa4901_13

Diener, E., Scollon, C. N., \& Lucas, R. E. (2009). The evolving concept of subjective well-being: The multifaceted nature of happiness. In E. Diener (Ed.), Assessing well-being: The collected works of Ed Diener (pp. 67-100). New York, NY: Springer.

Diener, E., \& Seligman, M. E. (2002). Very happy people. Psychological Science, 13, 81-84. doi:10.1111/1467-9280.00415

Diener, E., Suh, E. M., Lucas, R. E., \& Smith, H. L. (1999). Subjective well-being: Three decades of progress. Psychological Bulletin, 125, 276-302. doi:10.1037/0033-2909.125.2.276

Dockray, S., \& Steptoe, A. (2010). Positive affect and psychobiological processes. Neuroscience \& Biobehavioral Reviews, 35, 69-75. doi: 10.1016/j.neubiorev.2010.01.006

Dusek, J. A., Otu, H. H., Wohlhueter, A. L., Bhasin, M., Zerbini, L. F., Joseph, M. G., ... Libermann, T. A. (2008). Genomic counter-stress changes induced by the relaxation response. PLoS One, 3, e2576. doi: 10.1371/journal.pone.0002576

Einvik, G., Ekeberg, O., Klemsdal, T. O., Sandvik, L., \& Hjerkinn, E. M. (2009). Physical distress is associated with cardiovascular events in a high risk population of elderly men. BMC Cardiovascular Disorders, 9, 14. doi:10.1186/1471-2261-9-14

Elavsky, S., \& McAuley, E. (2007). Physical activity and mental health outcomes during menopause: A randomized controlled trial. Annals of Behavioral Medicine, 33, 132-142. doi:10.1007/BF02879894

Elkind, M. S., Sciacca, R., Boden-Albala, B., Rundek, T., Paik, M. C., \& Sacco, R. L. (2006). Moderate alcohol consumption reduces risk of ischemic stroke: The Northern Manhattan Study. Stroke, 37, 13-19. doi:10.1161/01.STR.0000195048.86810.5b

Feldman, P. J., \& Steptoe, A. (2003). Psychosocial and socioeconomic factors associated with glycated hemoglobin in nondiabetic middle-aged men and women. Health Psychology, 22, 398-405. doi:10.1037/02786133.22.4.398

Fredrickson, B. L., \& Levenson, R. W. (1998). Positive emotions speed recovery from the cardiovascular sequelae of negative emotions. Cognition \& Emotion, 12, 191-220. doi:10.1080/026999398379718

Fredrickson, B. L., Mancuso, R. A., Branigan, C., \& Tugade, M. M. (2000). The undoing effect of positive emotions. Motivation and Emotion, 24, 237-258. doi:10.1023/A:1010796329158

Friedman, E. M., Hayney, M., Love, G. D., Singer, B. H., \& Ryff, C. D. (2007). Plasma interleukin-6 and soluble IL-6 receptors are associated with psychological well-being in aging women. Health Psychology, 26, 305-313. doi:10.1037/0278-6133.26.3.305

Friedman, H. S., \& Booth-Kewley, S. (1987). The "disease-prone personality": A meta-analytic view of the construct. American Psychologist, 42, 539-555. doi:10.1037/0003-066X.42.6.539

Fuligni, A. J., \& Hardway, C. (2006). Daily variation in adolescents' sleep, activities, and psychological well-being. Journal of Research on Adolescence, 16, 353-378. doi:10.1111/j.1532-7795.2006.00498.x

Galambos, N. L., Dalton, A. L., \& Maggs, J. L. (2009). Losing sleep over it: Daily variation in sleep quantity and quality in Canadian students' first semester of university. Journal of Research on Adolescence, 19, 741-761. doi:10.1111/j.1532-7795.2009.00618.x

Gale, C. R., Batty, G. D., \& Deary, I. J. (2008). Locus of control at age 10 years and health outcomes and behaviors at age 30 years: The 1970 British Cohort Study. Psychosomatic Medicine, 70, 397-403. doi: 10.1097/PSY.0b013e31816a719e

Gallagher, M. W., \& Lopez, S. J. (2009). Positive expectancies and mental health: Identifying the unique contributions of hope and optimism. The Journal of Positive Psychology, 4, 548-556. doi:10.1080/ 17439760903157166

Gallagher, M. W., Lopez, S. J., \& Preacher, K. J. (2009). The hierarchical structure of well-being. Journal of Personality, 77, 1025-1050. doi 10.1111/j.1467-6494.2009.00573.x

Geisser, M. E., Cano, A., \& Foran, H. (2006). Psychometric properties of the Mood and Anxiety Symptom Questionnaire in patients with chronic pain. The Clinical Journal of Pain, 22, 1-9. doi:10.1097/ 01.ajp.0000146180.55778.4d

Gerstein, H. C. (2004). Glycosylated hemoglobin: Finally ready for prime time as a cardiovascular risk factor. Annals of Internal Medicine, 141, 475-476.

Giltay, E. J., Geleijnse, J. M., Zitman, F. G., Buijsse, B., \& Kromhout, D. (2007). Lifestyle and dietary correlates of dispositional optimism in men: The Zutphen Elderly Study. Journal of Psychosomatic Research, 63, 483-490. doi:10.1016/j.jpsychores.2007.07.014

Giltay, E. J., Geleijnse, J. M., Zitman, F. G., Hoekstra, T., \& Schouten, E. G. (2004). Dispositional optimism and all-cause and cardiovascular mortality in a prospective cohort of elderly Dutch men and women. Archives of General Psychiatry, 61, 1126-1135. doi:10.1001/ archpsyc.61.11.1126

Giltay, E. J., Kamphuis, M. H., Kalmijn, S., Zitman, F. G., \& Kromhout, D. (2006). Dispositional optimism and the risk of cardiovascular death: The Zutphen Elderly Study. Archives of Internal Medicine, 166, 431436. doi:10.1001/.431

Glazer, K. M., Emery, C. F., Frid, D. J., \& Banyasz, R. E. (2002). Psychological predictors of adherence and outcomes among patients in cardiac rehabilitation. Journal of Cardiopulmonary Rehabilitation, 22, 40-46. doi:10.1097/00008483-200201000-00006

Goldberger, A. L. (1996). Non-linear dynamics for clinicians: Chaos theory, fractals, and complexity at the bedside. Lancet, 347, 1312-1314. doi:10.1016/S0140-6736(96)90948-4

Gordon, T., Castelli, W. P., Hjortland, M. C., Kannel, W. B., \& Dawber, T. R. (1977). High density lipoprotein as a protective factor against 
coronary heart disease: The Framingham Study. The American Journal of Medicine, 62, 707-714. doi:10.1016/0002-9343(77)90874-9

Grant, A. M., \& Schwartz, B. (2011). Too much of a good thing: The challenge and opportunity of the inverted U. Perspectives on Psychological Science, 6, 61-76. doi:10.1177/1745691610393523

Grant, N., Wardle, J., \& Steptoe, A. (2009). The relationship between life satisfaction and health behavior: A cross-cultural analysis of young adults. International Journal of Behavioral Medicine, 16, 259-268. doi:10.1007/s12529-009-9032-x

Hamilton, M. T., Hamilton, D. G., \& Zderic, T. W. (2007). Role of low energy expenditure and sitting in obesity, metabolic syndrome, type 2 diabetes, and cardiovascular disease. Diabetes, 56, 2655-2667. doi: $10.2337 / \mathrm{db} 07-0882$

Hamilton, N. A., Gallagher, M. W., Preacher, K. J., Stevens, N., Nelson, C. A., Karlson, C., \& McCurdy, D. (2007). Insomnia and well-being. Journal of Consulting and Clinical Psychology, 75, 939-946. doi: 10.1037/0022-006X.75.6.939

Hamilton, N. A., Nelson, C. A., Stevens, N., \& Kitzman, H. (2007). Sleep and psychological well-being. Social Indicators Research, 82, 147-163. doi:10.1007/s11205-006-9030-1

Harding, S. D. (1982). Psychological well-being in Great Britain: An evaluation of the Bradburn Affect Balance Scale. Personality and Individual Differences, 3, 167-175. doi:10.1016/0191-8869(82)90031-9

Heron, M., Hoyert, D., Murphy, S., Xu, J., Kochanek, K., \& Tejada-Vera, B. (2009). Deaths: Final data for 2006. National vital statistics reports. Retrieved from http://www.cdc.gov/nchs/data/nvsr/nvsr57/nvsr57_14.pdf

Holahan, C. K., \& Suzuki, R. (2006). Motivational factors in health promoting behavior in later aging. Activities, Adaptation \& Aging, 30, 47-60. doi:10.1300/J016v30n01_03

Holt-Lunstad, J., Smith, T. B., \& Layton, J. B. (2010). Social relationships and mortality risk: A meta-analytic review. PLoS Medicine, 7, e1000316. doi:10.1371/journal.pmed.1000316

Howell, R. T., Kern, M. L., \& Lyubomirsky, S. (2007). Health benefits: Meta-analytically determining the impact of well-being on objective health outcomes. Health Psychology Review, 1, 83-136. doi:10.1080/ 17437190701492486

Hu, F. B., Rimm, E. B., Stampfer, M. J., Ascherio, A., Spiegelman, D., \& Willett, W. C. (2000). Prospective study of major dietary patterns and risk of coronary heart disease in men. American Journal of Clinical Nutrition, 72, 912-921.

Hu, F. B., \& Willett, W. C. (2002). Optimal diets for prevention of coronary heart disease. JAMA, 288, 2569-2578. doi:10.1001/ jama.288.20.2569

Hussong, A. M., Hicks, R. E., Levy, S. A., \& Curran, P. J. (2001). Specifying the relations between affect and heavy alcohol use among young adults. Journal of Abnormal Psychology, 110, 449-461. doi: 10.1037/0021-843X.110.3.449

Ikeda, A., Schwartz, J., Peters, J. L., Fang, S., Spiro, A., Sparrow, D., . . Kubzansky, L. D. (2011). Optimism in relation to inflammation and endothelial dysfunction in older men: The VA Normative Aging Study. Psychosomatic Medicine, 73, 664-671. doi:10.1097/PSY.0b013e3182312497

Ikehara, S., Iso, H., Toyoshima, H., Date, C., Yamamoto, A., Kikuchi, S., ... Japan Collaborative Cohort Study Group. (2008). Alcohol consumption and mortality from stroke and coronary heart disease among Japanese men and women: The Japan Collaborative Cohort Study. Stroke, 39, 2936-2942. doi:10.1161/STROKEAHA.108.520288

Kahneman, D., Diener, E., \& Schwarz, N. (1999). Well-being: The foundations of hedonic psychology. New York, NY: Russell Sage Foundation.

Kahneman, D., Krueger, A. B., Schkade, D. A., Schwarz, N., \& Stone, A. A. (2004). A survey method for characterizing daily life experience: The Day Reconstruction Method. Science, 306, 1776-1780. doi: 10.1126/science. 1103572

Kashdan, T. B., Biswas-Diener, R., \& King, L. A. (2008). Reconsidering happiness: The costs of distinguishing between hedonics and eudaimonia. The Journal of Positive Psychology, 3, 219-233. doi:10.1080/ 17439760802303044

Katzmarzyk, P. T., Church, T. S., Craig, C. L., \& Bouchard, C. (2009). Sitting time and mortality from all causes, cardiovascular disease, and cancer. Medicine \& Science in Sports \& Exercise, 41, 998-1005. doi 10.1249/MSS.0b013e3181930355

Kelloniemi, H., Ek, E., \& Laitinen, J. (2005). Optimism, dietary habits, body mass index and smoking among young Finnish adults. Appetite, 45, 169-176. doi:10.1016/j.appet.2005.05.001

Keyes, C. L. M., \& Annas, J. (2009). Feeling good and functioning well: Distinctive concepts in ancient philosophy and contemporary science. The Journal of Positive Psychology, 4, 197-201. doi:10.1080/ 17439760902844228

Keyes, C. L. M., Shmotkin, D., \& Ryff, C. D. (2002). Optimizing wellbeing: The empirical encounter of two traditions. Journal of Personality and Social Psychology, 82, 1007-1022. doi:10.1037/0022-3514 82.6.1007

Khaw, K. T., Wareham, N., Bingham, S., Luben, R., Welch, A., \& Day, N. (2004). Association of hemoglobin A1C with cardiovascular disease and mortality in adults: The European Prospective Investigation into Cancer in Norfolk. Annals of Internal Medicine, 141, 413-420.

Koizumi, M., Ito, H., Kaneko, Y., \& Motohashi, Y. (2008). Effect of having a sense of purpose in life on the risk of death from cardiovascular diseases. Journal of Epidemiology, 18, 191-196. doi:10.2188/ jea.JE2007388

Konkolÿ Thege, B., Bachner, Y. G., Kushnir, T., \& Kopp, M. S. (2009). Relationship between meaning in life and smoking status: Results of a national representative survey. Addictive Behaviors, 34, 117-120. doi: 10.1016/j.addbeh.2008.09.001

Korkeila, M., Kaprio, J., Rissanen, A., Koshenvuo, M., \& Sorensen, T. I. (1998). Predictors of major weight gain in adult Finns: Stress, life satisfaction and personality traits. International Journal of Obesity and Related Metabolic Disorders, 22, 949-957. doi:10.1038/sj.ijo.0800694

Kubzansky, L. D., \& Adler, G. K. (2010). Aldosterone: A forgotten mediator of the relationship between psychological stress and heart disease. Neuroscience \& Biobehavioral Reviews, 34, 80-86. doi: 10.1016/j.neubiorev.2009.07.005

Kubzansky, L. D., Kawachi, I., Weiss, S. T., \& Sparrow, D. (1998). Anxiety and coronary heart disease: A synthesis of epidemiological, psychological, and experimental evidence. Annals of Behavioral Medicine, 20, 47-58. doi:10.1007/BF02884448

Kubzansky, L. D., Sparrow, D., Vokonas, P., \& Kawachi, I. (2001). Is the glass half empty or half full? A prospective study of optimism and coronary heart disease in the Normative Aging Study. Psychosomatic Medicine, 63, 910-916.

Kubzansky, L. D., \& Thurston, R. C. (2007). Emotional vitality and incident coronary heart disease: Benefits of healthy psychological functioning. Archives of General Psychiatry, 64, 1393-1401. doi:10.1001/ archpsyc.64.12.1393

Leineweber, C., Kecklund, G., Janszky, I., Akerstedt, T., \& Orth-Gomer, K. (2003). Poor sleep increases the prospective risk for recurrent events in middle-aged women with coronary disease: The Stockholm Female Coronary Risk Study. Journal of Psychosomatic Research, 54, 121-127. doi:10.1016/S0022-3999(02)00475-0

Lemola, S., Räikkönen, K., Scheier, M. F., Matthews, K. A., Pesonen, A. K., Heinonen, K., . . Kajantie, E. (2010). Sleep quantity, quality and optimism in children. Journal of Sleep Research, 20, 12-20.

Leventhal, A. M., Ramsey, S. E., Brown, R. A., LaChance, H. R., \& Kahler, C. W. (2008). Dimensions of depressive symptoms and smoking cessation. Nicotine \& Tobacco Research, 10, 507-517. doi:10.1080/ 14622200801901971

Linley, P. A., Maltby, J., Wood, A. M., Osborne, G., \& Hurling, R. (2009). Measuring happiness: The higher order factor structure of subjective and 
psychological well-being measures. Personality and Individual Differences, 47, 878-884. doi:10.1016/j.paid.2009.07.010

Litt, M. D., Tennen, H., Kadden, R., \& Affleck, G. (2001). Optimism and pessimism in matching clients to alcoholism treatments. Journal of Applied Social Psychology, 31, 2484-2501. doi:10.1111/j.15591816.2001.tb00186.x

Lloyd-Jones, D. M., Hong, Y., Labarthe, D., Mozaffarian, D., Appel, L. J., Van Horn, L., ... Rosamond, W. D. (2010). Defining and setting national goals for cardiovascular health promotion and disease reduction: The American Heart Association's strategic impact goal through 2020 and beyond. Circulation, 121, 586-613. doi:10.1161/CIRCULATIONAHA.109.192703

Lyubomirsky, S., King, L., \& Diener, E. (2005). The benefits of frequent positive affect: Does happiness lead to success? Psychological Bulletin, 131, 803-855. doi:10.1037/0033-2909.131.6.803

Lyubomirsky, S., \& Lepper, H. S. (1999). A measure of subjective happiness: Preliminary reliability and construct validation. Social Indicators Research, 46, 137-155. doi:10.1023/A:1006824100041

Lyubomirsky, S., Sheldon, K. M., \& Schkade, D. (2005). Pursuing happiness: The architecture of sustainable change. Review of General Psychology, 9, 111-131. doi:10.1037/1089-2680.9.2.111

Manson, J. E., Colditz, G. A., Stampfer, M. J., Willett, W. C., Rosner, B., Monson, R. R., .. Hennekens, C. H. (1990). A prospective study of obesity and risk of coronary heart disease in women. New England Journal of Medicine, 322, 882-889. doi:10.1056/NEJM199003293221303

Marsh, A., Smith, L., Piek, J., \& Saunders, B. (2003). The purpose in life scale: Psychometric properties for social drinkers and drinkers in alcohol treatment. Educational and Psychological Measurement, 63, 859-871.

Martin, G. J., Magid, N. M., Myers, G., Barnett, P. S., Schaad, J. W., Weiss, J. S., . . Singer, D. H. (1987). Heart rate variability and sudden death secondary to coronary artery disease during ambulatory electrocardiographic monitoring. American Journal of Cardiology, 60, 86-89. doi:10.1016/0002-9149(87)90990-8

Martin, L. R., Friedman, H. S., Tucker, J. S., Tomlinson-Keasey, C., Criqui, M. H., \& Schwartz, J. E. (2002). A life course perspective on childhood cheerfulness and its relation to mortality risk. Personality and Social Psychology Bulletin, 28, 1155-1165. doi:10.1177/ 01461672022812001

Matthews, K. A., Owens, J. F., Edmundowicz, D., Lee, L., \& Kuller, L. H. (2006). Positive and negative attributes and risk for coronary and aortic calcification in healthy women. Psychosomatic Medicine, 68, 355-361. doi:10.1097/01.psy.0000221274.21709.d0

Matthews, K. A., Räikkönen, K., Sutton-Tyrrell, K., \& Kuller, L. H. (2004). Optimistic attitudes protect against progression of carotid atherosclerosis in healthy middle-aged women. Psychosomatic Medicine, 66, 640-644. doi:10.1097/01.psy.0000139999.99756.a5

McAuley, E., Morris, K. S., Motl, R. W., Hu, L., Konopack, J. F., \& Elavsky, S. (2007). Long-term follow-up of physical activity behavior in older adults. Health Psychology, 26, 375-380. doi:10.1037/02786133.26.3.375

McCrae, C. S., McNamara, J. P. H., Rowe, M. A., Dzierzewski, J. M., Dirk, J., Marsiske, M., \& Craggs, J. G. (2008). Sleep and affect in older adults: Using multilevel modeling to examine daily associations. Journal of Sleep Research, 17, 42-53. doi:10.1111/j.1365-2869.2008 .00621.x

Meier, A., \& Edwards, H. (1974). Purpose-in-Life Test: Age and sex differences. Journal of Clinical Psychology, 30, 384-386. doi:10.1002/ 1097-4679(197407)30:3<384::AID-JCLP2270300351>3.0.CO;2-V

Menninger, K. A., \& Menninger, W. C. (1936). Psychoanalytic observations in cardiac disorders. American Heart Journal, 11, 10-21. doi: 10.1016/S0002-8703(36)90371-X

Mente, A., de Koning, L., Shannon, H. S., \& Anand, S. S. (2009). A systematic review of the evidence supporting a causal link between dietary factors and coronary heart disease. Archives of Internal Medicine, 169, 659-669. doi:10.1001/archinternmed.2009.38
Mezick, E. J., Matthews, K. A., Hall, M., Kamarck, T. W., Strollo, P. J., Buysse, D. J., . . Reis, S. E. (2010). Low life purpose and high hostility are related to an attenuated decline in nocturnal blood pressure. Health Psychology, 29, 196-204. doi:10.1037/a0017790

Middleton, R. A., \& Byrd, E. K. (1996). Psychosocial factors and hospital readmission status of older persons with cardiovascular disease. Journal of Applied Rehabilitation Counseling, 27, 3-10.

Mølgaard, H., Sorensen, K. E., \& Bjerregaard, P. (1991). Attenuated 24-h heart rate variability in apparently healthy subjects, subsequently suffering sudden cardiac death. Clinical Autonomic Research, 1, 233-237. doi:10.1007/BF01824992

Molnar, D. S., Busseri, M. A., Perrier, C. P., \& Sadava, S. W. (2009). A longitudinal examination of alcohol use and subjective well-being in an undergraduate sample. Journal of Studies on Alcohol and Drugs, 70, $704-713$.

Moskowitz, J. T. (2003). Positive affect predicts lower risk of AIDS mortality. Psychosomatic Medicine, 65, 620-626. doi:10.1097/ 01.PSY.0000073873.74829.23

Muntner, P., Wildman, R. P., Reynolds, K., Desalvo, K. B., Chen, J., \& Fonseca, V. (2005). Relationship between $\mathrm{HbA}_{1 \mathrm{c}}$ level and peripheral arterial disease. Diabetes Care, 28, 1981-1987. doi:10.2337/ diacare.28.8.1981

Myrtek, M., Aschenbrenner, E., \& Brugner, G. (2005). Emotions in everyday life: An ambulatory monitoring study with female students. Biological Psychology, 68, 237-255. doi:10.1016/j.biopsycho .2004.06.001

Nabi, H., Kivimaki, M., De Vogli, R., Marmot, M. G., \& Singh-Manoux, A. (2008). Positive and negative affect and risk of coronary heart disease: Whitehall II prospective cohort study. BMJ, 337, a118. doi: 10.1136/bmj.a118

Netz, Y., Wu, M. J., Becker, B. J., \& Tenenbaum, G. (2005). Physical activity and psychological well-being in advanced age: A meta-analysis of intervention studies. Psychology and Aging, 20, 272-284. doi 10.1037/0882-7974.20.2.272

Niemiec, C. P., Ryan, R. M., Patrick, H., Deci, E. L., \& Williams, G. C. (2010). The energization of health-behavior change: Examining the associations among autonomous self-regulation, subjective vitality, depressive symptoms, and tobacco abstinence. The Journal of Positive Psychology, 5, 122-138. doi:10.1080/17439760903569162

Nocon, M., Hiemann, T., Muller-Riemenschneider, F., Thalau, F., Roll, S. \& Willich, S. N. (2008). Association of physical activity with all-cause and cardiovascular mortality: A systematic review and meta-analysis. European Journal of Cardiovascular Prevention \& Rehabilitation, 15, 239-246. doi:10.1097/HJR.0b013e3282f55e09

Ockene, I. S., \& Miller, N. H. (1997). Cigarette smoking, cardiovascular disease, and stroke: A statement for healthcare professionals from the American Heart Association. Circulation, 96, 3243-3247.

O'Donovan, A., Lin, J., Dhabhar, F. S., Wolkowitz, O., Tillie, J. M., Blackburn, E., \& Epel, E. (2009). Pessimism correlates with leukocyte telomere shortness and elevated interleukin-6 in post-menopausal women. Brain, Behavior, and Immunity, 23, 446-449. doi:10.1016/ j.bbi.2008.11.006

Oishi, S., Diener, E., \& Lucas, R. E. (2007). The optimum level of well-being: Can people be too happy? Perspectives on Psychological Science, 2, 346-360. doi:10.1111/j.1745-6916.2007.00048.x

Ostir, G. V., Berges, I. M., Markides, K. S., \& Ottenbacher, K. J. (2006). Hypertension in older adults and the role of positive emotions. Psychosomatic Medicine, 68, 727-733. doi:10.1097/01.psy.0000234028.93346.38

Ostir, G. V., Markides, K. S., Peek, M. K., \& Goodwin, J. S. (2001). The association between emotional well-being and the incidence of stroke in older adults. Psychosomatic Medicine, 63, 210-215.

Papousek, I., Nauschnegg, K., Paechter, M., Lackner, H. K., Goswami, N., \& Schulter, G. (2010). Trait and state positive affect and cardiovascular 
recovery from experimental academic stress. Biological Psychology, 83, 108-115. doi:10.1016/j.biopsycho.2009.11.008

Paradise, A. W., \& Kernis, M. H. (2002). Self-esteem and psychological well-being: Implications of fragile self-esteem. Journal of Social and Clinical Psychology, 21, 345-361. doi:10.1521/jscp.21.4.345.22598

Paschalides, C., Wearden, A. J., Dunkerley, R., Bundy, C., Davies, R., \& Dickens, C. M. (2004). The associations of anxiety, depression and personal illness representations with glycaemic control and health-related quality of life in patients with type 2 diabetes mellitus. Journal of Psychosomatic Research, 57, 557-564. doi:10.1016/j.jpsychores.2004.03.006

Pavot, W., \& Diener, E. (2008). The Satisfaction With Life Scale and the emerging construct of life satisfaction. The Journal of Positive Psychology, 3, 137-152. doi:10.1080/17439760701756946

Pearlin, L. I., \& Schooler, C. (1978). The structure of coping. Journal of Health and Social Behavior, 19, 2-21. doi:10.2307/2136319

Pearson, T. A., Mensah, G. A., Alexander, R. W., Anderson, J. L., Cannon, R. O., III, Criqui, M., . . Vinicor, F. (2003). Markers of inflammation and cardiovascular disease: Application to clinical and public health practice: A statement for healthcare professionals from the Centers for Disease Control and Prevention and the American Heart Association. Circulation, 107, 499-511. doi:10.1161/01.CIR.0000052939.59093.45

Peterson, C., \& Vaidya, R. S. (2001). Explanatory style, expectations, and depressive symptoms. Personality and Individual Differences, 31, 12171223. doi:10.1016/S0191-8869(00)00221-X

Phelan, C. H., Love, G. D., Ryff, C. D., Brown, R. L., \& Heidrich, S. M. (2010). Psychosocial predictors of changing sleep patterns in aging women: A multiple pathway approach. Psychology and Aging, 25, 858-866. doi:10.1037/a0019622

Phillips, B., \& Mannino, D. M. (2007). Do insomnia complaints cause hypertension or cardiovascular disease? Journal of Clinical Sleep Medicine, 3, 489-494.

Pradhan, A. D., Manson, J. E., Rifai, N., Buring, J. E., \& Ridker, P. M. (2001). C-reactive protein, interleukin 6, and risk of developing type 2 diabetes mellitus. JAMA, 286, 327-334. doi:10.1001/jama.286.3.327

Prather, A. A., Marsland, A. L., Muldoon, M. F., \& Manuck, S. B. (2007). Positive affective style covaries with stimulated IL-6 and IL-10 production in a middle-aged community sample. Brain, Behavior, and Iтmиnity, 21, 1033-1037. doi:10.1016/j.bbi.2007.04.009

Prescott, C. A., Neale, M. C., Corey, L. A., \& Kendler, K. S. (1997). Predictors of problem drinking and alcohol dependence in a populationbased sample of female twins. Journal of Studies on Alcohol, 58, 167-181.

Pressman, S. D., \& Cohen, S. (2005). Does positive affect influence health? Psychological Bulletin, 131, 925-971. doi:10.1037/0033-2909.131 .6 .925

Radloff, L. S. (1977). The CES-D Scale: A self-report depression scale for research in the general population. Applied Psychological Measurement, 1, 385-401. doi:10.1177/014662167700100306

Rahe, R. H., Rubin, R. T., Gunderson, E. K., \& Arthur, R. J. (1971). Psychologic correlates of serum cholesterol in man: A longitudinal study. Psychosomatic Medicine, 33, 399-410.

Räikkönen, K., \& Matthews, K. A. (2008). Do dispositional pessimism and optimism predict ambulatory blood pressure during school days and nights in adolescents? Journal of Personality, 76, 605-630. doi:10.1111/ j.1467-6494.2008.00498.x

Räikkönen, K., Matthews, K. A., Flory, J. D., \& Owens, J. F. (1999). Effects of hostility on ambulatory blood pressure and mood during daily living in healthy adults. Health Psychology, 18, 44-53. doi:10.1037/ 0278-6133.18.1.44

Rainville, P., Bechara, A., Naqvi, N., \& Damasio, A. R. (2006). Basic emotions are associated with distinct patterns of cardiorespiratory activity. International Journal of Psychophysiology, 61, 5-18. doi:10.1016/ j.ijpsycho.2005.10.024

Rasmussen, H. N., Scheier, M. F., \& Greenhouse, J. B. (2009). Optimism and physical health: A meta-analytic review. Annals of Behavioral Medicine, 37, 239-256. doi:10.1007/s12160-009-9111-x

Richman, L. S., Kubzansky, L. D., Maselko, J., Ackerson, L. K., \& Bauer, M. (2009). The relationship between mental vitality and cardiovascular health. Psychology \& Health, 24, 919-932. doi:10.1080/ 08870440802108926

Richman, L. S., Kubzansky, L., Maselko, J., Kawachi, I., Choo, P., \& Bauer, M. (2005). Positive emotion and health: Going beyond the negative. Health Psychology, 24, 422-429. doi:10.1037/02786133.24.4.422

Roberts, C., Troop, N., Connan, F., Treasure, J., \& Campbell, I. C. (2007). The effects of stress on body weight: Biological and psychological predictors of change in BMI. Obesity, 15, 3045-3055. doi:10.1038/ oby. 2007.363

Rosenman, R. H., Friedman, M., Straus, R., Wurm, M., Kositchek, R., Hahn, W., \& Werthessen, N. T. (1964). A predictive study of coronary heart disease. JAMA, 189, 15-22. doi:10.1001/jama.1964 03070010021004

Rosenthal, R. (1991). Meta-analytic procedures for social research (Rev. ed.). Thousand Oaks, CA: Sage.

Rotter, J. B. (1966). Generalized expectancies for internal versus external control of reinforcement. Psychological Monographs: General and Applied, 80, 1-28. doi:10.1037/h0092976

Roy, B., Diez-Roux, A. V., Seeman, T., Ranjit, N., Shea, S., \& Cushman, M. (2010). Association of optimism and pessimism with inflammation and hemostasis in the Multi-Ethnic Study of Atherosclerosis (MESA). Psychosomatic Medicine, 72, 134-140. doi:10.1097/PSY $.0 \mathrm{~b} 013 \mathrm{e} 3181 \mathrm{cb} 981 \mathrm{~b}$

Rozanski, A. (2005). Integrating psychologic approaches into the behavioral management of cardiac patients. Psychosomatic Medicine, 67(1, Suppl.), S67-S73. doi:10.1097/01.psy.0000164252.07368.81

Rozanski, A., Blumenthal, J. A., Davidson, K. W., Saab, P. G., \& Kubzansky, L. (2005). The epidemiology, pathophysiology, and management of psychosocial risk factors in cardiac practice: The emerging field of behavioral cardiology. Journal of the American College of Cardiology, 45, 637-651. doi:10.1016/j.jacc.2004.12.005

Rozanski, A., Gransar, H., Kubzansky, L. D., Wong, N., Shaw, L., Miranda-Peats, R., ... Berman, D. S. (2011). Do psychological risk factors predict the presence of coronary atherosclerosis? Psychosomatic Medicine, 73, 7-15. doi:10.1097/PSY.0b013e3181fd94f5

Rozanski, A., \& Kubzansky, L. D. (2005). Psychologic functioning and physical health: A paradigm of flexibility. Psychosomatic Medicine, 67(1, Suppl.), S47-S53. doi:10.1097/01.psy.0000164253.69550.49

Rugulies, R. (2002). Depression as a predictor for coronary heart disease: A review and meta-analysis. American Journal of Preventive Medicine, 23, 51-61. doi:10.1016/S0749-3797(02)00439-7

Ryan, R. M., \& Frederick, C. (1997). On energy, personality, and health: Subjective vitality as a dynamic reflection of well-being. Journal of Personality, 65, 529-565. doi:10.1111/j.1467-6494.1997.tb00326.x

Ryan, R. M., Huta, V., \& Deci, E. L. (2008). Living well: A selfdetermination theory perspective on eudaimonia. Journal of Happiness Studies, 9, 139-170. doi:10.1007/s10902-006-9023-4

Ryff, C. D. (1989). Happiness is everything, or is it? Explorations on the meaning of psychological well-being. Journal of Personality and Social Psychology, 57, 1069-1081. doi:10.1037/0022-3514.57.6.1069

Ryff, C. D., \& Keyes, C. L. M. (1995). The structure of psychological well-being revisited. Journal of Personality and Social Psychology, 69, 719-727. doi:10.1037/0022-3514.69.4.719

Ryff, C. D., Love, G. D., Urry, H. L., Muller, D., Rosenkranz, M. A., Friedman, E. M., ... Singer, B. (2006). Psychological well-being and ill-being: Do they have distinct or mirrored biological correlates? Psychotherapy and Psychosomatics, 75, 85-95. doi:10.1159/000090892

Ryff, C. D., \& Singer, B. (1998). The contours of positive human health. Psychological Inquiry, 9, 1-28. doi:10.1207/s15327965pli0901_1 
Ryff, C. D., \& Singer, B. (2007). Reply: What to do about positive and negative items in studies of psychological well-being and ill-being? Psychotherapy and Psychosomatics, 76, 61-62. doi:10.1159/000096369

Ryff, C. D., Singer, B. H., \& Love, G. D. (2004). Positive health: Connecting well-being with biology. Philosophical Transactions of the Royal Society: B. Biological Sciences, 359, 1383-1394. doi:10.1098/ rstb.2004.1521

Saloumi, C., \& Plourde, H. (2010). Differences in psychological correlates of excess weight between adolescents and young adults in Canada. Psychology, Health \& Medicine, 15, 314-325. doi:10.1080/ 13548501003668711

Sarwar, N., Danesh, J., Eiriksdottir, G., Sigurdsson, G., Wareham, N., Bingham, S., ... Gudnason, V. (2007). Triglycerides and the risk of coronary heart disease: 10,158 incident cases among 262,525 participants in 29 Western prospective studies. Circulation, 115, 450-458. doi:10.1161/CIRCULATIONAHA.106.637793

Scheier, M. F., \& Carver, C. S. (1985). Optimism, coping, and health: Assessment and implications of generalized outcome expectancies. Health Psychology, 4, 219-247. doi:10.1037/0278-6133.4.3.219

Scheier, M. F., Carver, C. S., \& Bridges, M. W. (1994). Distinguishing optimism from neuroticism (and trait anxiety, self-mastery, and selfesteem): A reevaluation of the Life Orientation Test. Journal of Personality and Social Psychology, 67, 1063-1078. doi:10.1037/00223514.67.6.1063

Scheier, M. F., Matthews, K. A., Owens, J. F., Magovern, G. J., Sr., Lefebvre, R. C., Abbott, R. A., \& Carver, C. S. (1989). Dispositional optimism and recovery from coronary artery bypass surgery: The beneficial effects on physical and psychological well-being. Journal of Personality and Social Psychology, 57, 1024-1040. doi:10.1037/00223514.57.6.1024

Scheier, M. F., Matthews, K. A., Owens, J. F., Schulz, R., Bridges, M. W., Magovern, G. J., \& Carver, C. S. (1999). Optimism and rehospitalization after coronary artery bypass graft surgery. Archives of Internal Medicine, 159, 829-835. doi:10.1001/archinte.159.8.829

Scheier, M. F., Wrosch, C., Baum, A., Cohen, S., Martire, L. M., Matthews, K. A., ... Zdaniuk, B. (2006). The Life Engagement Test: Assessing purpose in life. Journal of Behavioral Medicine, 29, 291-298. doi:10.1007/s10865-005-9044-1

Schwartz, S. W., Cornoni-Huntley, J., Cole, S. R., Hays, J. C., Blazer, D. G., \& Schocken, D. D. (1998). Are sleep complaints an independent risk factor for myocardial infarction? Annals of Epidemiology, 8, 384392. doi:10.1016/S1047-2797(97)00238-X

Schwarz, A. M., Schachinger, H., Adler, R. H., \& Goetz, S. M. (2003). Hopelessness is associated with decreased heart rate variability during championship chess games. Psychosomatic Medicine, 65, 658-661. doi:10.1097/01.PSY.0000075975.90979.2A

Seeman, J. (1989). Toward a model of positive health. American Psychologist, 44, 1099-1109. doi:10.1037/0003-066X.44.8.1099

Seeman, T. E. (1991). Personal control and coronary artery disease: How generalized expectancies about control may influence disease risk. Journal of Psychosomatic Research, 35, 661-669. doi:10.1016/00223999(91)90116-6

Segerstrom, S. C., \& Nes, L. S. (2007). Heart rate variability reflects self-regulatory strength, effort, and fatigue. Psychological Science, 18, 275-281. doi:10.1111/j.1467-9280.2007.01888.x

Seligman, M. E. P., Steen, T. A., Park, N., \& Peterson, C. (2005). Positive psychology progress: Empirical validation of interventions. American Psychologist, 60, 410-421. doi:10.1037/0003-066X.60.5.410

Shankar, A., Koh, W. P., Yuan, J. M., Lee, H. P., \& Yu, M. C. (2008). Sleep duration and coronary heart disease mortality among Chinese adults in Singapore: A population-based cohort study. American Journal of Epidemiology, 168, 1367-1373. doi:10.1093/aje/kwn281

Shapiro, D. H. (1994). Manual for the Shapiro Control Inventory. Palo Alto, CA: Behaviordata.
Shepperd, J. A., Maroto, J. J., \& Pbert, L. A. (1996). Dispositional optimism as a predictor of health changes among cardiac patients. Journal of Research in Personality, 30, 517-534. doi:10.1006/ jrpe.1996.0038

Shirai, K., Iso, H., Ohira, T., Ikeda, A., Noda, H., Honjo, K., . . . Tsugane, S. (2009). Perceived level of life enjoyment and risks of cardiovascular disease incidence and mortality: The Japan public health center-based study. Circulation, 120, 956-963. doi:10.1161/CIRCULATIONAHA 108.834176

Shiroma, E. J., \& Lee, I. M. (2010). Physical activity and cardiovascular health: Lessons learned from epidemiological studies across age, gender, and race/ethnicity. Circulation, 122, 743-752. doi:10.1161/ CIRCULATIONAHA.109.914721

Smith, A. W., \& Baum, A. (2003). The influence of psychological factors on restorative function in health and illness. In J. Suls \& K. A. Wallston (Eds.), Social psychological foundations of health and illness (pp. 431457). Malden, MA: Blackwell. doi:10.1002/9780470753552.ch16

Sone, T., Nakaya, N., Ohmori, K., Shimazu, T., Higashiguchi, M., Kakizaki, M., ... Tsuji, I. (2008). Sense of life worth living (ikigai) and mortality in Japan: Ohsaki Study. Psychosomatic Medicine, 70, 709715. doi:10.1097/PSY.0b013e31817e7e64

Stamatakis, E., Hamer, M., \& Dunstan, D. W. (2011). Screen-based entertainment time, all-cause mortality, and cardiovascular events: Population-based study with ongoing mortality and hospital events follow-up. Journal of the American College of Cardiology, 57, 292-299. doi:10.1016/j.jacc.2010.05.065

Stamler, J., Daviglus, M. L., Garside, D. B., Dyer, A. R., Greenland, P., \& Neaton, J. D. (2000). Relationship of baseline serum cholesterol levels in 3 large cohorts of younger men to long-term coronary, cardiovascular, and all-cause mortality and to longevity. JAMA, 284, 311-318. doi: 10.1001/jama.284.3.31

Stampfer, M. J., Colditz, G. A., Willett, W. C., Speizer, F. E., \& Hennekens, C. H. (1988). A prospective study of moderate alcohol consumption and the risk of coronary disease and stroke in women. New England Journal of Medicine, 319 , 267-273. doi:10.1056/NEJM198808043190503

Steptoe, A., Dockray, S., \& Wardle, J. (2009). Positive affect and psychobiological processes relevant to health. Journal of Personality, 77, 1747-1776. doi:10.1111/j.1467-6494.2009.00599.x

Steptoe, A., Gibson, E. L., Hamer, M., \& Wardle, J. (2007). Neuroendocrine and cardiovascular correlates of positive affect measured by ecological momentary assessment and by questionnaire. Psychoneuroendocrinology, 32, 56-64. doi:10.1016/j.psyneuen.2006.10.001

Steptoe, A., O’Donnell, K., Badrick, E., Kumari, M., \& Marmot, M. (2008). Neuroendocrine and inflammatory factors associated with positive affect in healthy men and women: The Whitehall II study. American Journal of Epidemiology, 167, 96-102. doi:10.1093/aje/kwm252

Steptoe, A., O’Donnell, K., Marmot, M., \& Wardle, J. (2008). Positive affect, psychological well-being, and good sleep. Journal of Psychosomatic Research, 64, 409-415. doi:10.1016/j.jpsychores.2007.11.008

Steptoe, A., \& Wardle, J. (2005). Positive affect and biological function in everyday life. Neurobiology of Aging, 26(1, Suppl.), 108-112. doi: 10.1016/j.neurobiolaging.2005.08.016

Steptoe, A., Wardle, J., \& Marmot, M. (2005). Positive affect and healthrelated neuroendocrine, cardiovascular, and inflammatory processes. Proceedings of the National Academy of Sciences, USA, 102, 65086512. doi:10.1073/pnas.0409174102

Steptoe, A., Wright, C., Kunz-Ebrecht, S. R., \& Iliffe, S. (2006). Dispositional optimism and health behaviour in community-dwelling older people: Associations with healthy ageing. British Journal of Health Psychology, 11, 71-84. doi:10.1348/135910705X42850

Stok, F. M., De Ridder, D. T., Adriaanse, M. A., \& De Wit, J. B. (2010). Looking cool or attaining self-rule. Different motives for autonomy and their effects on unhealthy snack purchase. Appetite, 54, 607-610. doi: 10.1016/j.appet.2010.02.017 
Strack, S., Carver, C. S., \& Blaney, P. H. (1987). Predicting successful completion of an aftercare program following treatment for alcoholism: The role of dispositional optimism. Journal of Personality and Social Psychology, 53, 579-584. doi:10.1037/0022-3514.53.3.579

Strine, T. W., Chapman, D. P., Balluz, L. S., Moriarty, D. G., \& Mokdad, A. H. (2008). The associations between life satisfaction and healthrelated quality of life, chronic illness, and health behaviors among U.S. community-dwelling adults. Journal of Community Health, 33, 40-50. doi:10.1007/s10900-007-9066-4

Suls, J., \& Bunde, J. (2005). Anger, anxiety, and depression as risk factors for cardiovascular disease: The problems and implications of overlapping affective dispositions. Psychological Bulletin, 131, 260-300. doi: 10.1037/0033-2909.131.2.260

Surtees, P. G., Wainwright, N. W. J., Luben, R., Khaw, K.-T., \& Day, N. E. (2006). Mastery, sense of coherence, and mortality: Evidence of independent associations from the epic-norfolk prospective cohort study. Health Psychology, 25, 102-110. doi:10.1037/0278-6133.25.1.102

Surtees, P. G., Wainwright, N. W. J., Luben, R., Wareham, N. J., Bingham, S. A., \& Khaw, K.-T. (2010). Mastery is associated with cardiovascular disease mortality in men and women at apparently low risk. Health Psychology, 29, 412-420. doi:10.1037/a0019432

Tanno, K., \& Sakata, K. (2007). Psychological factors and mortality in the Japan Collaborative Cohort Study for Evaluation of Cancer (JACC). Asian Pacific Journal of Cancer Prevention, 8(Suppl.), 113-122.

Tanno, K., Sakata, K., Ohsawa, M., Onoda, T., Itai, K., Yaegashi, Y., \& Tamakoshi, A. (2009). Associations of ikigai as a positive psychological factor with all-cause mortality and cause-specific mortality among middle-aged and elderly Japanese people: Findings from the Japan Collaborative Cohort Study. Journal of Psychosomatic Research, 67, 67-75. doi:10.1016/j.jpsychores.2008.10.018

Taylor, S. E., Lehman, B. J., Kiefe, C. I., \& Seeman, T. E. (2006). Relationship of early life stress and psychological functioning to adult C-reactive protein in the Coronary Artery Risk Development in Young Adults study. Biological Psychiatry, 60, 819-824. doi:10.1016/ j.biopsych.2006.03.016

Thayer, J. F., \& Lane, R. D. (2007). The role of vagal function in the risk for cardiovascular disease and mortality. Biological Psychology, 74, 224-242. doi:10.1016/j.biopsycho.2005.11.013

Tindle, H. A., Chang, Y. F., Kuller, L. H., Manson, J. E., Robinson, J. G., Rosal, M. C., ... Matthews, K. A. (2009). Optimism, cynical hostility, and incident coronary heart disease and mortality in the Women's Health Initiative. Circulation, 120, 656-662. doi:10.1161/CIRCULATIONAHA.108.827642

Toth, P. P. (2005). The "good cholesterol": High-density lipoprotein. Circulation, 111, e89-e91. doi:10.1161/01.CIR.0000154555.07002.CA

Tsenkova, V. K., Love, G. D., Singer, B. H., \& Ryff, C. D. (2007). Socioeconomic status and psychological well-being predict cross-time change in glycosylated hemoglobin in older women without diabetes. Psychosomatic Medicine, 69, 777-784. doi:10.1097/PSY.0b013e318157466f

Twisk, J. W. R., Snel, J., Kemper, H. C. G., \& van Mechelen, W. (1998). Relation between the longitudinal development of personality characteristics and biological and lifestyle risk factors for coronary heart disease. Psychosomatic Medicine, 60, 372-377.

Uchino, B. N. (2006). Social support and health: A review of physiological processes potentially underlying links to disease outcomes. Journal of Behavioral Medicine, 29, 377-387. doi:10.1007/s10865-006-9056-5

Uchino, B. N., Cacioppo, J. T., \& Kiecolt-Glaser, J. K. (1996). The relationship between social support and physiological processes: A review with emphasis on underlying mechanisms and implications for health. Psychological Bulletin, 119, 488-531. doi:10.1037/0033-2909 119.3.488

Uijtdehaage, S. H., \& Thayer, J. F. (2000). Accentuated antagonism in the control of human heart rate. Clinical Autonomic Research, 10, 107-110. doi:10.1007/BF02278013

van der Vlugt, M. J., van Domburg, R. T., Pedersen, S. S., Veerhoek, R. J.,
Leenders, I. M., Pop, G. A., . . Erdman, A. M. (2005). Feelings of being disabled as a risk factor for mortality up to 8 years after acute myocardial infarction. Journal of Psychosomatic Research, 59, 247-253. doi: 10.1016/j.jpsychores.2005.03.003

van Domburg, R. T., Pedersen, S. S., van den Brand, M. J. B. M., \& Erdman, R. A. M. (2001). Feelings of being disabled as a predictor of mortality in men 10 years after percutaneous coronary transluminal angioplasty. Journal of Psychosomatic Research, 51, 469-477. doi: 10.1016/S0022-3999(01)00221-5

van Loon, A. J. M., Tijhuis, M., Surtees, P. G., \& Ormel, J. (2001). Personality and coping: Their relationship with lifestyle risk factors for cancer. Personality and Individual Differences, 31, 541-553. doi: 10.1016/S0191-8869(00)00158-6

van Ravenswaaij-Arts, C. M., Kollee, L. A., Hopman, J. C., Stoelinga, G. B., \& van Geijn, H. P. (1993). Heart rate variability. Annals of Internal Medicine, 118, 436-447.

Waterman, A. S. (2007). On the importance of distinguishing hedonia and eudaimonia when contemplating the hedonic treadmill. American Psychologist, 62, 612-613. doi:10.1037/0003-066X62.6.612

Waterman, A. S. (2008). Reconsidering happiness: A eudaimonist's perspective. The Journal of Positive Psychology, 3, 234-252. doi:10.1080/ 17439760802303002

Watson, D., \& Clark, L. A. (1994). The PANAS-X: Manual for the Positive and Negative Affect Schedule-Expanded form. Iowa City, IA: University of Iowa.

Watson, D., Clark, L. A., \& Tellegen, A. (1988). Development and validation of brief measures of positive and negative affect: The PANAS scales. Journal of Personality and Social Psychology, 54, 1063-1070. doi:10.1037/0022-3514.54.6.1063

Watson, D., Weber, K., Assenheimer, J. S., Clark, L. A., Strauss, M. E., \& McCormick, R. A. (1995). Testing a tripartite model: I. Evaluating the convergent and discriminant validity of anxiety and depression symptom scales. Journal of Abnormal Psychology, 104, 3-14. doi:10.1037/0021843X.104.1.3

Wexler, L., Brundage, B., Crouse, J., Detrano, R., Fuster, V., Maddahi, J., . . AHA Staff. (1996). Coronary artery calcification: Pathophysiology, epidemiology, imaging methods, and clinical implications: A statement for health professionals from the American Heart Association Writing Group. Circulation, 94, 1175-1192.

Wharton, J. M., Coleman, R. E., \& Strauss, H. C. (1992). The role of the autonomic nervous system in sudden cardiac death. Trends in Cardiovascular Medicine, 2, 65-71. doi:10.1016/1050-1738(92)90007-F

What is health? The ability to adapt. (2009, March). Lancet, 373, 781.

Willett, W. C., Green, A., Stampfer, M. J., Speizer, F. E., Colditz, G. A., Rosner, B., ... Hennekens, C. H. (1987). Relative and absolute excess risks of coronary heart disease among women who smoke cigarettes. New England Journal of Medicine, 317, 1303-1309. doi:10.1056/ NEJM198711193172102

Williams, G. C., Gagne, M., Mushlin, A. I., \& Deci, E. L. (2005). Motivation for behavior change in patients with chest pain. Health Education, 105, 304-321. doi:10.1108/09654280510602516

Writing Committee for the ENRICHD Investigators. (2003). Effects of treating depression and low perceived social support on clinical events after myocardial infarction: The Enhancing Recovery in Coronary Heart Disease Patients (ENRICHD) randomized trial. JAMA, 289, 3106-3116. doi:10.1001/jama.289.23.3106

Zullig, K. J., Valois, R. F., Huebner, E. S., Oeltmann, J. E., \& Drane, J. W (2001). Relationship between perceived life satisfaction and adolescents substance abuse. Journal of Adolescent Health, 29, 279-288. doi: $10.1016 / \mathrm{S} 1054-139 \mathrm{X}(01) 00269-5$

Received August 10, 2010

Revision received January 6, 2012 Accepted January 17, 2012 